Andréa Júlia Soares

\title{
ANÁLISE DE AUTOCORRELAÇÃO EM REDES APLICADA AO CASO DE ACIDENTES URBANOS DE TRÂNSITO
}

Orientador: Prof. Assoc. Antônio Nélson Rodrigues da Silva

Dissertação apresentada a Escola de Engenharia de São Carlos da Universidade de São Paulo, como parte dos requisitos para a obtenção do título de Mestre em Engenharia Civil: Planejamento e Operação de Sistemas de Transportes 


\begin{abstract}
AUTORIZO A REPRODUC̄̃O E DIVULGACÃO TOTAL OU PARCIAL DESTE TRABALHO, POR QUALQUER MEIO CONVENCIONAL OU ELETRÔNICO, PARA FINS DE ESTUDO E PESQUISA, DESDE QUE CITADA A FONTE.
\end{abstract}

Ficha catalográfica preparada pela Seção de Tratamento da Informação do Serviço de Biblioteca - EESC/USP

Análise de autocorrelação em redes aplicada ao caso de acidentes urbanos de trânsito / Andréa Júlia Soares ; orientador Antônio Nélson Rodrigues da Silva. -- São Carlos, 2007.

Dissertação (Mestrado-Programa de Pós-Graduação em Engenharia de Transportes e Área de Concentração em Planejamento e Operação de Sistemas de Transportes) -Escola de Engenharia de São Carlos da Universidade de São Paulo.

1. Autocorrelação em redes. 2. Planejamento urbano. 3. Acidentes de trânsito. 4. Estatítica espacial. I. Título. 
Dedico este trabalho a principal responsável por mais esta fase da minha vida profissional: Professora Léa Cristina L. de Souza. 



\section{AGRADECIMENTOS}

Muitos agradecimentos a fazer... (tentarei ser breve!!!).

Tenho muito a agradecer a força maior que me move e sempre posso contar - Deus.

Não saberei demonstrar minha gratidão ao Prof. Antônio Nélson; muitíssimo obrigada. Por tudo, paciência, compreensão, apoio e principalmente por mostrar que é possível ser um profissional brilhante, sem deixar de ser humano.

É na família que aprendemos as primeiras e principais lições da vida: honra, caráter, justiça, lealdade. E eu tive ótimos professores; obrigada mãe, obrigada pai!!! E espero continuar sendo motivo de orgulho para vocês!!!

Tive o privilégio de trabalhar com pessoas maravilhosas na EMDEL. Aprendi muito com os amigos que por lá fiz e mesmo depois pude continuar a contar com o carinho, a amizade e a colaboração de todos, mas algumas pessoas são especiais... Edimilson, Israel, Valéria, Renata, Isabel, Paulo Rondan, Ernesto e João Santarosa, muito obrigada!!!

Não quero ser injusta e esquecer ninguém, por isso quero agradecer a TODOS da Secretaria Municipal de Transportes, Trânsito e Vias Públicas de São Carlos. Obrigada por me ajudarem e me compreenderem neste momento.

Há pessoas que marcam a nossa vida para sempre. É muito bom ter uma história para contar, ainda mais se for com muito amor... Não tenho como agradecer a presença de Christian na minha história. Foi companheiro constante, amigo fiel, conselheiro sensato...

Amigos!!! Ah, os amigos... como é bom tê-los. Não gostaria de ser indelicada e nem deixar de demonstrar todo o carinho que sinto por todos, por isso peço desculpas se acaso não citar alguém, mas se são meus amigos me compreenderão. Mesmo assim vou arriscar agradecer algumas pessoas queridas, pela força, carinho, amizade e por acreditarem tanto em mim: Valzinha e Pimenta - minhas irmãs da UNESP; meus irmãozinhos de sala: Gustavo, Vanessa Naomi, Fabíola e Cia; galera da USP: Diogo, Bruno, Marcão, Marcelo Massulo, Cira, Jesner, Weslley, Celane, Vivianne, Thaís, Cida Cris, Karênina, André Balan e Tatiane Renata - única representante da terra. 
Como fazer um agradecimento especial para pessoas especiais, que em muito me ajudaram? $\mathrm{Na}$ UNESP conquistei um amigo para a eternidade - Fernando; aqui conquistei outro - André "Dotadão". E o que falar das super-poderosas Carol, Elaine e Camilla? Vocês foram demais, de coração, muito obrigada!!!

Devo agradecer também ao pessoal do Departamento de Transportes, afinal aprendi muito com vocês. Obrigada por tudo.

E a Fundação de Amparo à Pesquisa do Estado de São Paulo - FAPESP, pelo auxílio através da concessão da bolsa de estudo. 
"O homem não é nada além daquilo que a educação faz dele".

Kant 



\section{RESUMO}

SOARES, A. J. (2007). Análise de autocorrelação em redes aplicada ao caso de acidentes urbanos de trânsito. Dissertação (Mestrado) - Escola de Engenharia de São Carlos, Universidade de São Paulo, São Carlos, 2007.

O objetivo deste estudo é explorar uma metodologia para análises de autocorrelação em redes, utilizando um atributo de fenômenos cuja ocorrência esteja de alguma forma vinculada ou que seja dependente de uma rede. Para isso foram utilizados dados de acidentes de trânsito em um estudo de caso para a cidade de São Carlos, referentes aos anos de 2001, 2002 e 2003. Foram considerados inicialmente os dados totais dos acidentes e, em seguida, separados por tipos (atropelamentos, acidentes com danos materiais e acidentes com vítimas). A próxima etapa considerou os valores dos acidentes totais majorados pela UPS (Unidade Padrão de Severidade). A última etapa do estudo levou ainda em consideração a localização dos acidentes nos arcos ou interseções, que permitiu concluir que esta forma de caracterização espacial dos acidentes pode interferir significativamente nos resultados da análise. Outra conclusão relevante foi a identificação de autocorrelação espacial elevada e positiva no caso estudado. Finalmente a comparação com análise semelhante realizada por áreas demonstra vantagens para a análise por redes.

Palavras-chave: autocorrelação em redes, planejamento urbano, acidentes de trânsito, estatística espacial. 



\begin{abstract}
SOARES, A. J. Network autocorrelation analysis applied to the case of urban traffic accidents. Dissertation (Master) - São Carlos School of Engineering, University of São Paulo, São Carlos, 2007.

The objective of this study is to explore a methodology for network spatial autocorrelation analysis by applying it to an attribute of phenomena that are somehow connected to or dependent of a network. In other to do so, traffic accident data recorded in the years 2001, 2002, and 2003 in the city of São Carlos were selected for a case study. A first analysis considered all data, followed by analyses per accident type. In another phase of the study, the total accidents were weighted according to their severity. The last part of the study included in the analysis information about the location of each accident, either at a link or at an intersection. A conclusion drawn from the later analysis indicated that the consideration of the accidents locations can produce significant changes in the results. Another relevant conclusion was the identification of high and positive spatial autocorrelation in the case studied. Finally, the comparison with a similar analysis carried out with areas shows advantages for the network analysis.
\end{abstract}

Key works: network, autocorrelation analysis, urban planning, traffic accidents, spatial statistics. 



\section{LISTA DE TABELAS}

Tabela 3.1 - Custos por acidente de trânsito, segundo IPEA (2006) ……............................. 19

Tabela 3.2 - Total de acidente de trânsito (DENATRAN - 2006) ........................................21

Tabela 4.1 - Distribuição dos acidentes por tipo e por ano ....................................................29

Tabela 5.1 - Distribuição dos acidentes por tipo, por ano e por localização na rede..............37

Tabela 5.2 - Valores de I em função do ano e da classificação do tipo de dado analisado ....38

Tabela 5.3 - Tabela com a distribuição do número de segmentos por quadrante....................38

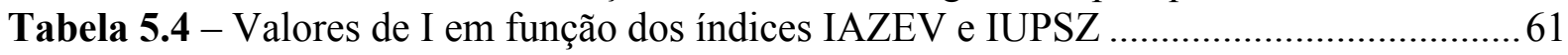





\section{LISTA DE FIGURAS}

Figura 3.1 - Evolução da frota de veículos ao longo dos anos (DENATRAN, 2005) ........... 22 Figura 3.2 - Número de vítimas fatais/10 mil veículos ao longo dos anos (DENATRAN, 2005)

Figura 4.1 - Rede viária da cidade de São Carlos em janela do programa TransCAD ......... 31

Figura 4.2 - Georreferenciamento dos acidentes de 2001 juntamente com a rede viária de São

Carlos

Figura 4.3 - A partir da estrutura de Santos (2005) desenvolveu-se a $4{ }^{\mathrm{a}}$ etapa..................... 32

Figura 5.1 - Box Maps com Total de acidente em 2001 .................................................. 40

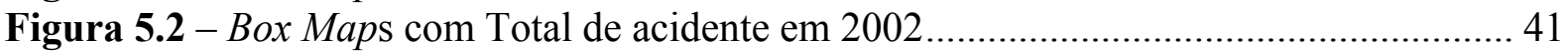

Figura 5.3 - Box Maps com Total de acidente em 2003 ...................................................... 42

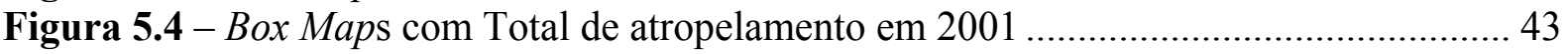

Figura 5.5 - Box Maps com Total de atropelamentos em 2002 ...................................... 44

Figura 5.6 - Box Maps com Total de atropelamentos em 2003 ….................................... 45

Figura 5.7 - Box Maps com Total de acidentes com danos materiais em 2001 ................... 46

Figura 5.8 - Box Maps com Total de acidentes com danos materiais em 2002 .................... 47

Figura 5.9 - Box Maps com Total de acidentes com danos materiais em 2003 ................... 48

Figura 5.10 - Box Maps com Total de acidentes com vítimas não fatais em 2001 ................ 49

Figura 5.11 - Box Maps com Total de acidentes com vítimas não fatais em 2002 ............... 50

Figura 5.12 - Box Maps com Total de acidentes com vítimas não fatais em 2003 ............... 51

Figura 5.13 - Box Maps com Total de acidentes com UPS em 2001 ................................... 52

Figura 5.14 - Box Maps com Total de acidentes com UPS em 2002 ................................... 53

Figura 5.15 - Box Maps com Total de acidentes com UPS em 2003 ................................... 54

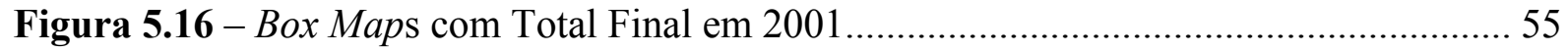

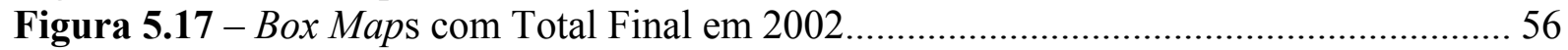

Figura 5.18 - Box Maps com Total Final em 2003 ............................................................ 57

Figura 5.19 - Índice de Acidentes na zona por extensão da malha viária (2001, 2002 e 2003)

Figura 5.20 - Índice de Unidade Padrão de Severidade por Zona (2001, 2002 e 2003) ........ 63

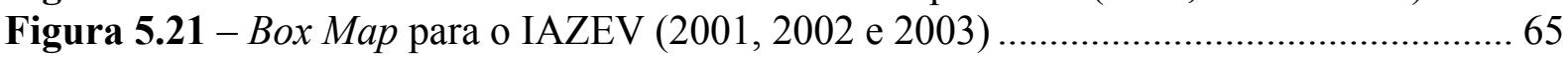

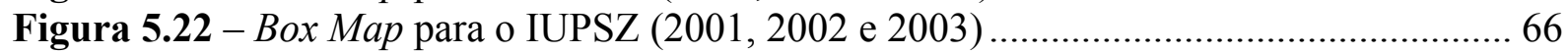





\section{SUMÁRIO}

1 INTRODUÇÃO .

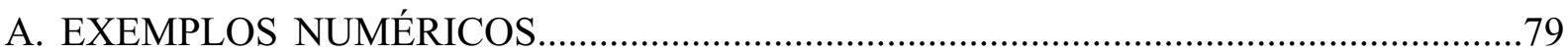

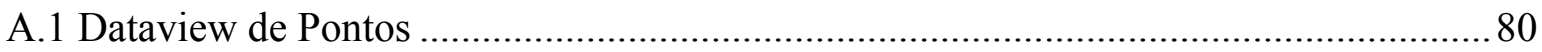

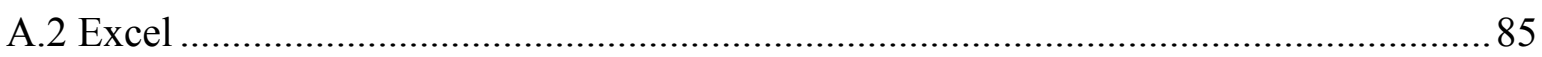

A.3 Preparação dos Dados no Transcad e criação da Matriz de Adjacência........................ 92

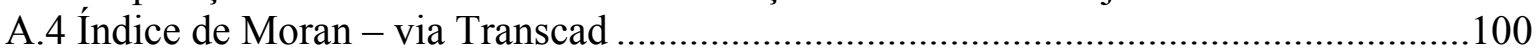

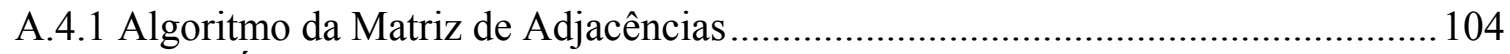

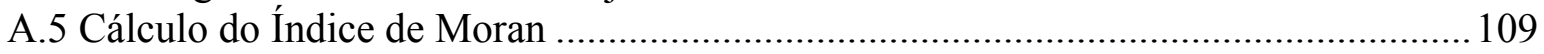

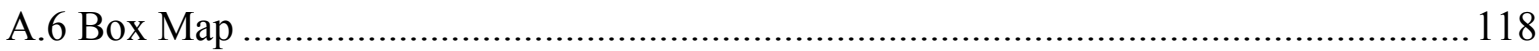

A.7 Distribuição dos Acidentes entre esquinas e quadras ................................................. 118 



\section{CAPITULO 1 INTRODUÇÃO}

Neste capítulo é feita, de forma sucinta, a caracterização do problema estudado, naquilo que diz respeito à estreita relação entre problemas urbanos e os transportes. Além disso, são apresentados a justificativa, o objetivo e a estrutura desse trabalho.

\subsection{CARACTERIZAÇÃO DO PROBLEMA}

A modernização das cidades tem trazido uma melhoria na vida da população urbana, embora as conseqüências negativas pesem consideravelmente. Muitas vezes os resultados positivos não se mostram tão marcantes como os efeitos negativos, já que estes últimos são muito mais incômodos e evidentes.

Com a modernização dos transportes no último século, e mais especificamente no transporte urbano, as cidades conheceram uma facilidade no ir e vir de pessoas e mercadorias sem precedentes. Em pouco mais de 100 anos, as mudanças foram rápidas e significativas, de tal forma que não se encontra nada parecido na história do Homem.

Em todo tipo de transformação, os efeitos negativos nem sempre são considerados e tratados de maneira a extingui-los ou ao menos minimizá-los. O trânsito é um claro exemplo deste fato. Não existem soluções imediatas e defintivas para resolver um dos maiores problemas da vida moderna, entretanto é necessário que medidas preventivas e corretivas sejam estudadas e aplicadas, pois a situação em algumas cidades é muito grave.

Muitas hipóteses podem explicar a situação atual nas cidades. Uma delas diz respeito a um aumento significativo na frota de veículos automotores em todo o mundo observado nos últimos anos. O grande número de veículos tem gerado inúmeros problemas 
urbanos, tais como: congestionamentos, poluição ambiental e acidentes de trânsito. De todos os problemas gerados é bem provável que os acidentes de trânsito seja o de maior dificuldade em solucionar e com o maior custo para a sociedade, pois resultam em prejuízos econômicos e sociais, inclusive mortes.

\subsection{JUSTIFICATIVA}

Em geral, aumentos na frota representam maior probabilidade de ocorrência de acidentes viários. Uma das formas de reduzir esse risco de aumento no número de acidentes é buscar soluções para tornar a rede viária mais segura. Para isso, é necessário saber onde e porque os acidentes ocorrem. Mais do que isso, é preciso conhecer detalhes da distribuição espacial dos acidentes na cidade e, sobretudo, na rede viária.

Uma maneira de caracterizar e compreender o problema pode ser através de técnicas de análise espacial, identificando padrões e, a partir desses, intervindo nos locais exatos da rede que eventualmente levarão a uma redução na quantidade e gravidade dos acidentes. Dentre as diversas formas de analisar problemas relacionados à cidade, uma maneira supostamente eficiente é caracterizá-la como uma rede, em que o traçado das ruas coincida com os segmentos que formam esta rede. A partir da caracterização da cidade como rede será possível aplicar técnicas de análise espacial.

Entre as possíveis técnicas para análise espacial de redes, a autocorrelação de redes constitui-se em uma medida quantitativa que resume algumas das características relacionadas à conectividade. Seu cálculo pode ter aplicação direta a problemas de transportes com forte vinculação a uma rede, como é o caso dos acidentes de trânsito.

O Índice de Moran, sendo um índice de autocorrelação espacial, pode ser aplicado para qualquer variável. Neste estudo, utilizou-se o número de acidentes de trânsito, mas essa 
variável pode ser substituída por outra variável que ocorra em rede e seja passível de representação espacial, o que o torna muito flexível enquanto ferramenta.

\subsection{OBJETIVOS}

O objetivo principal deste trabalho é desenvolver uma metodologia de análise de autocorrelação em redes através do Índice I de Moran para atributos ou eventos que ocorram essencialmente em redes e sejam passíveis de representação espacial. Por meio da metodologia pretende-se analisar mais especificamente, em um estudo de caso, a rede viária da cidade de São Carlos e a ocorrência dos acidentes de trânsito em um período de três anos $(2001,2002$ e 2003).

\subsection{ESTRUTURA DO TRABALHO}

Este trabalho foi estruturado a partir de uma revisão bibliográfica referente a conceitos de Conectividade através de diferentes formas de análise de rede, conforme discutido no capítulo 2. Em seguida, no capítulo 3, o assunto abordado serão os acidentes de trânsito, mostrando um panorama dos acidentes.

No capítulo 4 é apresentado o método desenvolvido nesta pesquisa, em que são descritas as etapas de tratamento e formatação dos dados, bem como os procedimentos de análise e avaliação dos resultados, seja de forma isolada, seja quando comparados com outras estratégias de análise.

Os resultados e suas análises obtidos por meio da aplicação do método proposto são apresentados no capítulo 5. O capítulo 6 apresenta as conclusões e recomendações e é seguido pelas referências bibliográficas e por um Apêndice com uma descrição detalhada da aplicação do método utilizando-se o software TransCAD. 


\section{CAPITULO 2}

\section{ANÁLISE EM REDES}

Este capítulo apresenta alguns conceitos baseados em uma revisão bibliográfica, descrevendo e demonstrando a importância do estudo das redes, especialmente no espaço urbano.

A história da civilização pode ser contada pelos registros deixados nas ruas e construções ao longo do tempo. A evolução do homem é percebida quando este resolveu fixar moradia e cultivar sua própria subsistência. Até o período das grandes navegações - fenômeno de transportes - a vida urbana era limitada em alguns poucos quilômetros, seu raio de atuação cotidiana não passava de relações entre uma ou duas cidades vizinhas.

A necessidade de locomover-se impulsionou as grandes invenções e descobertas, a busca de novos "mundos", o aprimoramento de novos meios de transportes e as conseqüências desta busca. Talvez sem muitos exageros, essa necessidade foi e continua sendo a grande mola propulsora de evolução humana. Porém, o preço de todo desenvolvimento também está refletido nas cidades, independentemente do porte que elas tenham, em todas há congestionamentos, acidentes, poluição.

As cidades, por serem o local de realização de muitas atividades humanas, apresentam alguns problemas crônicos, cuja solução não é simples, mas que não podem, no entanto, ser ignorados. É necessário considerá-los e a melhor maneira de fazê-lo é ter uma visão ampla do todo, considerando as cidades como algo ao mesmo tempo estático e dinâmico, um organismo vivo.

Os diversos fenômenos e processos observados nas cidades, bem com as múltiplas inter-relações entre eles, exigem o uso de diferentes conceitos para sua compreensão e estudo. 
Alguns deles se baseiam em uma visão subjetiva, como é o caso da cognição e conceitos de sustentabilidade e espalhamento.

Outros se baseiam em uma visão mais objetiva, como os índices de acessibilidade e conectividade. De maneira geral, no entanto, todas as abordagens buscam, de uma forma ou de outra, parâmetros para quantificar a percepção do cidadão quanto a sua qualidade de vida.

\subsection{SUSTENTABILIDADE, CIDADES COMPACTAS E ESPALHADAS}

Uma das referências mais conhecidas sobre sustentabilidade está em WCED (1987) apud Costa (2003) que define o conceito de desenvolvimento sustentável como "aquele que atende as necessidades da geração atual sem pôr em risco a capacidade das gerações futuras de atender às próprias necessidades”.

O desenvolvimento sustentável é uma questão bastante relevante, sendo uma abordagem constante em pesquisas, tanto em países desenvolvidos quanto nos países em desenvolvimento.

Em Maclaren (1996) apud Costa (2003), considera-se a sustentabilidade como um estado desejável ou um conjunto de condições que se mantém ao longo do tempo, portanto o desenvolvimento sustentável pode ser uma solução para o alcance do equilíbrio.

A preocupação com a sustentabilidade também deve ser aplicada ao ambiente urbano, já que é nele onde se centralizam e organizam praticamente todas as atividades humanas, desde as mais básicas: alimentação, locomoção e abrigo; passando pelas manifestações culturais, pelo trabalho e estudo, finalizando nas atividades de lazer.

As cidades contemporâneas enfrentam grandes problemas; escassez de recursos (naturais ou não), carência de infra-estrutura e planejamento, desigualdade social, são alguns dos conflitos gerados no meio urbano. E a tendência é somente aumentar, por isso que a busca por soluções coerentes, efetivas e de grande abrangência se faz urgente. 
Um aspecto fortemente relacionado ao conceito de sustentabilidade no ambiente urbano é o modo com que as redes de vias e os contornos das cidades são formados. A configuração da rede de vias pode ser fator importante em políticas públicas, determinando inclusive se a aplicação de recursos é ou não eficiente.

Newman e Kenworthy (1988) apresentaram como estratégias para economizar energia através de uma melhor utilização do solo urbano, o adensamento, a centralização e políticas de restrição de tráfego, incluindo melhorias no transporte público. Outros autores, Gordon e Wong (1985) e Gordon e Richardson (1989) rejeitaram as estratégias de centralização, defendendo padrões urbanos multinucleados como mais econômicos e a única estratégia de desenvolvimento capaz de satisfazer as preferências dos moradores por habitações em regiões de baixa densidade populacional. Os trabalhos de Newman, 1992; Gordon e Richardson, 1997; Ewing, 1997; Kenworthy e Laube, 1999 e Talen, 2001, também debatem o assunto mostrando a preocupação com o tema.

Uma questão de sustentabilidade bastante relevante é a organização do tecido urbano. Apesar de haver diversos modelos urbanos, este estudo tratará apenas das cidades com padrão europeu ou americano, por causa da configuração da rede de vias.

As cidades européias são compactas, muitas vezes mononucleadas, com um traçado peculiar, algumas com mais de 500 anos de história, o que se reflete no desenho de suas ruas. Com vias sinuosas, às vezes por causa de acidentes geográficos, as habitações concentram-se nos centros, são bem adensadas, e as pessoas necessitam caminhar pequenas distâncias para atingir seus objetivos. Na maioria delas o transporte público é privilegiado, visto que as ruas são estreitas e não comportam muitos veículos. O que a princípio era uma solução meramente espacial, tornou-se vital para as cidades européias, já que atualmente elas funcionam graças ao transporte público eficiente, caso contrário já teriam entrado em colapso. 
As cidades americanas retratam uma sociedade do consumo, que privilegia o bem maior, o automóvel; apesar de algumas já demonstrarem uma mudança no pensamento quanto ao uso do veículo particular, a maioria delas é espalhada, com grandes avenidas, ruas e viadutos; configurando uma paisagem urbana onde para deslocar-se é necessário o veículo. Apesar de possuir uma boa infra-estrutura de ruas e avenidas, o transporte público não recebe incentivo, inclusive por questões culturais. O veículo particular ainda é o grande agente urbano.

Muitos pesquisadores ressaltam os benefícios da forma das cidades compactas, como a redução das necessidades por transportes e as menores taxas de emissão de poluentes, uma utilização mais eficiente da infra-estrutura urbana, a preservação de áreas agrícolas e as diversidades sociais e culturais. Por outro lado, há a poluição, perda da qualidade urbana e redução de espaços abertos como contra-argumentos.

A grande crítica que se faz às cidades espalhadas é que são projetadas para o automóvel e não para o pedestre. Ao promover o espalhamento, grande parte dos recursos físicos e financeiros é gasta em infra-estrutura viária; cidades como Los Angeles, por exemplo, apresentam cerca de dois terços do espaço urbano ocupados com ruas, avenidas e viadutos. Além dos elevados custos operacionais, construção, manutenção e recuperação das vias e segurança viária, há também gastos energéticos (combustíveis) e de deslocamentos. Outro ponto é o isolamento das pessoas e a perda de identidade e da coletividade.

Uma avaliação superficial de estudos sobre o assunto mostra que as melhores alternativas de crescimento urbano estão divididas entre: cidades mais compactas, com um centro ativo e transporte público de boa qualidade, e cidades multinucleadas, teoricamente capazes de servir ao automóvel e fornecer uma opção de transporte àqueles que não podem dirigir. Apesar das divergências nos pontos de vista dos pesquisadores, alguns países já estão adotando políticas urbanas para encorajar maiores densidades, baseadas em teorias de 
sustentabilidade das cidades compactas. Estes são os casos da Austrália e de alguns países da Europa (NEWMAN, 1992; KENWORTHY e LAUBE, 1999).

Esta visão, no entanto, aborda a cidade e sua rede viária de forma global, sem atentar para aspectos microscópicos da rede, ao qual estão diretamente relacionadas questões importantes, tais como acessibilidade, a cognição e a conectividade.

\subsection{ACESSIBILIDADE}

Há muitas definições para o termo Acessibilidade; em Bruton (1979) apud Lima (1998), índices de acessibilidade "medem a facilidade com que uma área, com certas atividades atraentes, pode ser alcançada a partir de uma zona particular e através de um determinado sistema de transportes". Já Ingram (1971) diz que acessibilidade é " $a$ característica de um determinado local com respeito a alguma forma de fricção (alguma medida de tempo ou distância)".

Lima (1998) apresenta como uma definição de acessibilidade bastante freqüente na literatura "a medida de esforço para se transpor uma separação espacial caracterizada pelas oportunidades apresentadas ao indivíduo ou grupo de indivíduos para que possam exercer suas atividades, tomando parte do sistema de transportes".

Índices de acessibilidade são bons indicadores para avaliar a qualidade do sistema de transporte de uma cidade. Por isso, no planejamento de transportes, a busca por bons índices deve ser constante, já que a avaliação leva em conta tanto às características do uso do solo quanto a qualidade do sistema de transportes.

Haggett e Chorley (1969) introduzem outros conceitos:

- Acessibilidade relativa: é definida como o grau com que dois lugares ou pontos de uma mesma superfície estão conectados. Entretanto, a relação entre os pontos não é necessariamente de igual intensidade. Um 
exemplo desta característica é a assimetria de distâncias entre lugares locados numa rede de ruas de sentido único.

- Acessibilidade integral: é definida como o grau de interconexão de um ponto com os outros pontos da superfície, ou seja, a relação de cada ponto com todos os demais outros pontos.

Os índices de acessibilidade também podem ser reflexos da forma urbana, porque além da questão da atratividade, altos índices indicam que a cidade ou região apresenta um tecido urbano bem articulado, com pequenas distâncias médias entre os pontos resultando numa boa mobilidade. O tema acessibilidade foi exaustivamente tratado na literatura, como pode ser visto em Silva (1998) e Raia Jr. (2000).

\subsection{COGNIÇÃO}

A busca pela exploração da estrutura das redes viárias, a acessibilidade, a conectividade e a eventual influência na sustentabilidade do espaço construído resultam em uma percepção ambiental muito particular do cidadão. Muitos pesquisadores têm trabalhado a respeito, os autores Thorndyke e Hayes-Roth (1982) propõem modelos de conhecimento espacial em que são testados os níveis de percepção dos cidadãos, tanto através de mapas quanto de rotas de navegação. Estes testes mostram como o cidadão percebe e capta a imagem da cidade, formando um conjunto de informações mentais sobre seu "espaço", tais como sua identidade e sua relação com a cidade.

A cidade é um conjunto de relações interpessoais com o meio ambiente natural e o construído, tentando encontrar o equilíbrio e a simbiose entre todos os envolvidos. Caliandro (1978) afirma que a vida urbana contemporânea poderia ser espelhada na forma aparentemente acidental de nossas cidades. Apesar de tudo, há certa regularidade ambiental que poderia permitir uma intenção e, conseqüentemente, um papel para as vias urbanas. Pelas 
análises comparativas, esta regularidade da forma e uso emerge e ajuda na formulação de políticas e projetos urbanos publicamente responsáveis.

Assumindo que o traçado das ruas de uma cidade forma uma rede, é nesta em que ocorre uma interação das pessoas com os edifícios, com a localização e a circulação, com as atividades socioeconômicas e com o uso do solo. Enfim, pode-se dizer que as cidades são redes complexas, tanto do ponto de vista social quanto do estrutural.

Segundo Escolano (2003) a rede de ruas da cidade contém informações sobre o grau de organização desta. Estas informações associadas podem ser usadas como indicadores da complexidade estrutural, caracterizada pelo grau da eficiência, da legibilidade, entre outros. Tais informações podem ser de grande valia para o planejamento urbano, já que compreendem elementos da estrutura urbana, como por exemplo, a circulação de veículos.

\subsection{CONECTIVIDADE}

Podem-se aplicar os conceitos de conectividade de redes em várias ciências, destacando a física, ciência da computação, sociologia e o planejamento urbano, mais precisamente no estudo de redes viárias (LYNCH, 1981; SALINGAORS, 2003).

A topologia de rede é a forma através da qual ela se apresenta fisicamente, ou seja, como os nós e arcos estão dispostos. Em poucas palavras, a topologia de uma rede descreve como é o leiaute do meio através do qual há o tráfego de informações e também como os dispositivos estão conectados a ele.

Alguns elementos da rede recebem diferentes nomes conforme a ciência que os emprega. Newman (2003) apresenta algumas definições e nomes correlatos:

- Vértice (matemática), site (física), nó (ciência da computação) ou ator (sociologia): unidade fundamental da rede; 
- Edge, laço/bond (física), elo/link (ciência da computação) ou laço/tie (sociologia): linha que conecta dois vértices;

- Orientado, não-orientado: um grafo é orientado se todos os links são orientados e um grafo é não-orientado quando tem dois links entre cada par de vértices conectados, um em cada sentido. Link orientado às vezes é chamado de arco.

As redes são topologicamente representadas como grafos, onde um grafo $G$ compreende uma série de vértices ou nós $V$ (intersecções e finais de ruas) e segmentos de ruas $E$ conectadas a aqueles vértices (HAGGET e CHORLEY, 1969). Os nós são lugares onde o indivíduo tem que tomar a decisão sobre o movimento na cidade. São também importantes localizações para a construção de imagens na paisagem urbana.

Ruas com diferentes tipologias (CALIANDRO, 1978; BEN JOSEPH e SOUTHWORTH, 1997) fornecem a conexão para as cidades. Para Moles e Rohmer (1990) apud Escolano (2003), “a rede de ruas é uma parte essencial da teoria que concebe a estrutura física urbana como um labirinto geométrico, talvez estético e também um labirinto de experiências individuais, onde o desenvolvimento social individual e em grupos revela-se em diversas escalas".

Como as concepções do espaço urbano (GOULD e WHITE, 1974) são afetadas pela estrutura do mesmo (LYNCH, 1960), a desconectividade tem impactos sobre a orientação e a qualidade de vida dos cidadãos (APPLEYARD, 1981; WHYTE, 1980; GEHL, 1987; SOUTHWORTH e OWENS, 1993; OWENS, 1993; SOUTHWORTH e BEN JOSEPH, 1995; SOUTHWORTH, 1997; BOSSELMANN et al., 1999). Dupuy (1991, 1995), no entanto, sugere que as ruas das cidades contemporâneas são dominadas pelo automóvel, caracterizadas pela conectividade para os carros e desconectadas para os pedestres.

Entre as propriedades topológicas de maior interesse para este estudo, que se baseia em redes, caracterizando as cidades como redes complexas, estão os elementos: Small 
World, Índice de Centralidade, Estruturas Comunitárias e Autocorrelação de Redes, apresentados a seguir.

\subsubsection{Small World}

A teoria do Small World surgiu dos experimentos do psicólogo Stanley Milgram em 1967. O experimento partiu da hipótese que qualquer indivíduo pode se relacionar com qualquer outro individuo no mundo inteiro, desde que sua rede possua ao menos seis relações de amizade com indivíduos diferentes, e estes possuam redes de amizade distintas. A partir deste experimento novas pesquisas em sociologia foram desenvolvidas incorporando os conceitos de rede. O próximo passo foi introduzir os resultados das pesquisas em outras áreas. Este fenômeno é aplicado em áreas de estudo como a sociologia, antropologia, informática, biologia, etc.

O efeito "Small World" aplica-se, sobretudo a redes de informação e significa dizer que a transmissão da informação é exponencial. Por exemplo, se forem consideradas seis pessoas para espalhar uma informação para quaisquer outras seis pessoas e assim sucessivamente, então a informação se espalhará mais rápido que se forem consideradas centenas ou milhares de pessoas onde a transmissão da informação se dá apenas individualmente. Ao final, esta característica apresenta menores "distâncias de caminhada", embora com muitas opções entre as origens e destinos (WATTS e STROGATZ, 1998; DUCKHAM e KULIK, 2003; NEWMAN, 2003; KUIPERS, 2001).

\subsection{2 Índice de Centralidade}

O Índice de Centralidade é a capacidade de identificar o grau de centralidade da cidade (MARCHAND, 2002), característica potencialmente posta de lado pela 
policentralidade dos tempos modernos (BATTY, 2001). Segundo Escolano (2003), a estrutura das ruas dentro de uma cidade configura um sistema estático próximo ao equilíbrio, interagindo com o entorno com o qual mantém alguma relação (incluindo a de canalizador de movimentos entre os edifícios). Por isso, há a influência das ruas sobre o movimento, a localização das pessoas, as atividades econômicas e sobre o uso do solo. A estes, e outros efeitos combinados, dá-se o nome de centralidade, importante na caracterização de território.

\subsubsection{Estruturas Comunitárias}

As Estruturas Comunitárias são particularmente importantes para a representação mental voltada para a navegação humana, tendo em vista que essa é topologicamente orientada (segundo SIEGEL e WHITE, 1975; KUIPERS, 1978; THORNDYKE e HAYES-ROTH, 1982) e também hierárquica (STEVENS e COUPE, 1978). Posto de outra forma, a divisão das cidades em bairros (GIRVAN e NEWMAN, 2002, KUIPERS, 1978) leva à criação de uma identidade social (RAPOPORT, 1977; PROSHANSKY et al., 1983; UZZEL et al., 2002), que permite uma análise topológica relevante para a localização e orientação na navegação humana, cujo raciocínio espacial se dá por meio de mapas cognitivos (KUIPERS, 1978).

\subsubsection{Autocorrelação de Redes}

A Autocorrelação de redes existe sempre que uma variável exibe um padrão regular sobre uma rede na qual os valores de segmentos de dados sofrem influência dos valores de uma mesma variável em outros segmentos. Pode ser vista como uma medida derivada da autocorrelação espacial de áreas, na qual o método utilizado decorre das inferências estatísticas para testar as hipóteses por meio do Índice de Moran. Dadas as características 
predominantemente quantitativas usualmente presentes nas análises de transportes, essa abordagem foi aqui selecionada para aplicação e estudo. Por esse motivo, alguns dos seus fundamentos teóricos são comentados a seguir.

A análise espacial é utilizada para medir áreas e relações nelas envolvidas, considerando e incorporando o espaço nesta análise. Segundo Lopes (2005) a análise é “o estudo, exploração e modelagem de processos que se expressam através da distribuição no espaço". Tobler (1970) apud Lopes (2005) cita a Primeira Lei da Geografia: “todos os objetos no espaço estão relacionados, porém objetos mais próximos estão mais relacionados, assim a localização dos objetos influencia o resultado da análise".

A variação espacial de um fenômeno inscrito num conjunto de técnicas, inclusive com métodos estatísticos, resulta no que se chama Estatística Espacial.

A Autocorrelação Espacial, um dos conceitos da Análise Espacial, é uma relação entre valores de algumas variáveis que influenciam outras, mantendo uma interdependência; e a hipótese de interdependência é testada por métodos da estatística formal.

Os testes e a mensuração da interdependência requerem informações espaciais ou locais expressas em termos numéricos. O processo para testar as hipóteses segue a mesma lógica que qualquer teste estatístico (ODLAND, 1988). A autocorrelação de redes parte do mesmo princípio que a autocorrelação espacial, em que um fenômeno influencia seus vizinhos, numa relação de reciprocidade ou não. $\mathrm{Na}$ análise de redes, os valores são dos segmentos/arcos, não mais de áreas.

Um dos índices para avaliar o nível de autocorrelação espacial de redes é o Índice de Moran (1947).

$$
I=\frac{n}{\sum \sum_{i j} w_{i j}} \times \frac{\sum \sum_{i j} w_{i j} \times\left(x_{i}-\bar{x}\right) \times\left(x_{j}-\bar{x}\right)}{\sum_{i}\left(x_{i}-\bar{x}\right)^{2}}
$$


Sendo: I = Índice de Moran;

$\mathrm{n}=$ número de segmentos;

$\mathrm{W}_{\mathrm{ij}}=$ fator peso, indicando se o segmento $i$ é conectado ao segmento $j$ (por exemplo igual a 1), ou não (igual a 0);

$x_{i}=$ valor da variável $\mathrm{x}$ no segmento $\mathrm{i} ;$

$x_{j}=$ valor da variável $\mathrm{x}$ no segmento $\mathrm{j}$;

$\bar{x}=$ valor médio das variáveis.

$\mathrm{O}$ valor do índice varia de -1 a +1 . Valores iguais ou próximos a -1 indicam que há uma autocorrelação negativa, ou seja, os valores vizinhos são extremamente diferentes. Valores iguais ou próximos a +1 indicam que há autocorrelação positiva, ou seja, os valores são similares nos segmentos adjacentes. Se o valor do índice estiver próximo a zero indica que não há autocorrelação, nem positiva, nem negativa.

O uso de uma abordagem de análise dos acidentes através da aplicação de conceitos de autocorrelação espacial em redes já foi proposta por Black e Thomas (1998), que analisaram a autocorrelação dos acidentes de trânsito na rede de rodovias belgas.

No Brasil, no entanto, os trabalhos que aplicaram os conceitos de análise espacial para análise de acidentes, como Queiroz (2003) e Santos (2005), o fizeram a partir da distribuição original dos pontos ou da sua agregação em áreas.

Tendo em vista que os dados utilizados por Santos (2005) foram disponibilizados para o presente estudo, todas as análises aqui propostas são realizadas também na cidade de São Carlos. Isso permite uma comparação direta dos resultados obtidos com as diferentes abordagens de análise já que, ao contrário da proposta desse estudo, Santos (2005) realizou somente análises de padrões pontuais e análises espaciais de áreas baseadas em dados de acidentes de trânsito. 
Em síntese, o autor identificou os pontos e áreas críticas, além da distribuição espacial dos acidentes e identificação das tendências de deslocamento do fenômeno através de mapas temáticos, médias móveis e Box Map. Parte desses procedimentos foi aqui reproduzido a partir da análise de redes, como é detalhado na metodologia.

\subsection{CONSIDERAÇÕES FINAIS}

A revisão da literatura deixa claro que a qualidade de vida nas cidades tem sofrido uma deterioração lenta e silenciosa e, no intuito de frear o processo de degradação, o estudo do urbano é necessário e urgente. Uma das maneiras de se pensar a cidade é por uma visão subjetiva, como mostrada neste estudo pelo viés da cognição e pelos conceitos de sustentabilidade ou compacidade e espalhamento.

Entretanto, constatou-se também a existência de visões mais objetivas, em que se buscam parâmetros que quantifiquem a percepção do cidadão quanto a sua qualidade de vida, como é o caso dos índices de acessibilidade e conectividade. Para o último, a cidade é tratada como uma rede complexa formada pelas ruas e avenidas. Apesar dessa complexidade, as cidades entendidas como redes facilitam o seu estudo, pois as informações nelas contidas estão organizadas e relacionadas entre si, mostrando ao mesmo tempo uma estrutura orgânica e bem definida. O movimento em suas ruas e avenidas pode ser comparado a um organismo vivo e também é um elemento organizador.

Dentre as possíveis ferramentas aqui discutidas para análises objetivas, a autocorrelação de redes mostrou-se uma medida quantitativa que resume algumas das características relacionadas à conectividade discutidas nos itens anteriores, e foi por esse motivo selecionado para o presente estudo. O Índice de Moran, sendo um índice de autocorrelação, permite que seja aplicado para qualquer variável. Neste caso, utilizou-se o número de acidentes de trânsito, mas essa variável pode ser substituída por outras variáveis 
que sejam passíveis de representação espacial, o que o torna muito flexível enquanto ferramenta da análise. 


\section{CAPITULO 3}

\section{ACIDENTES DE TRÂNSITO}

A Organização Mundial de Saúde define acidente como "um evento independente do desejo do homem, causado por uma força externa, alheia, que atua subitamente e deixa ferimentos no corpo e na mente (...) Assim, um acidente de trânsito pode ser definido como um evento que envolve ao menos um veículo que circula, normalmente por um via para trânsito de veículo, podendo este ser motorizado ou não" (GOLD, 1998, p. 9).

Segundo Ferraz e Raia Jr. (2007, p. 6) acidente de trânsito é "um evento envolvendo um ou mais veículos, motorizados ou não, em movimento por uma via, que provoca ferimentos em pessoas e/ou danos físicos em veículos e/ou objetos de outra natureza (poste, muro, casa, sinal de trânsito, propaganda, etc.)".

O acidente de trânsito é um dos resultados negativos do crescimento desordenado nos níveis de motorização em escala mundial. Dificilmente encontra-se uma cidade ou país que não apresente problemas relacionados a acidentes de trânsito. Mais difícil ainda é encontrar políticas públicas eficientes que amenizem tais problemas. O cenário nas principais cidades do mundo apresenta uma visão catastrófica; milhões de mortes e outros milhares de feridos, que em muitos casos resultam em lesões permanentes.

Os acidentes de trânsito estão relacionados com os números da frota de veículos, já que o nível de desenvolvimento de um país está freqüentemente associado ao tamanho e qualidade de sua frota de veículos. Geralmente países em desenvolvimento, como o Brasil, apresentam uma frota com veículos muito velhos; falta de manutenção da frota, das estradas e da sinalização; fiscalização precária, sem policiamento e equipamentos adequados; ineficiência no atendimento médico especializado, etc. 
No Brasil, segundo DETRAN-PR (2006), IPEA (2006) estimam-se que ocorram cerca de um milhão de acidentes (sendo a maioria, cerca de $62 \%$, urbanos), 35 mil mortes, 500 mil feridos e 100 mil vítimas com lesões permanentes.

Outro ponto é quanto à questão econômica dos acidentes. Os gastos com acidentes representam $1 \%$ do Produto Interno Bruto (PIB) dos países pobres, 1,5\% dos países em desenvolvimento e $2 \%$ dos desenvolvidos (IPEA, 2006). Essas porcentagens representam gastos anuais com: perdas materiais (veículos, cargas, recuperação da infra-estrutura, etc.), perdas com vítimas permanentes e temporárias (despesas médicas e hospitalares, tratamentos, reabilitações, indenizações, pensões, aposentadorias, perda de produção, funerais, etc.), outros custos referentes ao atendimento da polícia e paramédicos, além de danos à propriedade pública e privada.

No estudo "Impacto social e econômico dos acidentes de trânsito nas rodovias brasileiras" realizado pelo IPEA, constatou-se que o custo de um acidente com apenas danos materiais corresponde a $\mathrm{R} \$ 1.040,00$, enquanto que em um acidente com vítima não fatal o valor sobe para $\mathrm{R} \$ 36.305,00$. Já uma vítima fatal representa um custo médio de $\mathrm{R} \$$ 270.165,00 (valores em dezembro/2005 - IPEA). A Tabela 3.1 exemplifica melhor os valores.

Tabela 3.1 - Custos por acidente de trânsito, segundo IPEA (2006)

\begin{tabular}{lcc}
\hline \multicolumn{1}{c}{$\begin{array}{c}\text { Condição da pessoa } \\
\text { envolvida }\end{array}$} & $\begin{array}{c}\text { Custo médio associado à } \\
\text { pessoa }\end{array}$ & $\begin{array}{c}\text { Custo médio adicionado ao } \\
\text { acidente }\end{array}$ \\
\hline Ileso $(\mathrm{R} \$)$ & $1.040,00$ & $1.207,00$ \\
Ferido $(\mathrm{R} \$)$ & $36.305,00$ & $38.256,00$ \\
Morto $(\mathrm{R} \$)$ & $270.165,00$ & $281.216,00$ \\
\hline
\end{tabular}

Os custos econômicos só não são maiores que o custo humano e social, já que não se pode quantificar o sofrimento físico e emocional das vítimas e familiares, além de problemas futuros de natureza psicológica tanto entre vítimas quanto seus familiares. 
Em acidentes com o transporte de cargas deve-se também computar custos ambientais, pois em caso de acidentes com produtos químicos podem ocorrer derramamentos e conseqüente contaminação de mananciais, flora e fauna.

Ainda segundo IPEA (2006), os atropelamentos representam uma parcela considerável no número de acidentes, principalmente por que quase um terço dos atropelados morre. Outro fator de preocupação é o horário em que ocorrem, geralmente à noite, entre as 18 e 20 horas, horário do retorno do trabalho para casa. Os acidentes com motocicletas guardam proporções semelhantes. Embora eles tenham representado 10,8\% de todos os acidentes, causaram $15,2 \%$ de todas as mortes.

A Tabela 3.2 apresenta o total dos acidentes com vítimas fatais e não fatais do Brasil e dos estados no ano de 2005, além dos números de acidentes com algum tipo de vítima.

A frota de veículos aumenta a cada ano e, conforme mostrado na Figura 3.1, em pouco mais de 10 anos houve um aumento significativo da frota nacional. Na Figura 3.2, em uma primeira observação pode-se constatar que houve redução do índice de vítimas fatais por 10 mil veículos em acidentes de trânsito nos últimos onze anos, principalmente de 1996 para 1997. A explicação para esta redução é que o novo Código de Trânsito Brasileiro (CTB) foi aprovado e entrou em vigor, o que aparentemente contribuiu para a redução, embora não tivesse condições de resolver sozinho o problema.

A simples aprovação do CTB não garantiu que os níveis de acidentes diminuíssem consideravelmente, mas criou mecanismos que auxiliam a desejada redução. Isso reforça a importância de políticas públicas que contemplem a prevenção de acidentes e a educação para o trânsito.

Uma forma que auxilia na prevenção é saber como os acidentes ocorrem, quais locais são mais freqüentes. O número de acidentes em um local (trecho da via, cidade, estado 
ou país) geralmente é agrupado por período, podendo ser expresso em meses ou anos. Isso é feito para facilitar os estudos e a incorporação dos dados em índices quantitativos.

Para gerenciar a rede viária é desejável o mapeamento dos acidentes no espaço e no tempo, visando identificar onde é a maior incidência e a partir da definição traçar estratégias para corrigir os problemas.

Tabela 3.2 - Total de acidentes de trânsito (DENATRAN, 2006)

\begin{tabular}{|c|c|c|c|c|}
\hline \multicolumn{5}{|c|}{ Número de Vítimas/Acidente } \\
\hline & Vítimas Fatais & Vítimas Não Fatais & Totais & Acidentes com Vítima \\
\hline BRASIL & 26.409 & 513.510 & 539.919 & 383.371 \\
\hline Acre & 96 & 2.399 & 2.495 & 1.863 \\
\hline Alagoas & 258 & 2.762 & 3.020 & 2.053 \\
\hline Amapá & 105 & 3.083 & 3.188 & 1.599 \\
\hline Amazonas & 332 & 6.124 & 6.456 & 5.274 \\
\hline Bahia & 1.073 & 15.983 & 17.056 & 11.387 \\
\hline Ceará & 1.481 & 11.196 & 12.677 & 9.654 \\
\hline Distrito Federal & 442 & 12.408 & 12.850 & 9.359 \\
\hline Espírito Santo & 530 & 13.410 & 13.940 & 10.096 \\
\hline Goiás & 3.963 & 61.255 & 65.218 & 30.305 \\
\hline Maranhão & 982 & 4.592 & 5.574 & 4.349 \\
\hline Mato Grosso & 508 & 8.652 & 9.160 & 6.590 \\
\hline Mato Grosso do Sul & 421 & 10.818 & 11.239 & 8.358 \\
\hline Minas Gerais & 1.248 & 35.209 & 36.457 & 27.356 \\
\hline Pará & 680 & 3.902 & 4.582 & 3.860 \\
\hline Paraíba & 395 & 3.450 & 3.845 & 2.681 \\
\hline Paraná & 1.631 & 52.086 & 53.717 & 38.329 \\
\hline Pernambuco & 701 & 4.904 & 5.605 & 4.061 \\
\hline Piauí & 400 & 3.021 & 3.421 & 2.398 \\
\hline Rio de Janeiro & 2.584 & 37.749 & 40.333 & 26.507 \\
\hline Rio Grande do Norte & 435 & 3.686 & 4.121 & 3.076 \\
\hline Rio Grande do Sul & 1.153 & 28.592 & 29.745 & 20.745 \\
\hline Rondônia & 326 & 6.446 & 6.772 & 4.704 \\
\hline Roraima & 112 & 1.468 & 1.580 & 1.234 \\
\hline Santa Catarina & 243 & 5.640 & 5.883 & 4.797 \\
\hline São Paulo & 6.091 & 169.532 & 175.623 & 138.814 \\
\hline Sergipe & 50 & 1.279 & 1.329 & 962 \\
\hline Tocantins & 169 & 3.864 & 4.033 & 2.963 \\
\hline
\end{tabular}




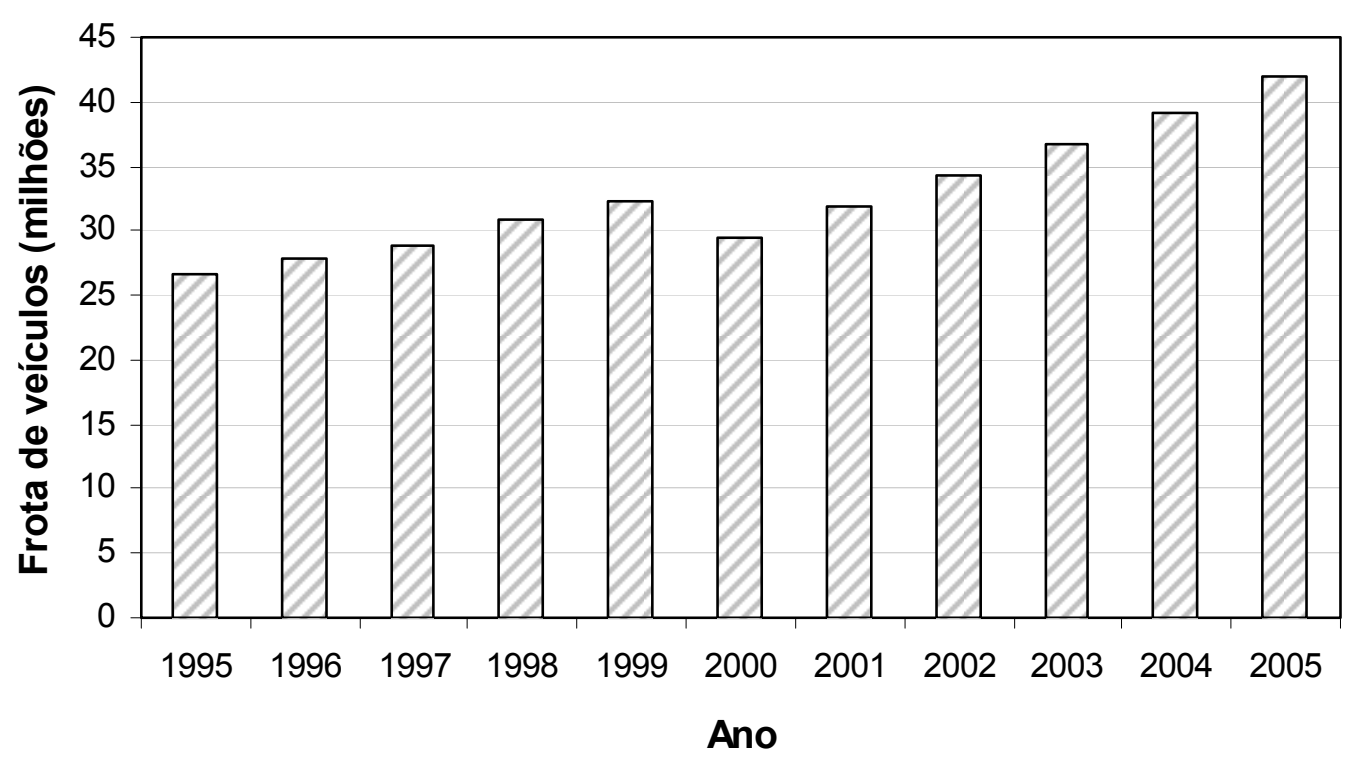

Figura 3.1 - Evolução da frota de veículos ao longo dos anos (DENATRAN, 2005)

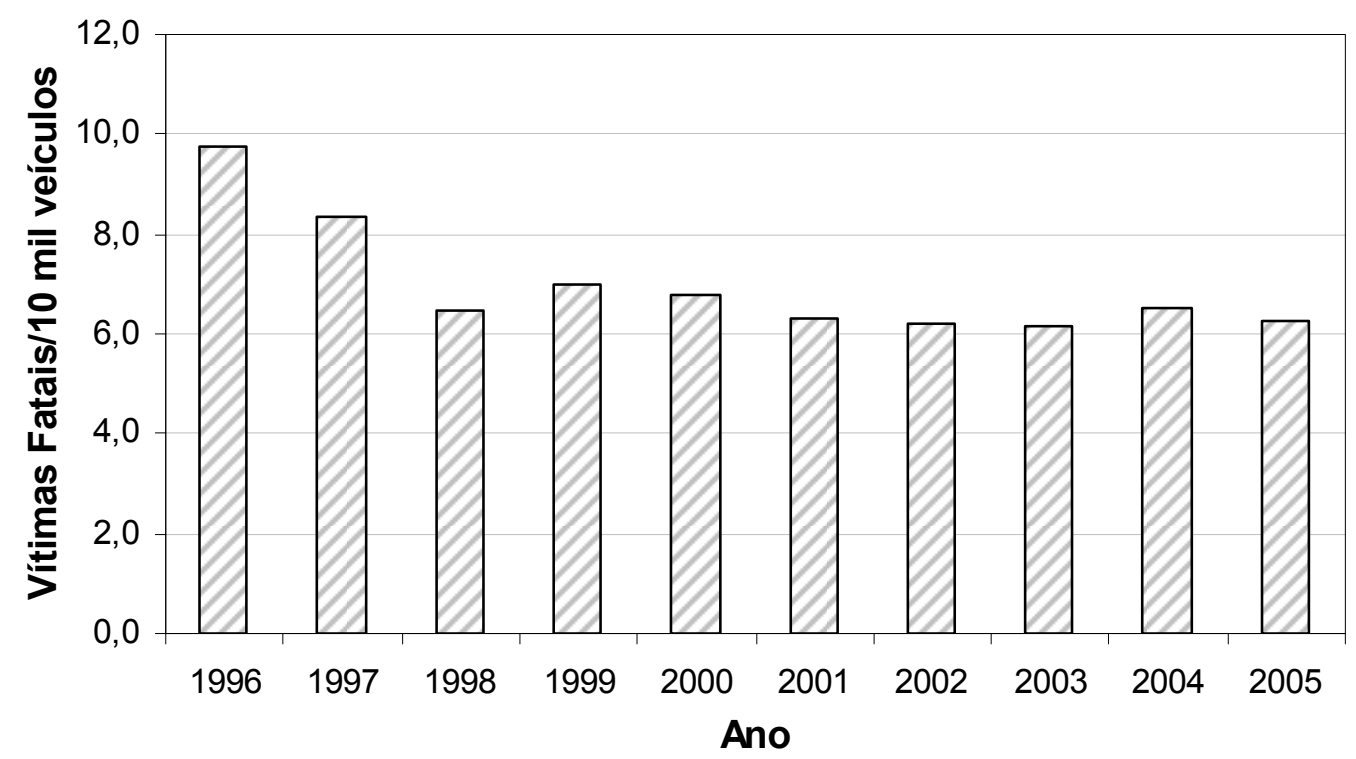

Figura 3.2 - Número de vítimas fatais/10 mil veículos ao longo dos anos (DENATRAN, 2005)

Dentre os diversos índices existentes, o MT (2002) apresenta uma metodologia de estudo que consiste em determinar os locais críticos, a partir de vários índices, quantificá-los e desenvolver estratégias de combate aos acidentes. Para a determinação de locais críticos, a metodologia apresenta a Técnica do Número de Acidentes, da Severidade de Acidentes, da Taxa de Acidentes e da Taxa de Severidade dos Acidentes. 
A Técnica do Número de Acidentes considera a quantidade de ocorrências em um segmento da rede viária (interseção ou segmento entre interseções consecutivas) durante um tempo definido. Caracterizam-se como locais críticos aqueles em que o número de acidentes for superior à média das ocorrências registradas em cada um dos locais em análise. O método tem como vantagem: baixo custo de execução e praticidade; e principal utilização é a identificação de locais críticos - interseções e trechos com grande quantidade de acidentes e elevados volumes de tráfego.

A Técnica da Severidade de Acidentes considera a quantidade e a gravidade dos acidentes, associando a cada situação um determinado peso. Estes pesos foram estabelecidos a partir da relação entre os custos atribuídos a cada tipo de severidade. Além das vantagens da técnica anterior, o uso da severidade prioriza aqueles acidentes cujos resultados foram mais severos em termos de vítimas. A determinação dos locais críticos é direcionada para interseções e segmentos com grande número de acidentes e elevados volumes de tráfego.

Para a sociedade, um acidente com vítima fatal $(A V F)$ possui custo econômico superior a um acidente com vítima não fatal $(A N F)$, que, possui custo superior àqueles somente com danos materiais $(A D M)$. O DENATRAN instituiu a Unidade Padrão de Severidade - a UPS, que é o resultado da soma dos produtos do número de ocorrências por severidade pelo peso atribuído à respectiva severidade, conforme a Equação 3.1. Sendo 1, 4, 6 e 13, respectivamente, os pesos atribuídos aos acidentes com danos materiais, acidentes com vítima não fatal, atropelamento (ATR) e acidentes com vítima fatal.

$$
U P S=(1 \times A D M)+(4 \times A N F)+(6 \times A T R)+(13 \times A V F)
$$

Segundo Gold (1998), acidente com danos materiais é aquele que produz danos materiais, sem que destes resultem em pessoas feridas fisicamente dentre as envolvidas 
no acidente. Já acidentes com vítimas não fatais são aqueles em que há feridos, em maior ou menor grau, de pelo menos uma das pessoas envolvidas. O grau pode ser leve ou grave, embora estes termos não estejam bem definidos.

Atropelamentos são acidentes em que a vítima é pedestre, não estando dentro do veículo (motorista ou carona). Apresentam uma classificação parecida com a do acidente com vítima não fatal, porém na maioria dos casos, o ferimento é mais grave, mantendo uma relação direta com altas velocidades. Acidente com vítima fatal é o resultado da morte de pelo menos uma das vítimas envolvidas.

A Técnica da Taxa de Acidentes relaciona a quantidade de acidentes de trânsito com o volume do tráfego em cada local. Como vantagem, tem-se a neutralização da influência do volume veicular no nível de acidentes, já que locais com elevados volumes de tráfego tendem a possuir maior número de acidentes. As taxas de acidentes são normalmente expressas em acidentes / milhões de veículos que entram em uma interseção ou acidentes por milhões de veículos x km em um trecho de via, podendo ser calculadas da forma apresentada nas Equações 3.2 e 3.3 .

Para interseções:

$$
T=\frac{\left(A \times 10^{6}\right)}{P \times V}
$$

Em que:

$\mathrm{T}=$ quantidade de acidentes por milhões de veículos;

$\mathrm{A}=$ quantidade de acidentes na interseção;

$\mathrm{P}=$ período do estudo, em dias (geralmente 365 dias);

$\mathrm{V}=$ volume médio diário que entra na interseção (soma das aproximações).

Para trechos viários: 


$$
T=\frac{\left(A \times 10^{6}\right)}{(P \times V \times E)}
$$

Em que:

$$
\begin{aligned}
& \mathrm{T}=\text { acidentes por milhões de veículos } / \mathrm{km} ; \\
& \mathrm{A}=\text { número de acidentes no trecho; } \\
& \mathrm{P}=\text { período do estudo, em dias (geralmente } 365 \text { dias); } \\
& \mathrm{V}=\text { volume médio diário que passa no trecho; } \\
& \mathrm{E}=\text { extensão do trecho }(\mathrm{em} \mathrm{km}) .
\end{aligned}
$$

A Técnica da Taxa de Severidade dos Acidentes combina as duas últimas técnicas ao relacionar a quantidade de acidentes, expressa em UPS com o volume de tráfego, sendo esta taxa normalmente expressa em UPS por milhões de veículos que entram em uma interseção ou UPS por milhões de veículos/ $\mathrm{km}$ em um trecho de via. As expressões para cálculo dessas taxas são as Equações 3.4 e 3.5.

Para interseções:

$$
T=\frac{\left(n^{o} d e U P S \times 10^{6}\right)}{P \times V}
$$

Em que:

$\mathrm{T}=$ acidentes em UPS por milhões de veículos;

UPS = unidade padrão de severidade;

$\mathrm{P}=$ período do estudo, em dias (geralmente 365 dias);

$\mathrm{V}=$ volume médio diário que entra na interseção (soma das aproximações).

Para trechos: 


$$
T=\frac{\left(n^{o} d e U P S \times 10^{6}\right)}{(P \times V \times E)}
$$

Em que: $\quad T=$ acidentes em UPS por milhões de veículos $\mathrm{x} \mathrm{km}$;

UPS = unidade padrão de severidade;

$\mathrm{P}=$ período do estudo, em dias (geralmente 365 dias);

$\mathrm{V}=$ volume médio diário que passa no trecho;

$\mathrm{E}=$ extensão do trecho $(\mathrm{em} \mathrm{km})$;

Do mesmo modo que na medida anterior, a desvantagem desta medida está no custo para determinação dos volumes de tráfego e a vantagem em relação àquela reside no fato de ser considerada a severidade dos acidentes. 


\section{CAPITULO 4}

\section{METODOLOGIA}

Este capítulo descreve o método adotado para o estudo da autocorrelação espacial em redes, referenciando aspectos da estatística espacial aplicada no presente trabalho. Em seguida, esses aspectos são detalhados em um estudo de caso para a cidade de São Carlos, apresentando a origem dos dados utilizados bem como o seu tratamento e formatação, e posterior análise. Nesse capítulo também estão inseridas algumas características da cidade referentes à distribuição dos acidentes pela rede viária.

\subsection{TÉCNICAS EMPREGADAS}

As ferramentas utilizadas neste estudo são provenientes da Estatística Espacial, a qual engloba, dentre outras técnicas, a Análise Exploratória de Dados Espaciais - AEDE (ou ESDA, da expressão em inglês Exploratory Spatial Data Analysis). Os principais elementos para a sua utilização são: matriz de proximidade espacial $(W)$, vetor de desvios $(Z)$ e vetor de médias ponderadas $\left(\mathrm{W}_{\mathrm{Z}}\right)$, podendo obtê-los de diversas maneiras, de acordo com o pacote computacional utilizado. Para análise de áreas, uma possibilidade é utilizar o software ArcView, com a extensão Spacestat incorporada ao programa (ANSELIN e BAO, 1997; ANSELIN e SMIRNOV, 1998). Já Lopes (2005), apresenta os passos para a obtenção desses elementos por meio do software SPRING. Outra opção é o software TransCAD, que foi aqui empregada e é apresentada em detalhes ao final deste trabalho, no Apêndice.

A utilização da técnica sobre qualquer variável espacial pode ter os resultados visualizados através de mapas e gráficos, por exemplo, o gráfico e o mapa de Moran. 
Qualquer que seja a maneira de visualizar os resultados, estes serão classificados em quadrantes, assim nomeados: Q1, Q2, Q3 e Q4.

O uso desta técnica se justifica pelo fato de que a representação em mapas temáticos facilita uma comparação direta entre as diversas variáveis, o que é mais difícil quando os resultados são simplesmente apresentados de forma numérica. Além disso, a padronização dos resultados torna a informação mais clara, permitindo verificar ou não a semelhança entre as variáveis ao considerar relações de vizinhança entre as entidades espaciais.

O diferencial desta pesquisa é caracterizar a cidade como uma estrutura em rede. Considerando suas ruas e avenidas como segmentos conectados entre si, a "visualização mental" apresenta-se muito próxima da realidade, tornando a identificação muito fácil e simples de se perceber. Além disso, a visualização da incorporação de novos segmentos à rede é facilmente captada, tanto quanto novos bairros incorporados à estrutura urbana.

Outra questão importante é a ocorrência de eventos urbanos que têm lugar essencialmente em redes. Considerá-los em sua estrutura original assegura uma precisão maior dos dados e de quaisquer cálculos com eles realizados, já que sua estrutura incorpora-se ao cálculo e conseqüentemente à análise final. Como exemplo de eventos dessa natureza pode-se citar: a infra-estrutura urbana básica (água, esgoto, telefonia, energia elétrica, etc.), a coleta de lixo, o transporte público urbano e os acidentes de trânsito, que são o foco desse estudo.

\subsection{ESTUDO DE CASO}

Como este trabalho se propõe a realizar uma complementação do estudo de Santos (2005), trabalhou-se com a mesma base de dados de acidentes e no mesmo programa TransCAD, que é um Sistema de Informações Geográficas para Transportes-SIG-T. 
Diferentemente de Santos, que primeiro analisou a extensão da rede sem observar a gravidade dos acidentes e depois analisou a gravidade sem considerar a extensão da rede; esta pesquisa trabalhou a rede toda incorporando os acidentes e sua gravidade, além de considerar os casos em arcos e interseções de forma distinta.

Tendo em vista que as análises propostas neste trabalho baseiam-se em redes, foram identificados fenômenos cuja ocorrência estivesse de alguma forma vinculada ou, mais do que isso, fosse dependente da rede. Esse parece ser o caso dos acidentes de trânsito, hipótese que foi aqui testada através de um estudo de caso realizado na cidade de São Carlos, região central do estado de São Paulo. Com aproximadamente 218 mil habitantes, a cidade contava em 2006 com uma das maiores frotas de veículos automotores do estado em termos relativos - aproximadamente 62 mil veículos, o que representa 0,28 veículo/habitante ou pouco mais que um carro por família, se considerado o padrão médio de cerca de quatro indivíduos por família.

No estudo de caso realizado foram utilizados os mesmos dados de acidentes de trânsito dos anos de 2001, 2002 e 2003, restritos à área urbana, trabalhados por Santos (2005), até mesmo para facilitar a comparação das metodologias trabalhadas. A Tabela 4.1 apresenta a distribuição dos acidentes válidos por tipo e por ano.

Tabela 4.1 - Distribuição dos acidentes por tipo e por ano

\begin{tabular}{lrrr}
\hline \multirow{1}{*}{ Tipo de acidentes } & \multicolumn{3}{c}{ Anos } \\
\cline { 2 - 4 } & $\mathbf{2 0 0 1}$ & $\mathbf{2 0 0 2}$ & $\mathbf{2 0 0 3}$ \\
\hline Atropelamentos & 100 & 98 & 92 \\
Com danos materiais & 2296 & 2223 & 2161 \\
Com vitimas não fatais & 579 & 548 & 615 \\
Com vitimas fatais & 2 & 3 & 4 \\
\hline Totais & 2.977 & 2.872 & 2.872 \\
\hline
\end{tabular}

O estudo proposto inclui as seguintes etapas: o cálculo do Índice I de Moran, a classificação pelos quadrantes e a análise pela visualização dos Box Map. 


\subsubsection{Tratamento e Formatação dos Dados}

A base cartográfica da cidade de São Carlos foi obtida junto ao Departamento de Transportes da Escola de Engenharia de São Carlos da Universidade de São Paulo e passou por uma conferência para eliminar possíveis inconsistências, resultando em uma rede com 9.786 segmentos (Figura 4.1), georreferenciada com o software TransCAD. A versão utilizada do programa foi a 3.6, para uso acadêmico.

Os dados de acidentes desta pesquisa foram extraídos dos registros dos Boletins de Ocorrência (BOs) da Polícia Militar. Uma vez eliminados registros que continham inconsistências ou dados de natureza particular, tais como acidentes em locais fora da rede urbana ou em locais particulares (em estacionamentos privados, como no Shopping Center, por exemplo); os dados em que foi aplicada a metodologia foram aqueles resumidos na Tabela 4.1. Naquela Tabela, os acidentes são separados por tipo (atropelamentos, com danos materiais, com vítimas não fatais e com vítimas fatais), e por ano (2001, 2002 e 2003), mas é possível classificá-los ainda de acordo com sua localização na rede (em arcos ou interseções).

A Figura 4.2 mostra, a título de exemplo, a locação dos acidentes no ano de 2001 georreferenciados e com a rede viária. Numa análise preliminar já é possível visualizar os locais que apresentam maiores incidências de ocorrências, com destaque para algumas avenidas como a São Carlos (principal eixo norte-sul), Getúlio Vargas e Miguel Petroni, sendo as duas últimas importantes ligações do centro com regiões periféricas. 


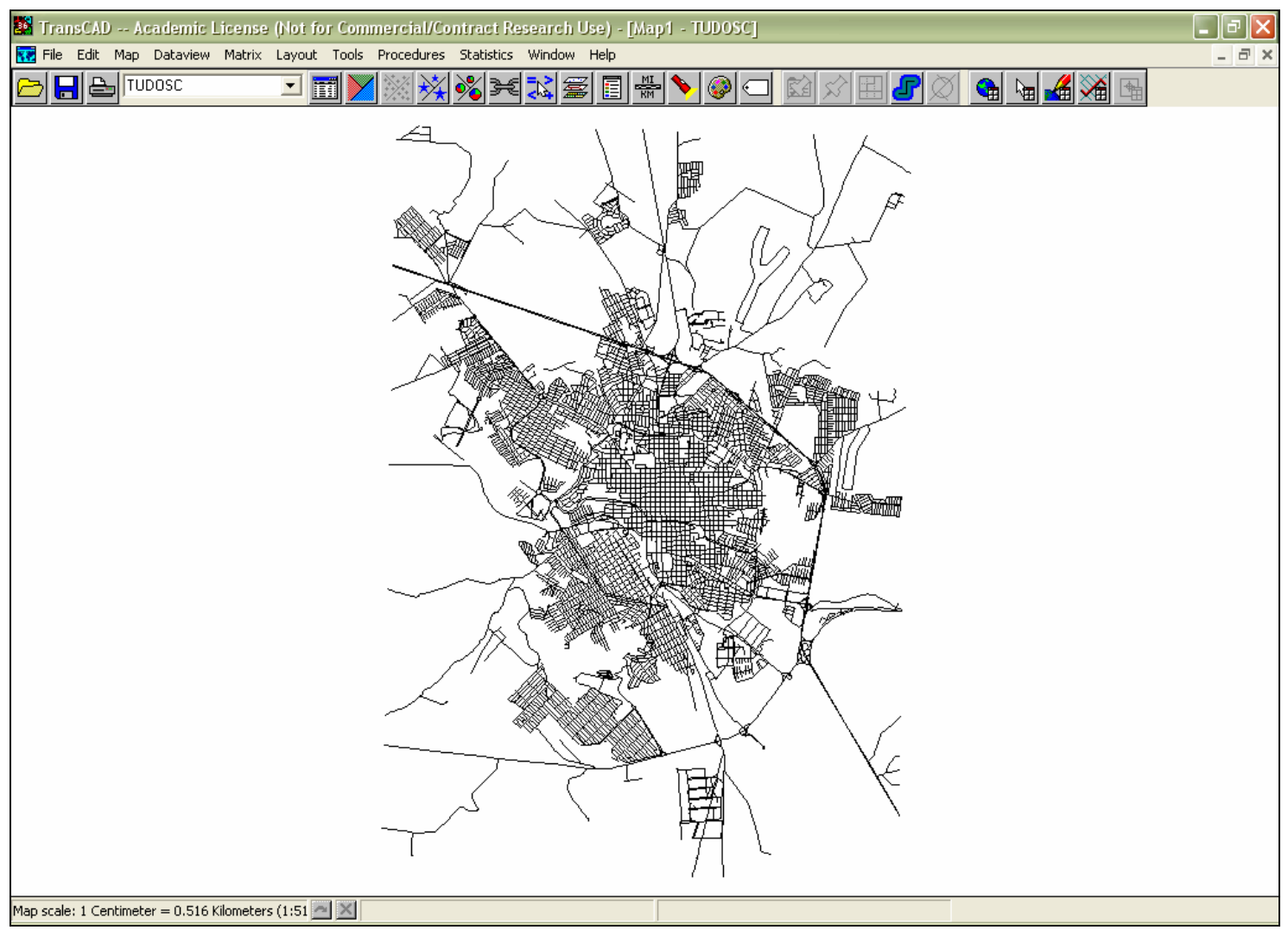

Figura 4.1 - Rede viária da cidade de São Carlos em janela do programa TransCAD

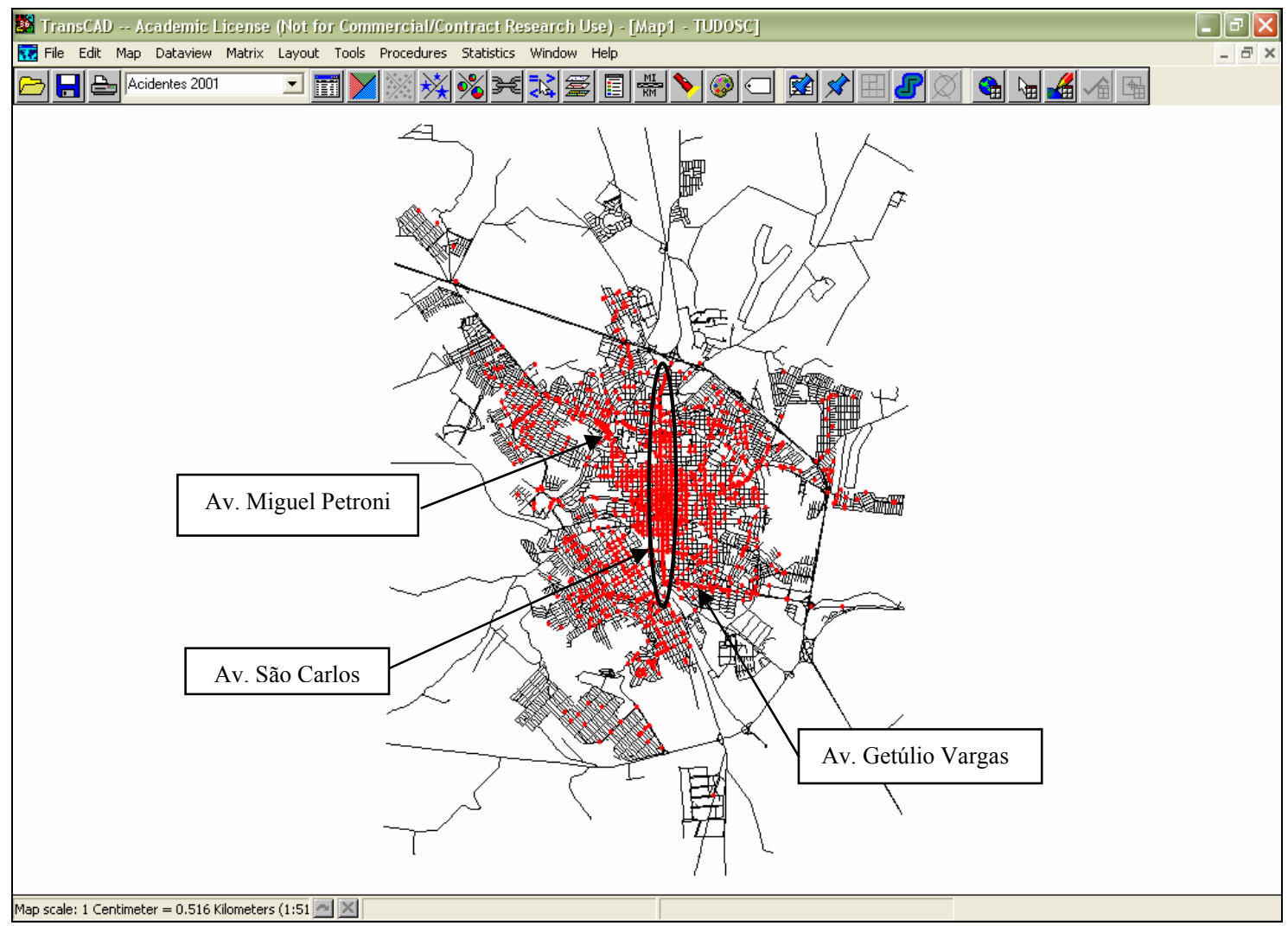

Figura 4.2 - Georreferenciamento dos acidentes de 2001 juntamente com a rede viária de São Carlos 


\subsection{CONTRIBUIÇÃO DA PESQUISA}

Tendo como referência os trabalhos de Queiroz (2003) e principalmente de Santos (2005), esta pesquisa se propõe a complementá-los, desenvolvendo o que se poderia chamar de $4^{\mathrm{a}}$ etapa, conforme mostrado na Figura 4.3.

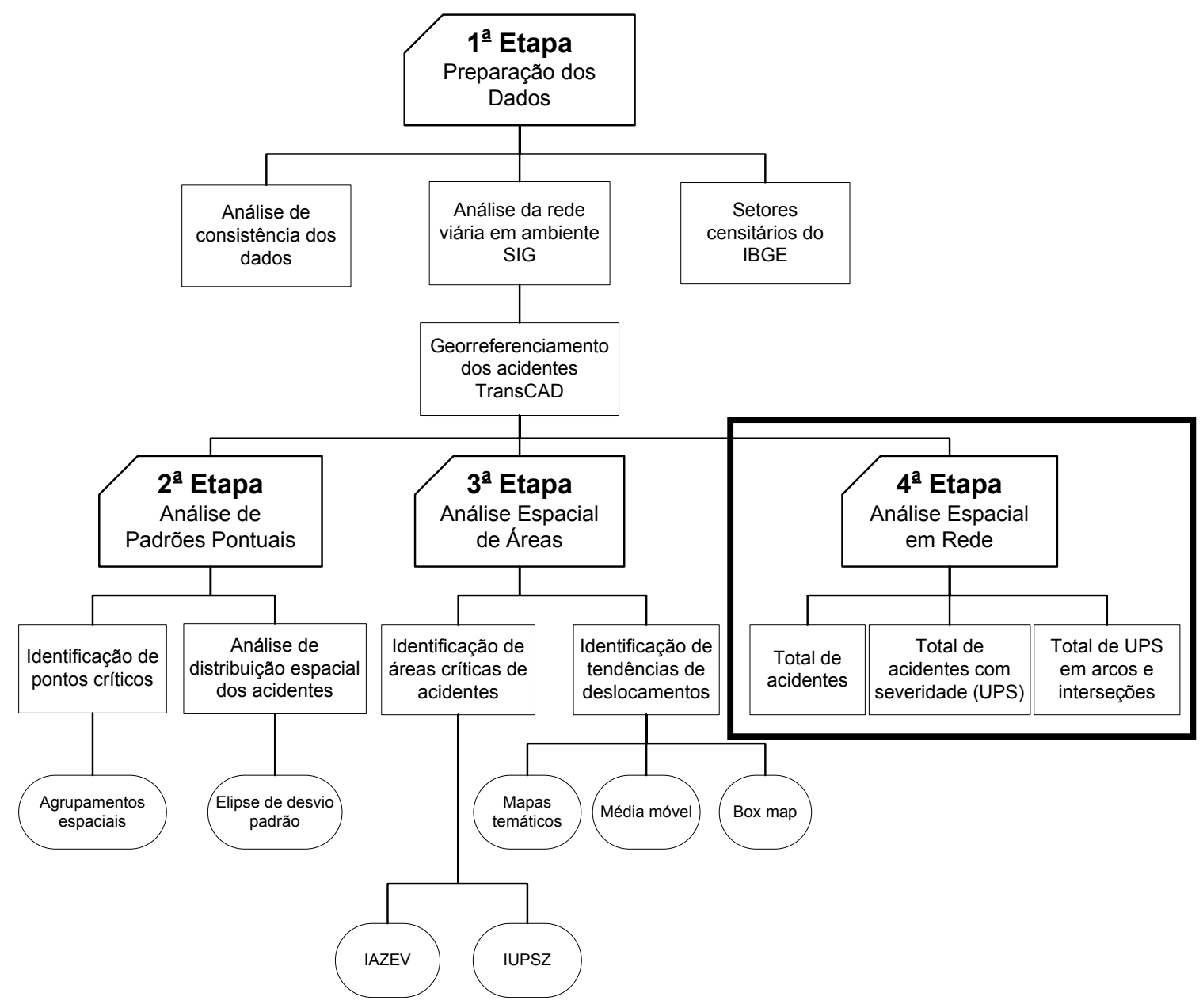

Figura 4.3 - A partir da estrutura de Santos (2005) desenvolveu-se a $4^{\mathrm{a}}$ etapa

\subsubsection{Procedimentos de análise}

Segundo a metodologia proposta, a análise dos dados tem início com a caracterização do grau de autocorrelação espacial, através do cálculo do índice I de Moran, 
para cada um dos tipos de acidentes, nos três anos considerados. O procedimento passo a passo com o uso do software TransCAD está demonstrado no Apêndice.

Após uma análise preliminar nos dados, calculou-se o índice através da Equação (4.1), uma das formas de obtenção do Índice de Moran. Na forma matricial, $\mathrm{Z}$ e $\mathrm{W}_{\mathrm{z}}$ são vetores e $Z^{t}$ é o transposto de $Z$.

$$
I=\frac{Z^{t} \times W_{Z}}{Z^{t} \times Z}
$$

Sendo: $Z$ é o vetor de desvios calculado com os acidentes de trânsito, sendo a diferença entre o valor do atributo e a média geral no conjunto de dados; $W_{z}$ é o vetor que representa a diferença entre as médias ponderadas e a média geral do conjunto de dados.

Terminado o cálculo dos índices, realizou-se a distribuição dos segmentos segundo sua classificação quanto aos quadrantes. Para isso, ainda no Transcad, foi definida a seguinte condição: if $\left(Z>0\right.$ and $\left.W_{z}>0\right)$ then 1 else if $\left(Z<0\right.$ and $\left.W_{z}<0\right)$ then 2 else if $(Z<0$ and $\left.W_{z}>0\right)$ then 3 else if $(Z>0$ and $W z<0)$ then 4 else 0.

O resultado das classificações pelos quadrantes pode ser visualizado através de Box Maps. Nesta fase foram calculados os Totais de acidentes, Atropelamentos, Acidentes com danos materiais e Acidentes com vítimas para os três anos.

$\mathrm{Na}$ próxima etapa, os valores Totais dos acidentes foram ponderados pela Unidade Padrão de Severidade - a UPS. Esta majoração é em função da gravidade que as pessoas estão expostas ao tráfego e do valor econômico que um acidente representa. $\mathrm{O}$ valor de um acidente com vítima fatal é muito mais grave social e financeiramente que um acidente com vítimas não-fatais, que por sua vez é muito mais grave que um acidente sem vítimas. 
Os Atropelamentos também foram majorados, já que a vítima (pedestre) não está envolvida diretamente na ação de dirigir um veículo. Os valores (pesos) atribuídos foram: Acidente com danos materiais $=1$, Acidente com vítima $=4$, Atropelamento $=6$ e com vítima fatal $=13$. Para os valores majorados com a UPS também se calculou o índice I, a distribuição nos quadrantes e os Box Maps.

Com o resultado nos primeiros cálculos, a segunda etapa serviu também para verificar se haveria alguma alteração significativa nos mesmos, visto que novas informações foram acrescentadas, pois além do número de acidentes também foi considerada sua gravidade.

$\mathrm{Na}$ última etapa buscou-se verificar quanto a localização específica dos acidentes interfere nos cálculos, dado que foi observada a ocorrência de um grande número de acidentes em esquinas. Se um acidente acontece numa esquina, este não deve ser atribuído somente a um segmento, mas a todos os componentes do cruzamento, porque o acontecido, na maioria das vezes, é justamente em função do próprio cruzamento.

A distribuição dos acidentes pelos segmentos nas últimas simulações ocorreu de duas maneiras:

- Acidentes ocorridos no meio da quadra foram atribuídos ao segmento onde estavam georreferenciados;

- Acidentes ocorridos na esquina ou próximos a ela, num raio de 10 metros, foram atribuídos aos segmentos constituintes do cruzamento. Em uma esquina formada, por exemplo, pelo encontro de quatro segmentos, o valor total de acidentes foi dividido por quatro e atribuído aos quatro segmentos.

Resumindo, no total foram realizadas 18 análises. Inicialmente foram considerados todos os tipos de acidentes conjuntamente. Em seguida, os mesmos dados foram divididos em: Atropelamentos, Acidentes com danos materiais e Acidentes com vítimas não 
fatais. Não foram feitas análises separadas com os valores de Acidentes com vitimas fatais, tendo em vista o reduzido número observado em relação ao Total de Acidentes: dois em 2001, três em 2002 e quatro em 2003.

O conjunto total de dados foi novamente computado, com a UPS, de duas maneiras distintas. Na primeira delas, os dados de acidentes foram atribuídos aos arcos da rede de forma individualizada (ou seja, cada acidente era atribuído ao segmento da rede mais próximo). A diferença desse caso (e do próximo) para as primeiras análises passou a ser a consideração dos valores de UPS, que majoraram os valores de acidentes de acordo com a severidade. No último caso, cada acidente de esquina passou a contar como uma fração, calculada a partir do número de aproximações da interseção onde ocorreu. Assim, um atropelamento numa esquina com quatro aproximações resultaria em um valor de um e meio (um acidente com peso seis, valor do atropelamento na UPS, dividido por quatro aproximações).

\subsection{SÍNTESE DAS ATIVIDADES DESENVOLVIDAS}

A seguir está descrita uma síntese das etapas desenvolvidas, desde o processo de tratamento e formatação dos dados até a obtenção dos Box Maps e a comparação com os resultados de trabalhos anteriores.

1. Obtenção dos dados de acidentes e rede viária para cada ano estudado;

2. Tratamento e formatação dos dados;

3. Determinação dos elementos $\mathrm{W}, \mathrm{Z}$ e $\mathrm{W}_{\mathrm{z}}$ referentes à análise dos dados com Totais de acidentes, Atropelamentos, Acidentes com danos materiais e Acidentes com Vitimas, para cada um dos três anos;

4. Determinação dos elementos $\mathrm{W}, \mathrm{Z}$ e $\mathrm{W}_{\mathrm{z}}$ referentes à análise dos dados com Totais de acidentes majorados pela UPS, também para os três anos; 
5. Determinação dos elementos $\mathrm{W}, \mathrm{Z}$ e Wz referentes à análise dos dados com Totais de acidentes majorados pela UPS e com a localização na rede, para o período estudado;

6. Determinação dos quadrantes a que pertencem os valores obtidos em cada uma das 18 avaliações;

7. Construção dos Box Maps para cada uma das análises;

8. Análise dos resultados;

9. Comparação dos resultados desta pesquisa com aqueles obtidos por Santos (2005). 


\section{CAPITULO 5}

\section{RESULTADOS E ANÁLISES}

Este capítulo tem início com a apresentação e análise da distribuição espacial dos acidentes em rede, conforme metodologia apresentada na seção anterior. Em seguida, são apresentadas outras formas de análise da distribuição espacial do mesmo conjunto de dados, segunda a sua representação como pontos ou áreas, com base nos resultados obtidos por Santos (2005). Por fim, os resultados das distintas abordagens são, na medida do possível, comparados.

\subsection{DISTRIBUIÇÃO ESPACIAL DOS ACIDENTES EM REDE}

A Tabela 5.1 mostra os números de acidentes nos anos de 2001, 2002 e 2003, separados por tipos de acidentes e sua localização na rede. Os números mostram que os acidentes foram em torno de 2.900 por ano no período considerado, na sua maioria acidentes somente com danos materiais. Além disso, predominaram os acidentes em cruzamentos ou nas aproximações destes. Isto não ocorreu, no entanto, com os atropelamentos, que na sua maioria aconteceram nos arcos da rede e não nas esquinas, ou seja, geralmente no meio da quadra.

Tabela 5.1 - Distribuição dos acidentes por tipo, por ano e por localização na rede

\begin{tabular}{|c|c|c|c|c|c|c|c|c|c|}
\hline \multirow{2}{*}{$\begin{array}{c}\text { Tipos de } \\
\text { acidentes }\end{array}$} & \multicolumn{3}{|c|}{2001} & \multicolumn{3}{|c|}{2002} & \multicolumn{3}{|c|}{2003} \\
\hline & Arcos & Esquinas & Total & Arcos & Esquinas & Total & Arcos & Esquinas & Total \\
\hline Atropelamentos & 63 & 37 & 100 & 56 & 42 & 98 & 55 & 37 & 92 \\
\hline $\begin{array}{l}\text { Acidentes com } \\
\text { danos materiais }\end{array}$ & 954 & 1.342 & 2.296 & 796 & 1.427 & 2.223 & 766 & 1.395 & 2.161 \\
\hline $\begin{array}{l}\text { Acidentes com } \\
\text { vítimas não fatais }\end{array}$ & 202 & 377 & 579 & 168 & 380 & 548 & 169 & 446 & 615 \\
\hline $\begin{array}{l}\text { Acidentes com } \\
\text { vítimas fatais }\end{array}$ & 1 & 1 & 2 & 1 & 2 & 3 & 1 & 3 & 4 \\
\hline Totais & 1.220 & 1.757 & 2.977 & 1.021 & 1.851 & 2.872 & 991 & 1.881 & 2.872 \\
\hline
\end{tabular}


Na Tabela 5.2 são mostrados os resultados das 18 simulações realizadas, em que foram definidos os valores de I de Moran.

Tabela 5.2 - Valores de I em função do ano e da classificação do tipo de dado analisado

\begin{tabular}{lccc}
\hline \multirow{2}{*}{ Dados analisados } & \multicolumn{3}{c}{ I de Moran } \\
\cline { 2 - 4 } & $\mathbf{2 0 0 1}$ & $\mathbf{2 0 0 2}$ & $\mathbf{2 0 0 3}$ \\
\hline Total de acidentes & 0,15041 & 0,12860 & 0,10392 \\
Atropelamentos & 0,02398 & 0,04115 & 0,00583 \\
Acidentes com danos materiais & 0,15584 & 0,13091 & 0,11456 \\
Acidentes com vitimas não fatais & 0,05357 & 0,05331 & 0,03060 \\
Total de acidentes com severidade (UPS) & 0,12442 & 0,10941 & 0,07255 \\
Total com UPS em arcos e interseções & 0,67049 & 0,70284 & 0,67560 \\
\hline
\end{tabular}

Outro elemento importante de avaliação foi a distribuição dos resultados por quadrante, cujos valores aparecem na Tabela 5.3, obtidos com as três análises que utilizaram a totalidade dos dados.

Tabela 5.3 - Tabela com a distribuição do número de segmentos por quadrante

\begin{tabular}{lccccc}
\hline \multirow{2}{*}{ Dados analisados } & \multirow{2}{*}{ Ano } & \multicolumn{4}{c}{ Segmentos por Quadrante } \\
\cline { 3 - 6 } & & Q1 & Q2 & Q3 & Q4 \\
\hline Total de acidentes & 2001 & 565 & 7.029 & 1.647 & 543 \\
& 2002 & 583 & 7.089 & 1.590 & 522 \\
& 2003 & 572 & 7.036 & 1.657 & 519 \\
\hline Total de acidentes & 2001 & 528 & 7.085 & 1.591 & 580 \\
com severidade (UPS) & 2002 & 546 & 7.081 & 1.598 & 559 \\
& 2003 & 555 & 7.096 & 1.597 & 536 \\
\hline Total com UPS em & 2001 & 1.461 & 7.401 & 738 & 180 \\
arcos e interseções & 2002 & 1.489 & 7.256 & 866 & 135 \\
& 2003 & 1.495 & 7.256 & 812 & 158 \\
\hline
\end{tabular}

Os mapas das Figuras 5.1 a 5.18 contêm os Box Map das simulações com os dados totais e separados por tipo de acidente conforme apresentados nas Tabelas 5.1 e 5.2. Considerando que a rede viária da cidade de São Carlos é relativamente grande, cada figura apresenta quatro mapas para sua melhor compreensão, pois o tamanho reduzido da imagem poderia dificultar a apreensão do todo se os quadrantes fossem representados em único mapa com quatro classes. 
Buscou-se manter o mesmo padrão em todos os resultados a fim de facilitar a comparação entre as caracterizações. Assim sendo, tem-se sempre no canto superior direito destacado os segmentos no quadrante Q1; no canto inferior esquerdo os segmentos de Q2; à esquerda no alto os segmentos de Q3, e à direita, na parte inferior, os segmentos de Q4.

Nas Figuras 5.1, 5.2 e 5.3, onde aparecem representados os quadrantes do Total de acidentes para os três anos, percebe-se uma maior concentração de valores nos quadrantes Q2 e Q3, (7.029, 7.089 e 7.036 segmentos, 1.647, 1.590 e 1.657 segmentos, respectivamente), o que também havia sido observado na Tabela 5.3. As Figuras 5.4 a 5.12 apresentam os resultados por tipo de acidente.

Nas Figuras 5.13, 5.14 e 5.15, onde o Total de acidentes foi ponderado com a UPS, a concentração em Q2 e Q3 também ocorre, como mostrado também na Tabela 5.3, mantendo a concentração de segmentos - 7.085, 7.081 e 7.096 segmentos em Q2 e 1.591, 1.598 e 1.597 segmentos em Q3.

Nas Figuras 5.16, 5.17 e 5.18, onde o Total de acidentes foi ponderado com a UPS considerando os casos em arcos e interseções de forma distinta percebe-se uma mudança na distribuição dos valores que, embora ainda estejam fortemente concentrados em Q2 (7.401, 7.256 e 7.256 segmentos), apresentam uma grande concentração em Q1, que passou a registrar $1.461,1.489$ e 1.495 casos. Esses valores representam a migração dos quadrantes Q3 e Q4 para Q1.

O deslocamento gradual dos acidentes para regiões periféricas ao longo do tempo é observado nos três conjuntos de dados (Total de acidentes, Total de acidentes com severidade e Total com UPS em arcos e interseções) de forma semelhante, como se pode inferir a partir da análise das Tabelas 5.2 e 5.3, inclusive para os dados de acidentes em separado - Atropelamentos, Acidentes com danos materiais e Acidentes com vítimas. 


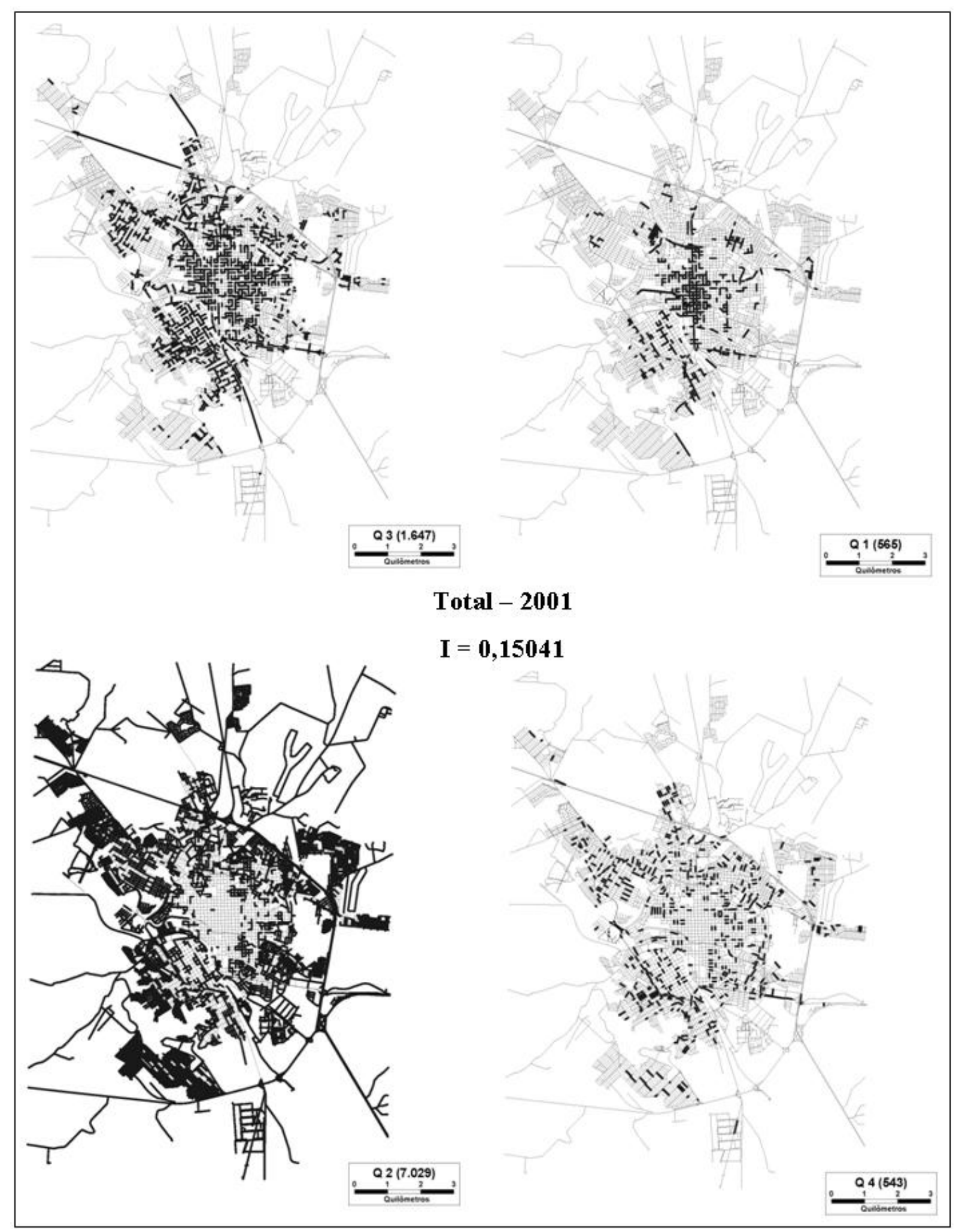

Figura 5.1 - Box Maps com Total de acidente em 2001 


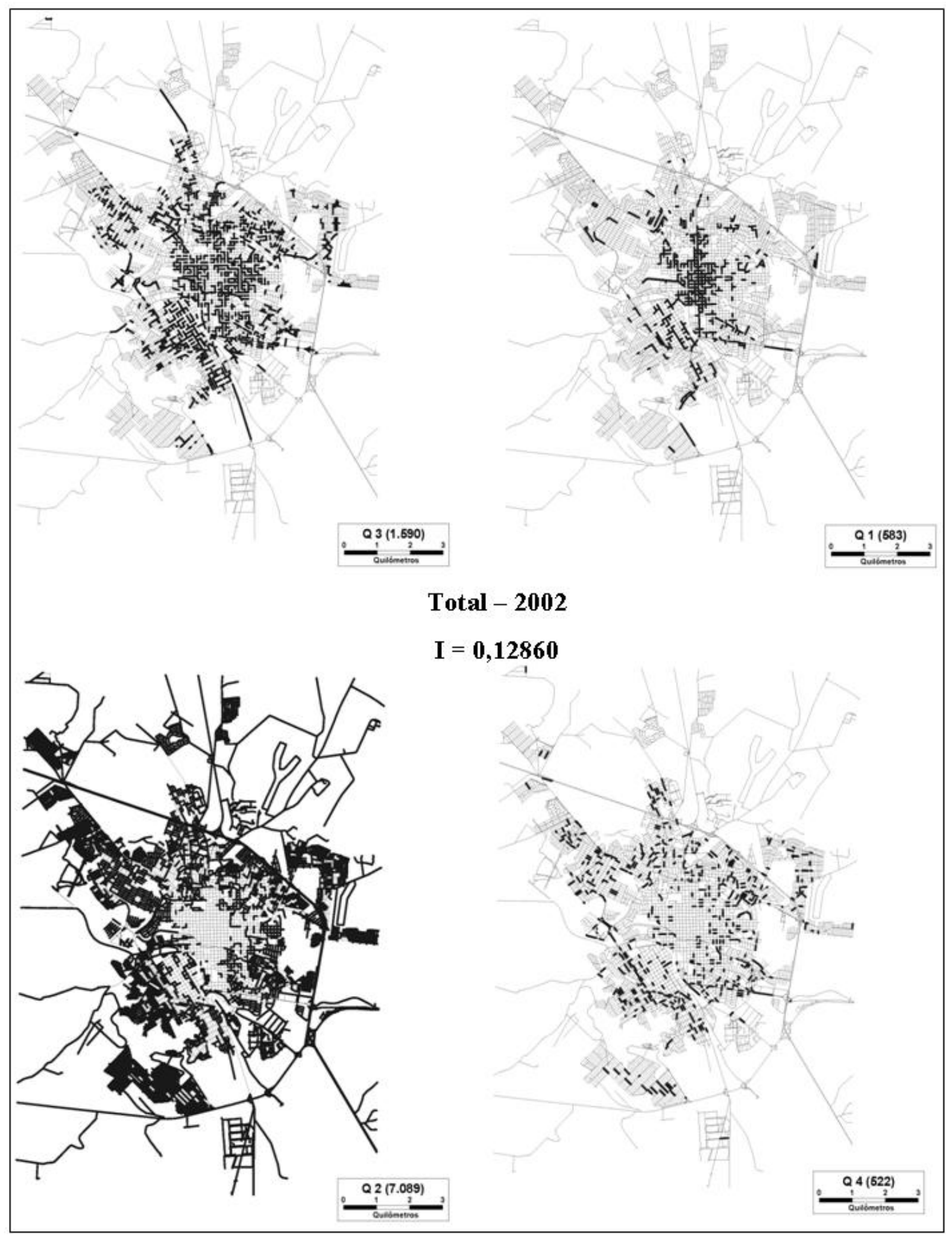

Figura 5.2 - Box Maps com Total de acidente em 2002 


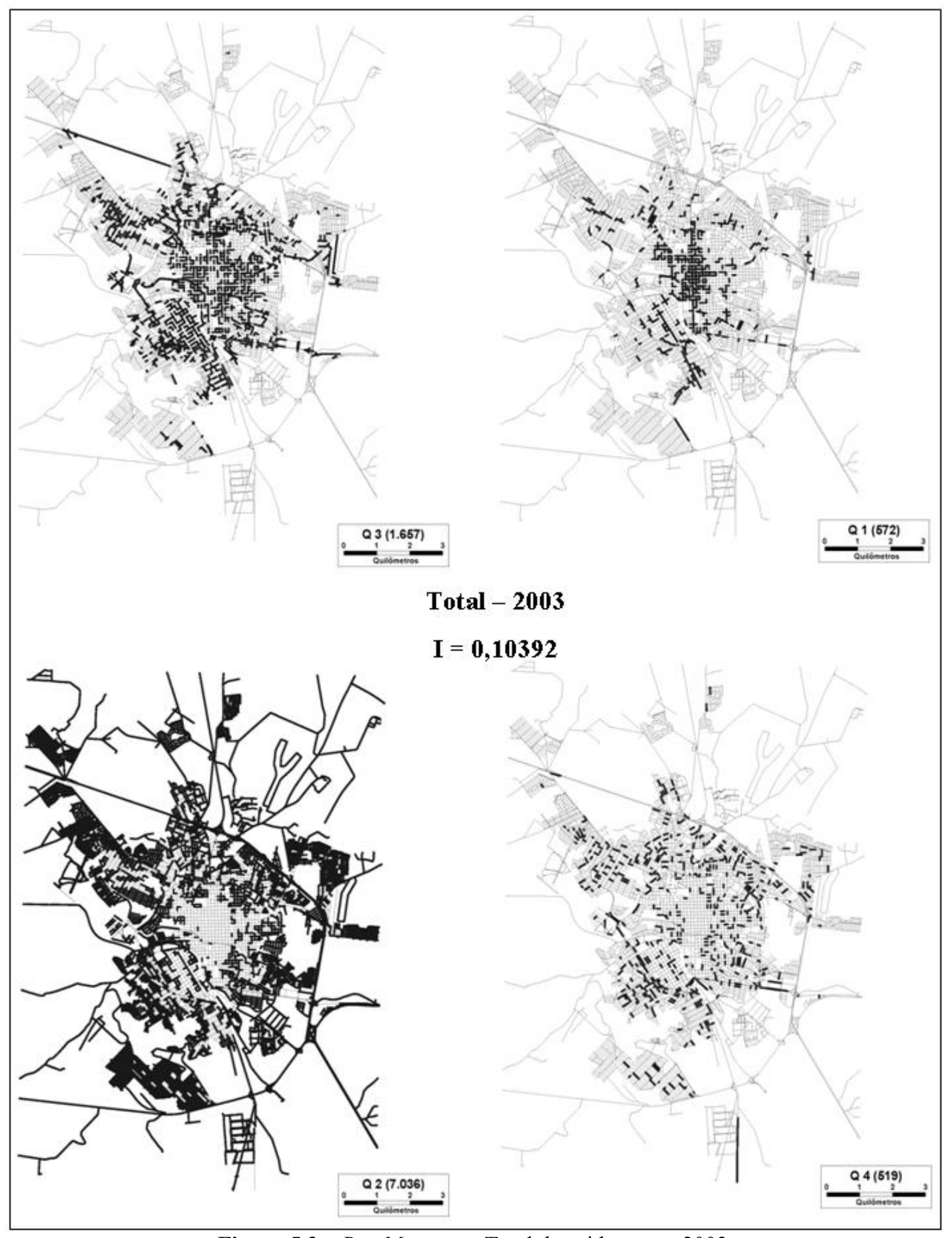

Figura 5.3 - Box Maps com Total de acidente em 2003 


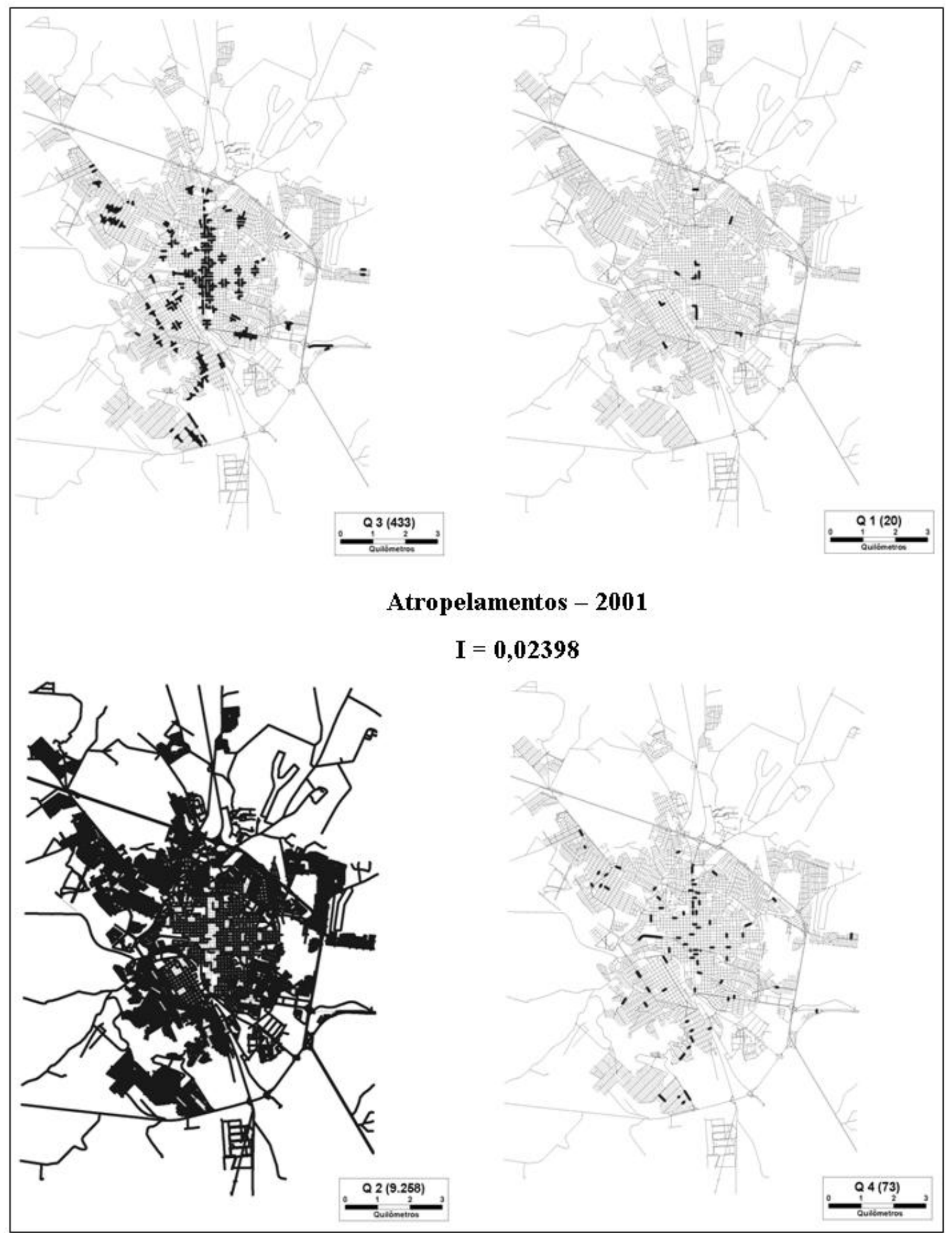

Figura 5.4 - Box Maps com Total de atropelamento em 2001 


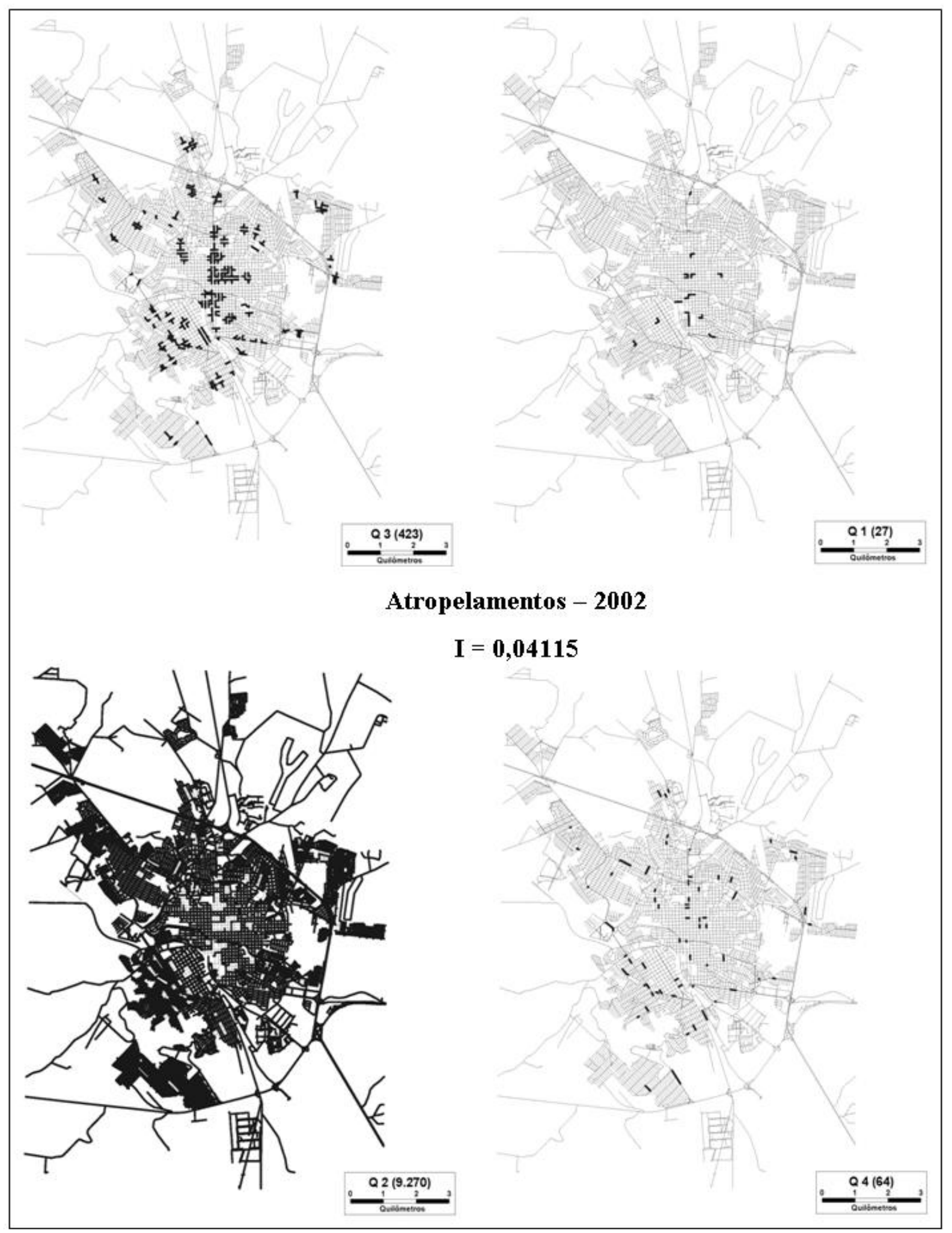

Figura 5.5 - Box Maps com Total de atropelamentos em 2002 


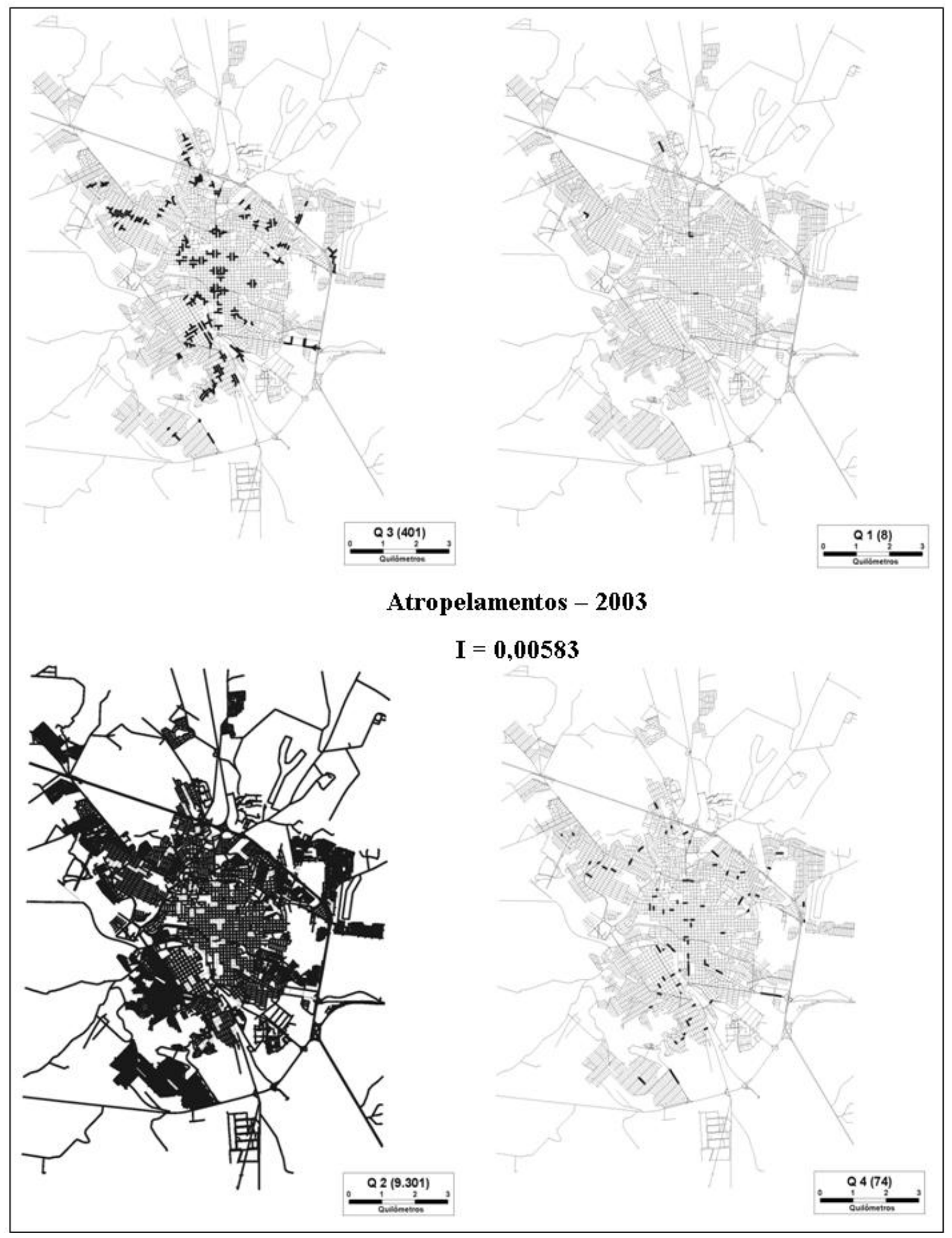

Figura 5.6 - Box Maps com Total de atropelamentos em 2003 


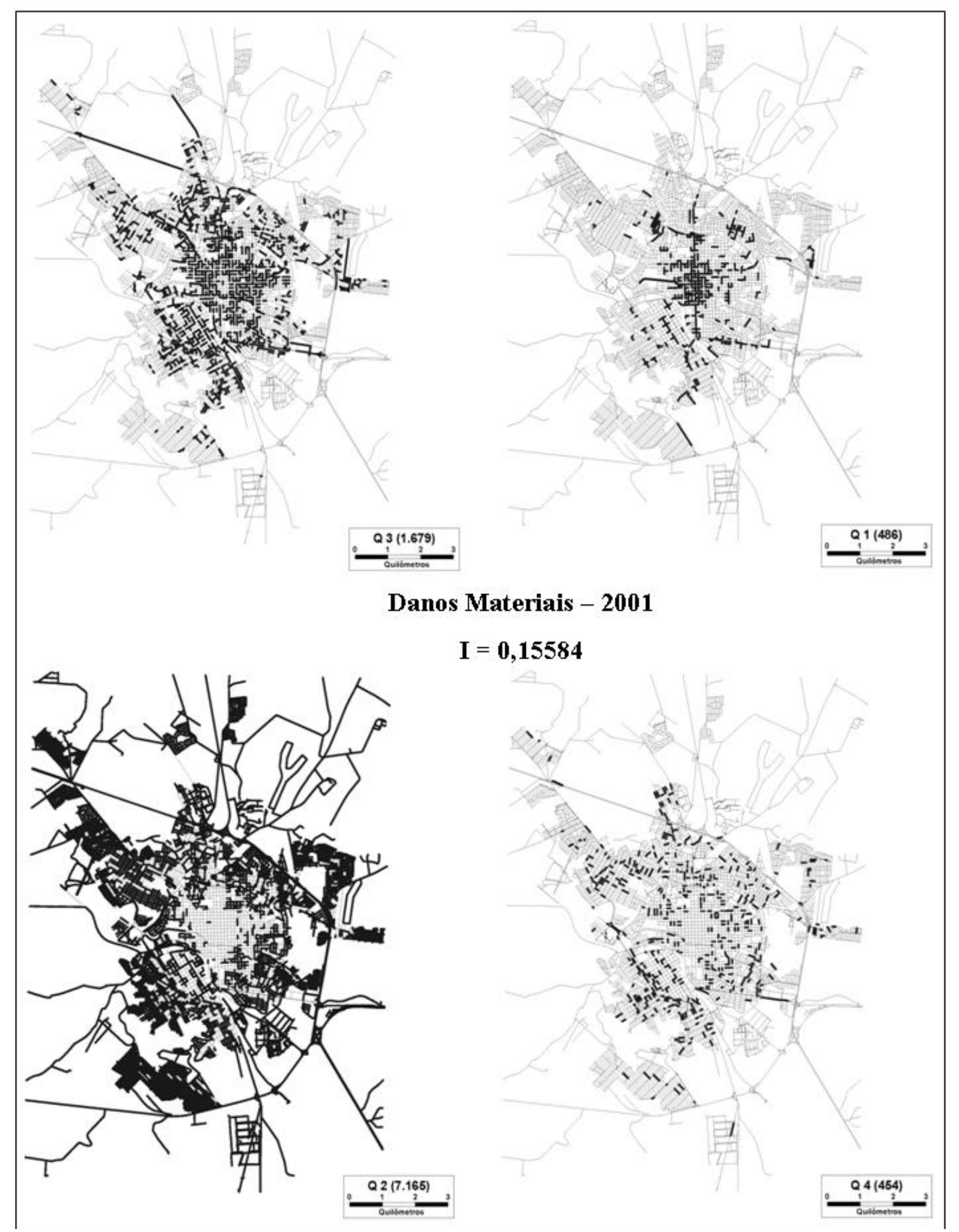

Figura 5.7 - Box Maps com Total de acidentes com danos materiais em 2001 


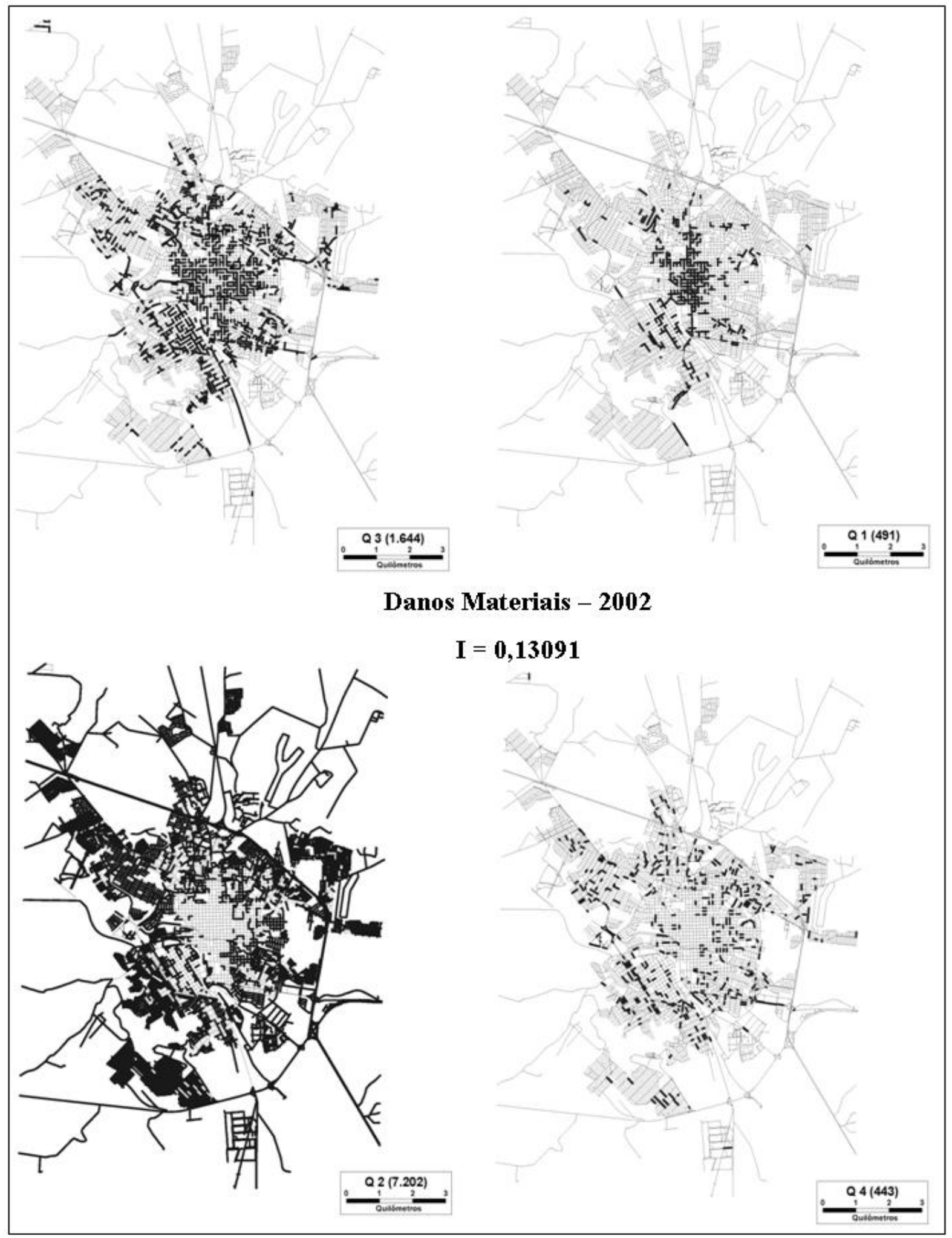

Figura 5.8 - Box Maps com Total de acidentes com danos materiais em 2002 


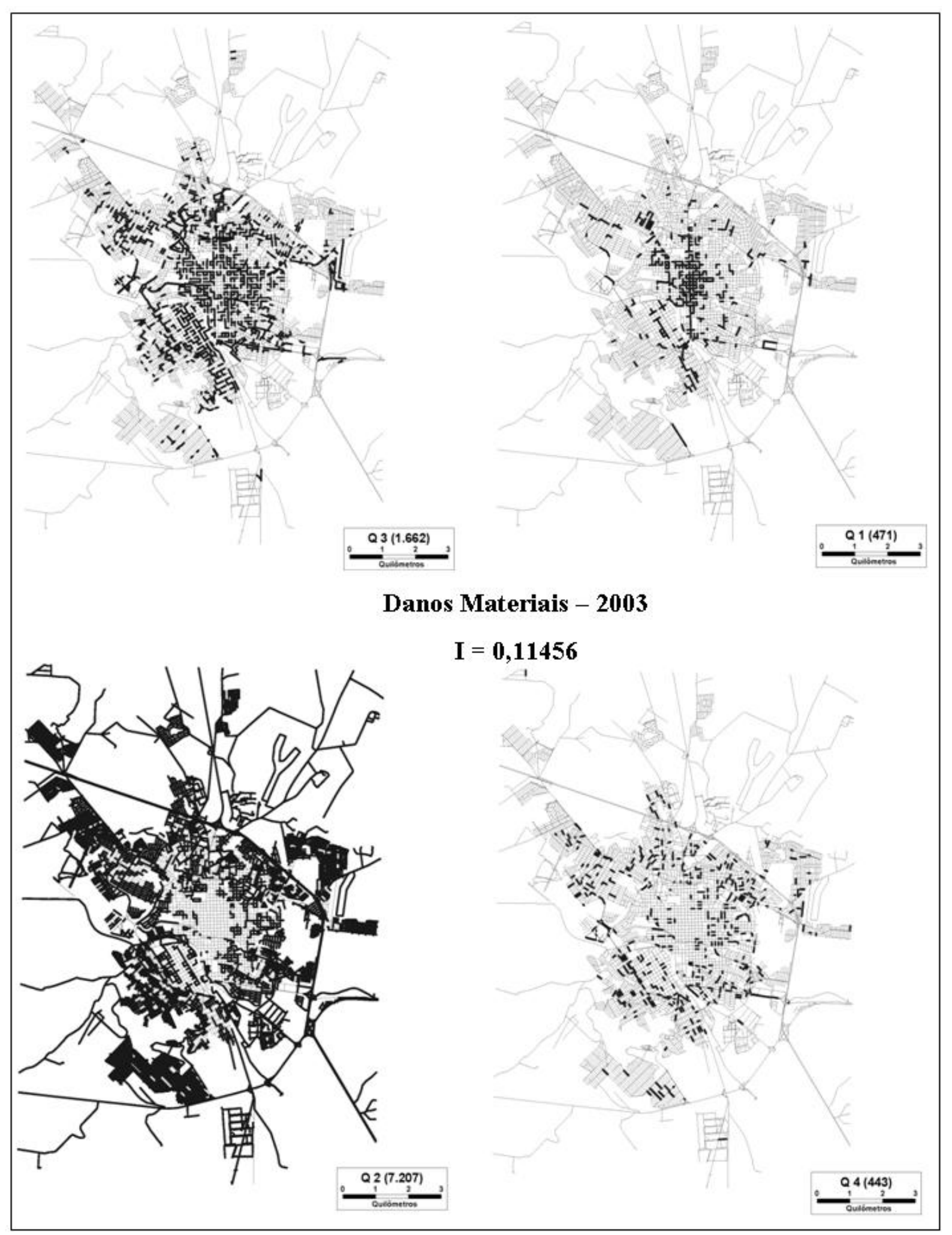

Figura 5.9 - Box Maps com Total de acidentes com danos materiais em 2003 


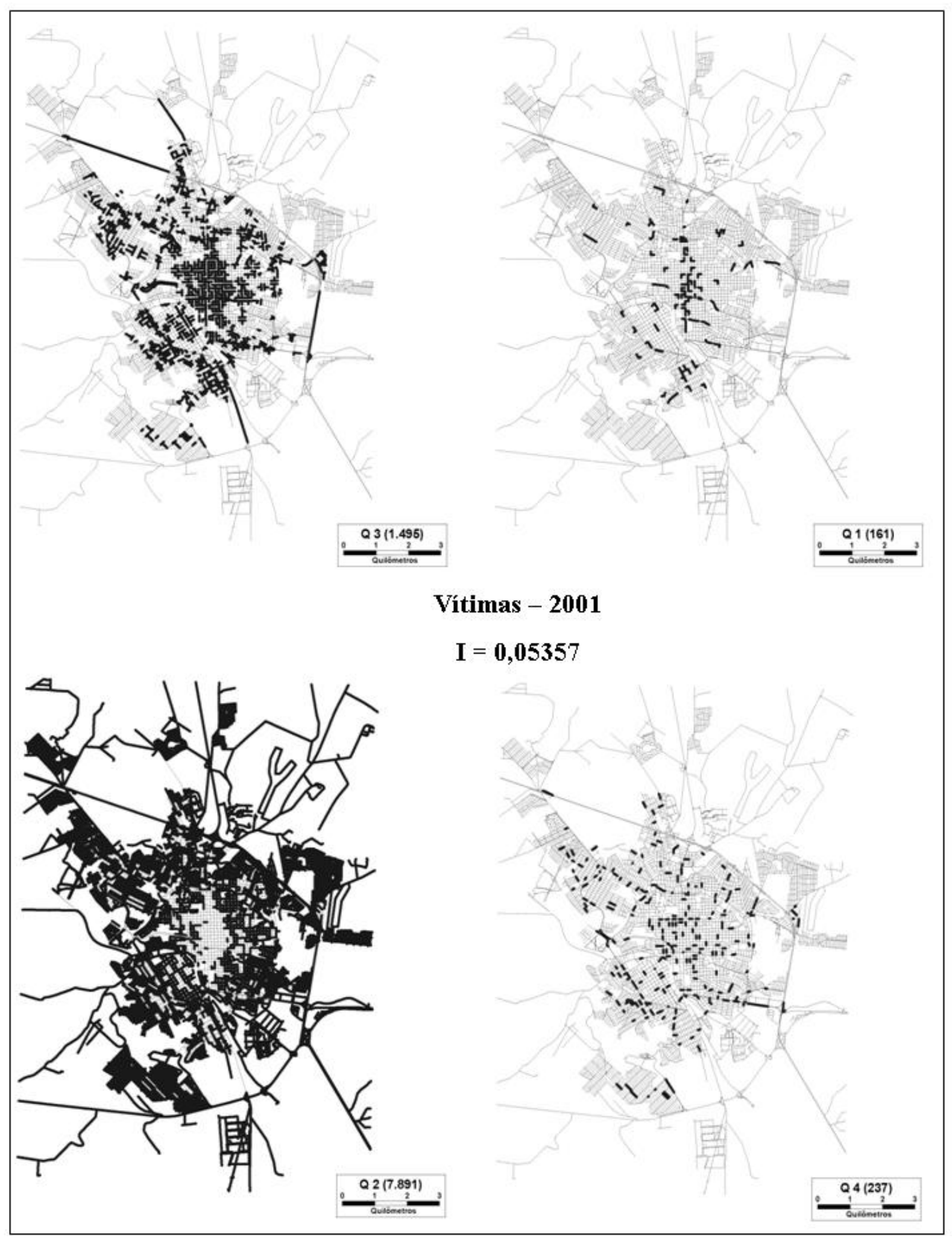

Figura 5.10 - Box Maps com Total de acidentes com vítimas não fatais em 2001 


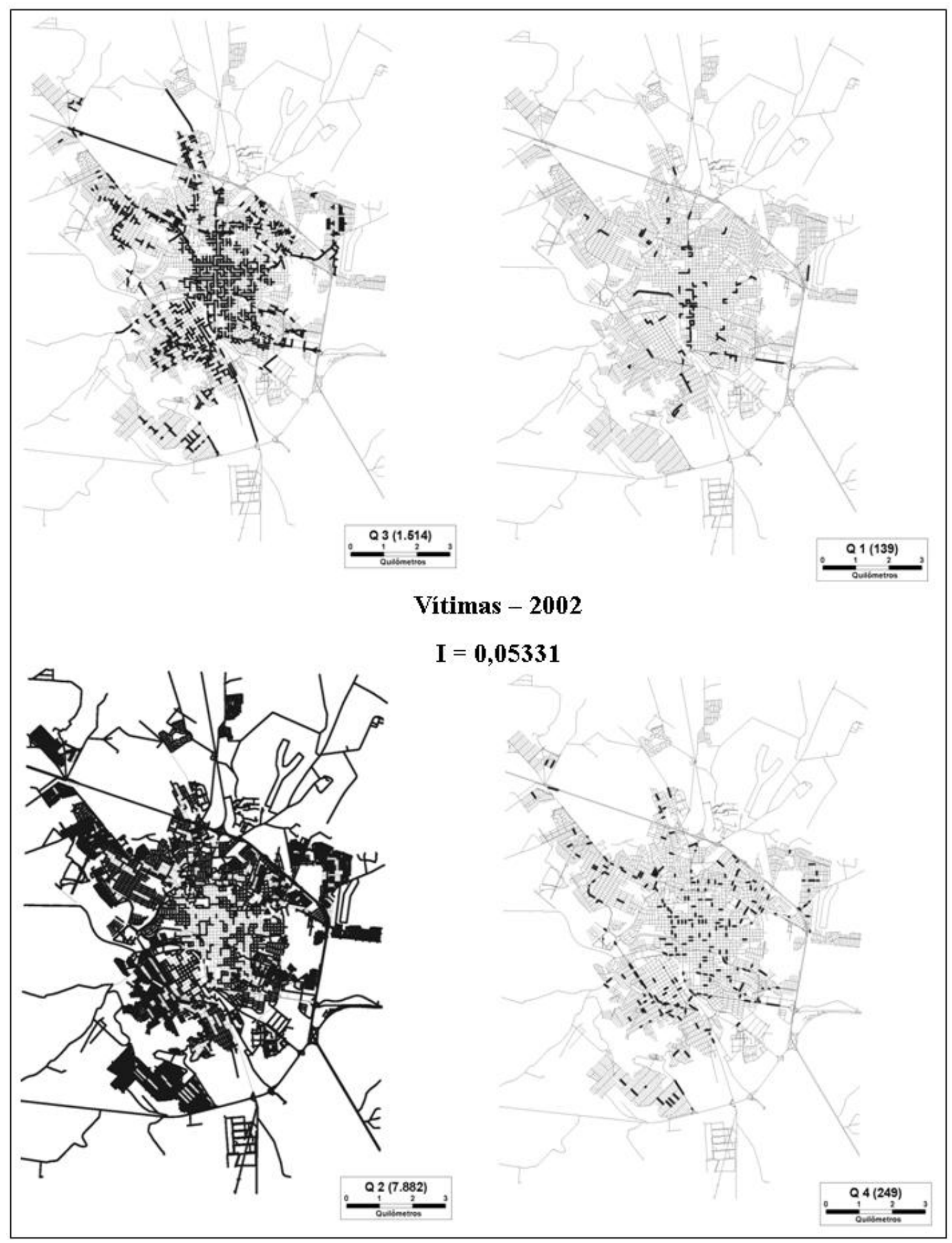

Figura 5.11 - Box Maps com Total de acidentes com vítimas não fatais em 2002 


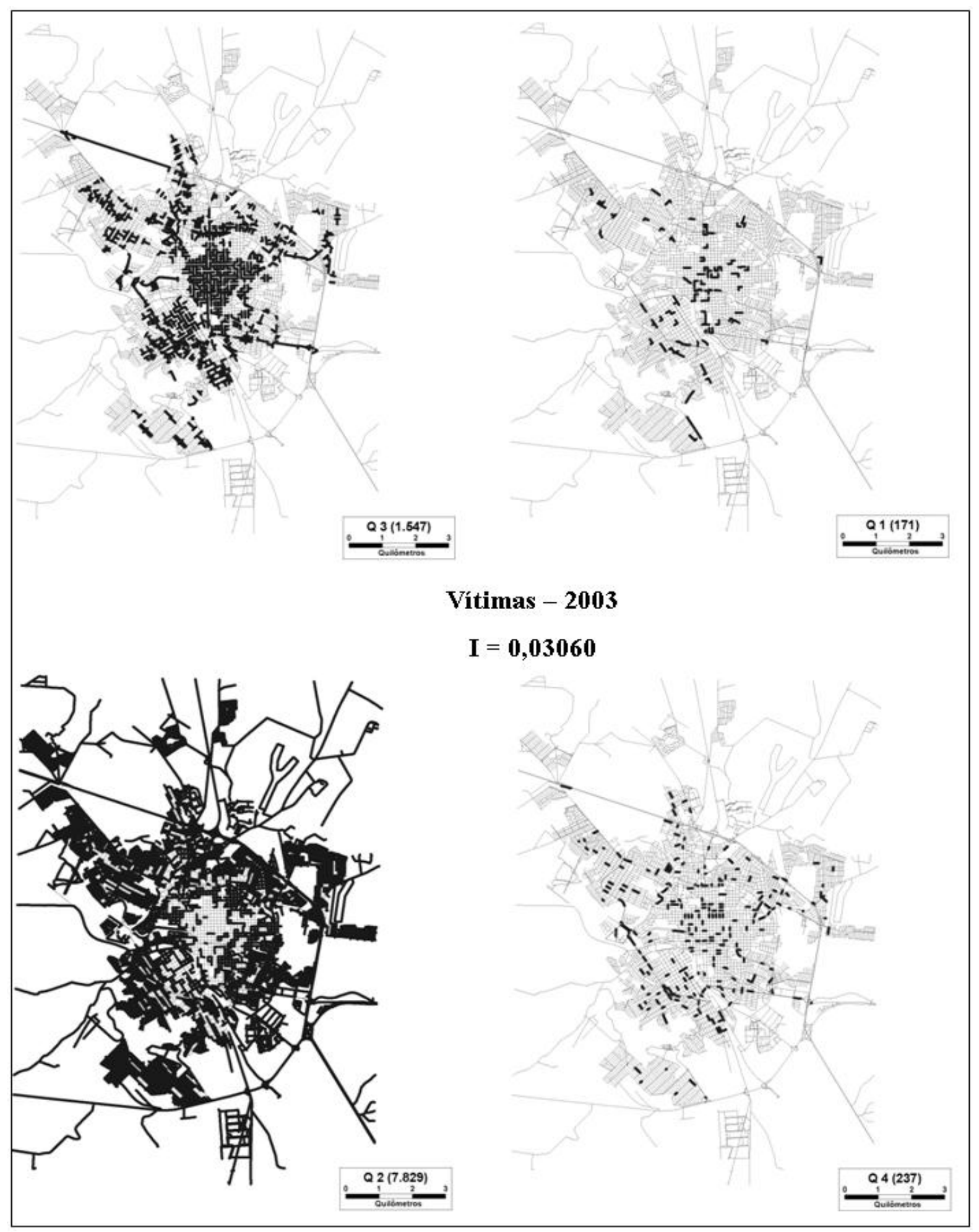

Figura 5.12 - Box Maps com Total de acidentes com vítimas não fatais em 2003 


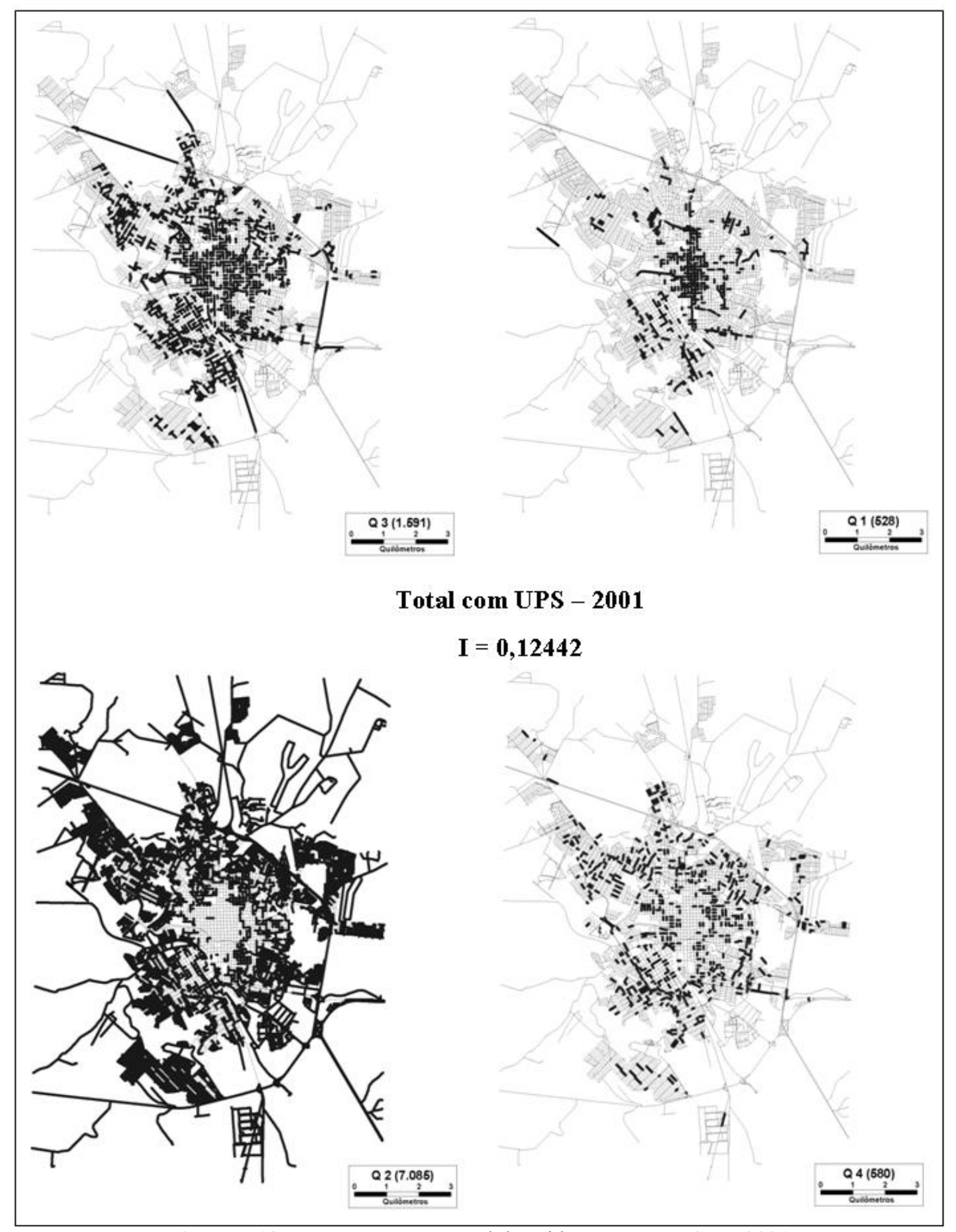

Figura 5.13 - Box Maps com Total de acidentes com UPS em 2001 


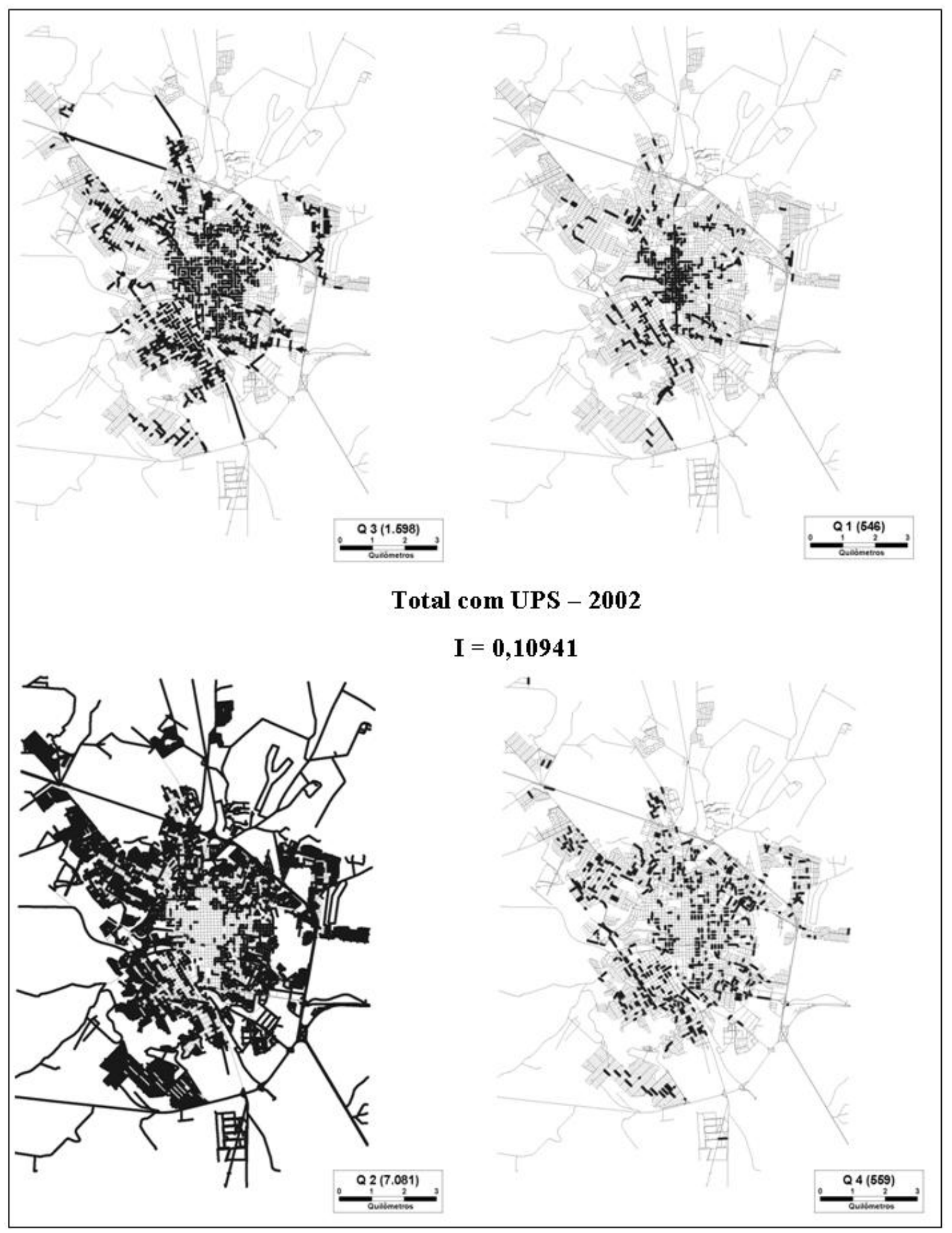

Figura 5.14 - Box Maps com Total de acidentes com UPS em 2002 


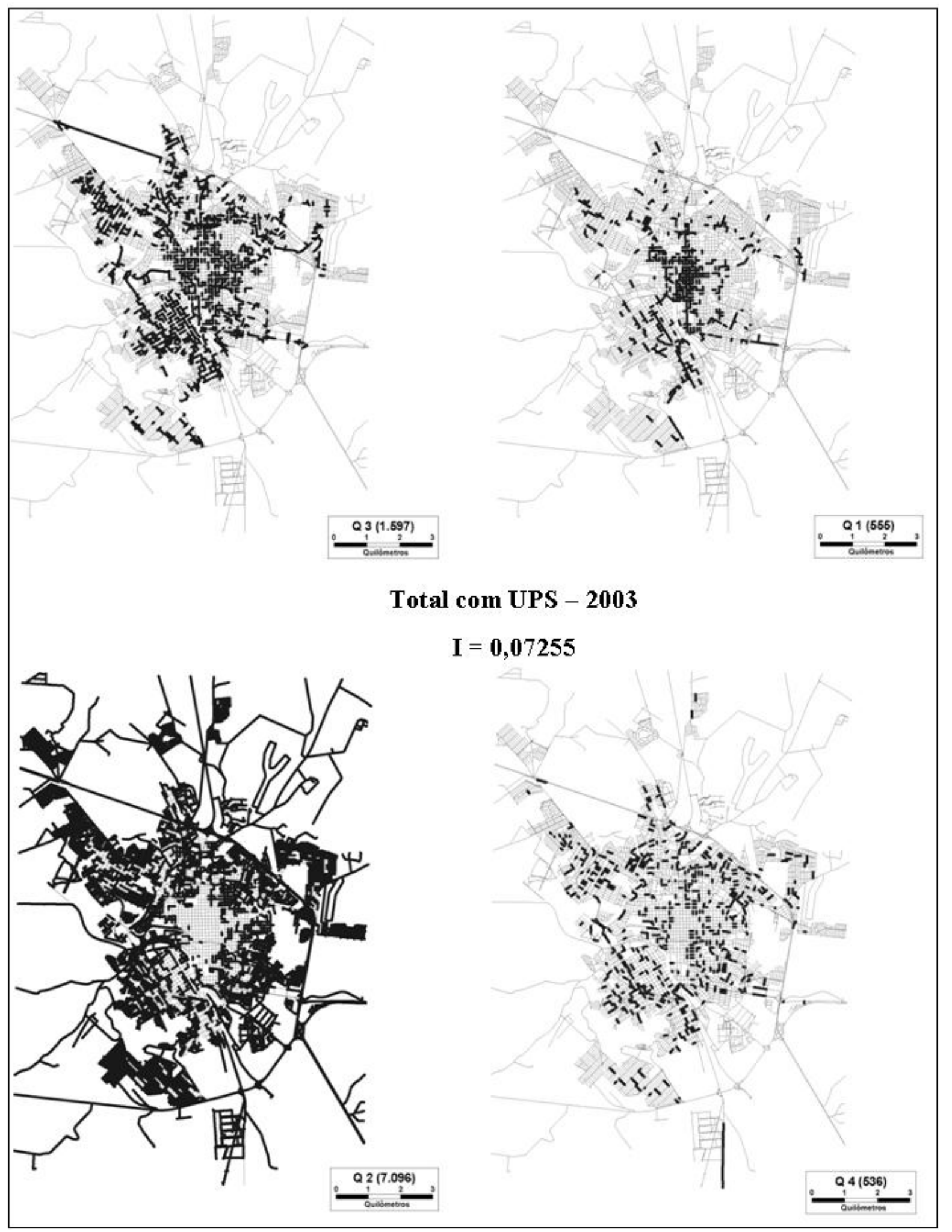

Figura 5.15 - Box Maps com Total de acidentes com UPS em 2003 


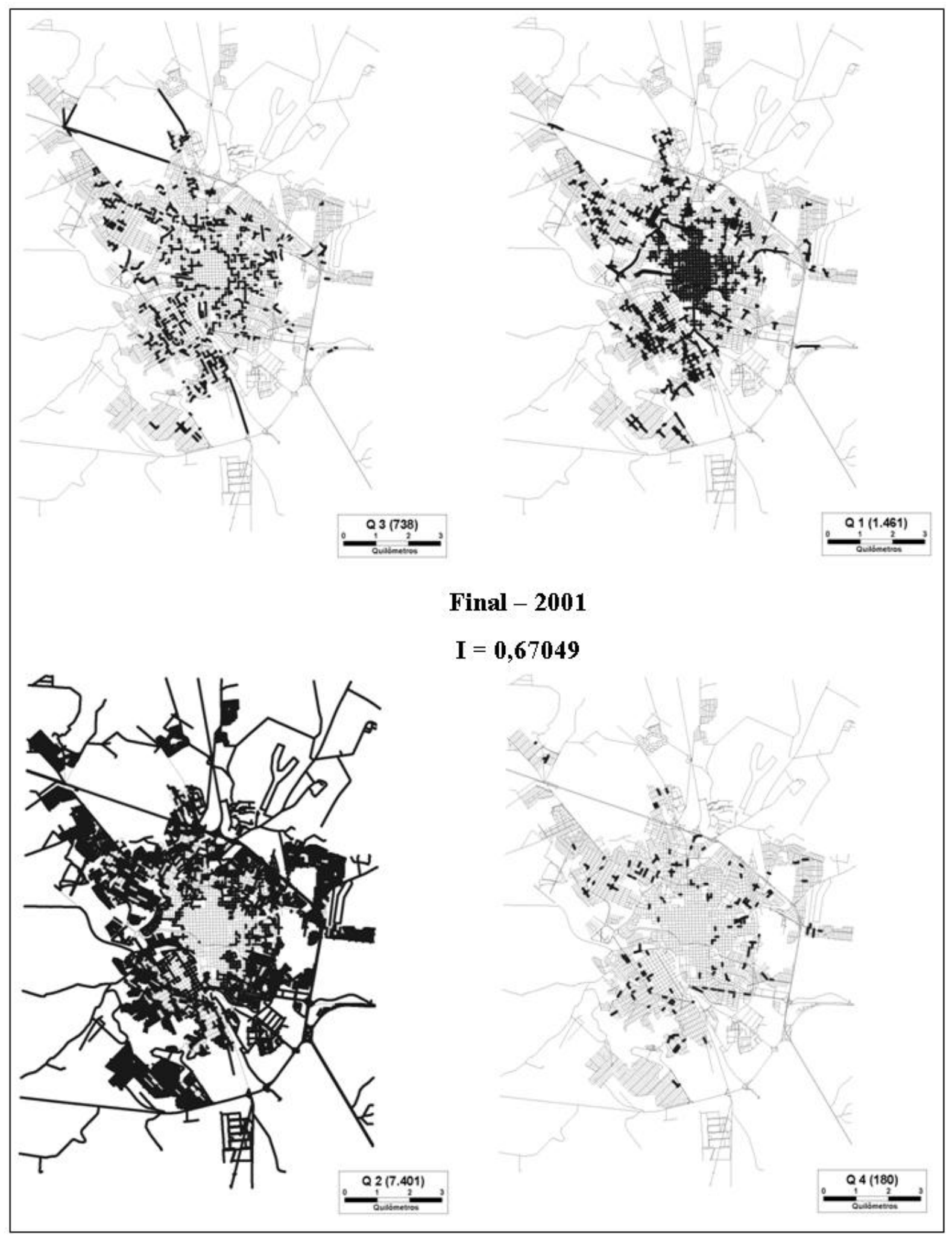

Figura 5.16 - Box Maps com Total Final em 2001 


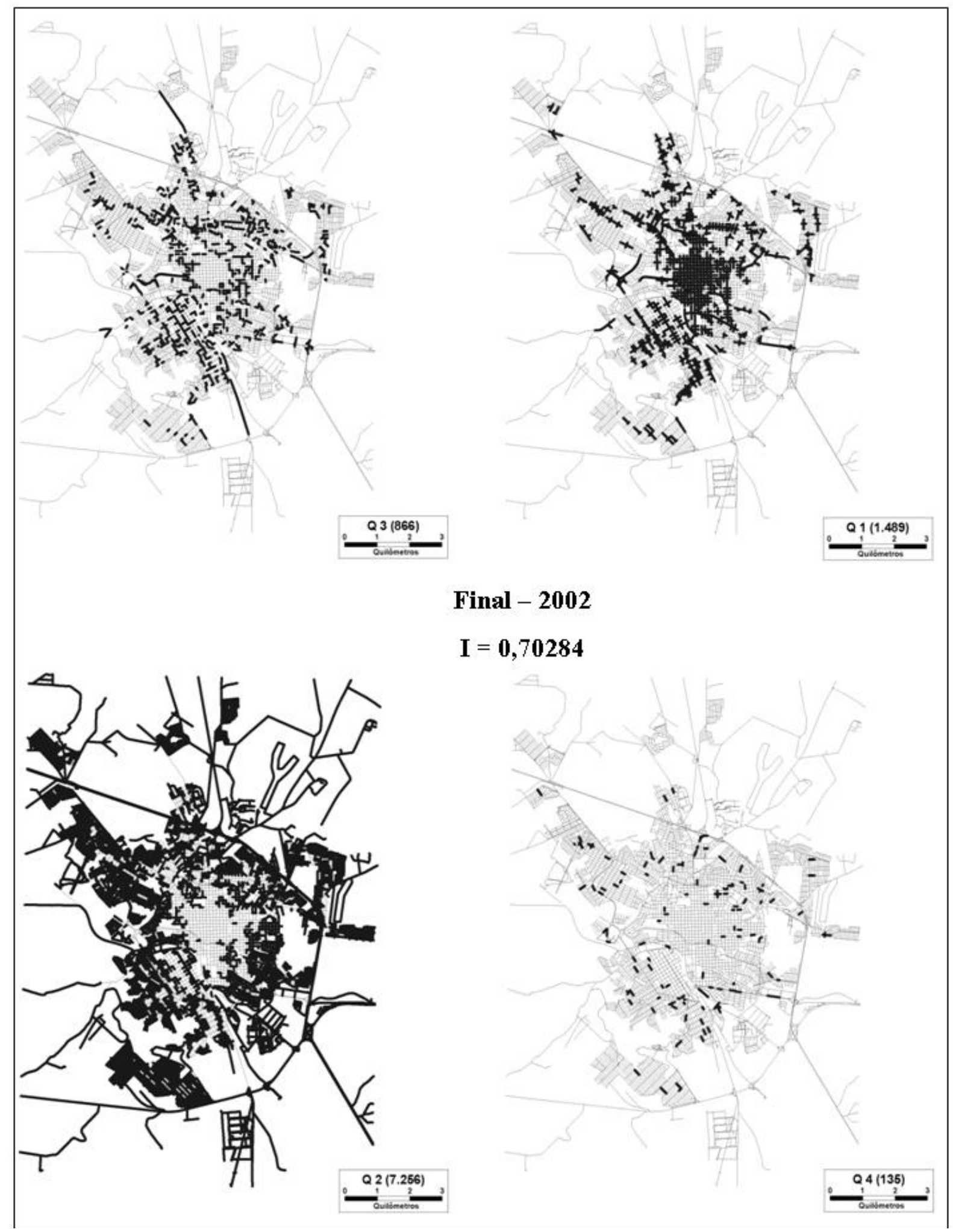

Figura 5.17 - Box Maps com Total Final em 2002 


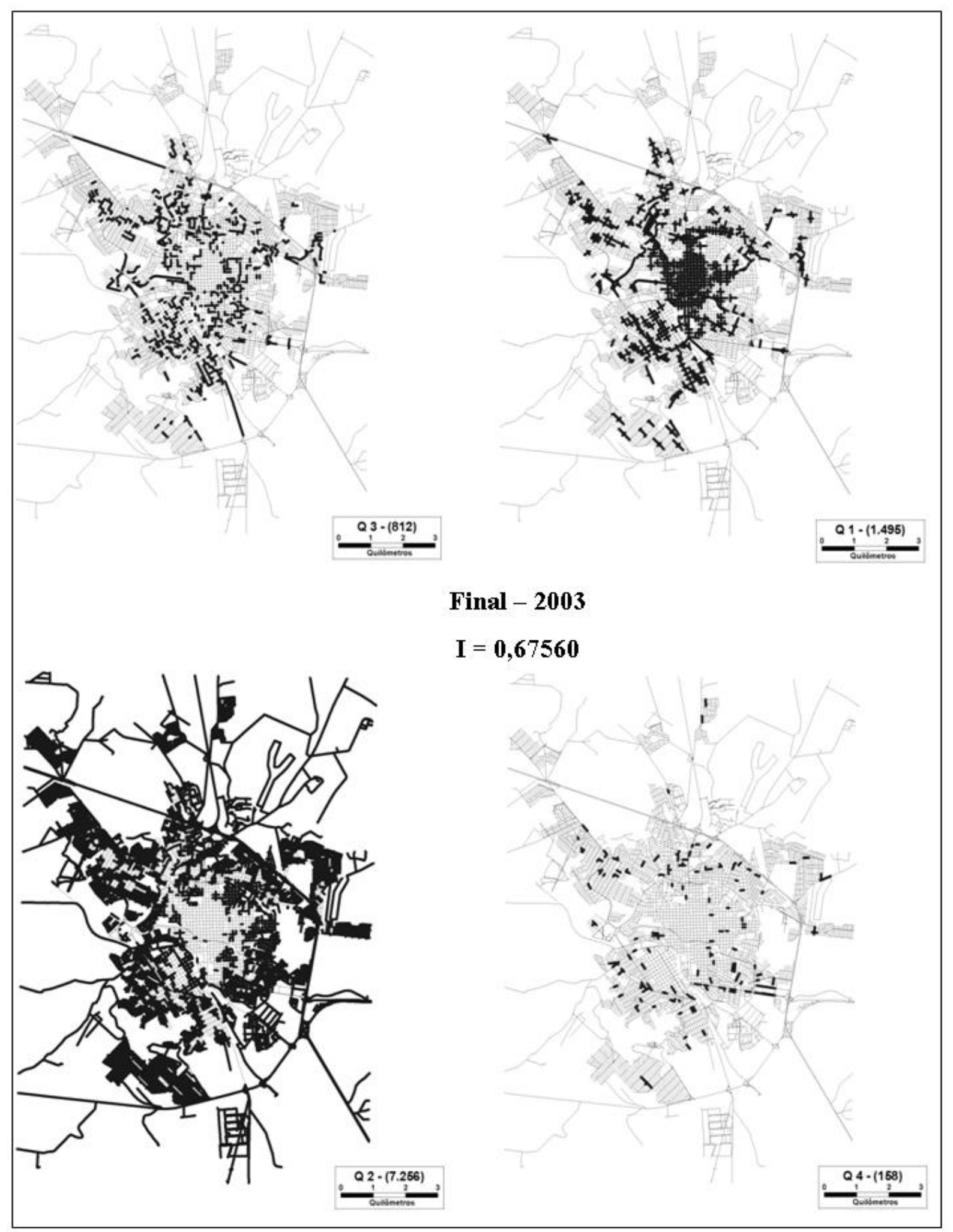

Figura 5.18 - Box Maps com Total Final em 2003 


\subsection{ANÁLISE DA DISTRIBUIÇÃO ESPACIAL DOS ACIDENTES EM REDE}

Os Índices de Moran encontrados nas primeiras análises apresentaram valores baixos, próximos a zero, indicando ausência de autocorrelação espacial (Figuras 5.1 a 5.12). Isso foi verificado tanto para os Totais de acidentes como para os dados separados por tipo de acidente, conforme resultados apresentados na Tabela 5.2.

As simulações com os Totais de acidentes para os três anos apresentaram valores de I de Moran entre 0,15 e 0,10. Já para as simulações com os acidentes separados por tipo, os valores foram: Acidentes com danos materiais - entre 0,15 e 0,11; Atropelamento entre 0,02 e 0,005; Acidentes com vítimas - entre 0,05 e 0,03. Em uma primeira análise podese dizer que a quantidade de acidentes atribuída ao segmento está diretamente relacionada com os resultados obtidos, visto que as simulações com maior quantidade de segmentos com valores diferentes de zero apresentaram maiores valores de I, como por exemplo, Total de acidentes e Acidentes com Danos Materiais, o que poderia explicar a ausência de autocorrelação nesses casos.

Na próxima etapa de análise, os acidentes foram majorados pela sua severidade de acordo com a UPS. Considerando que os acidentes mais graves acontecem na maioria das vezes na periferia, a majoração poderia eventualmente equipará-los com a alta concentração de acidentes mais leves (danos materiais) que ocorrem na região central. Com isso esperavase que os resultados do índice se alterassem significativamente.

A suposição inicial foi a de que valores altos espalhados por toda a rede iriam apresentar elevado valor de autocorrelação, positiva ou negativa. Contudo, embora os valores encontrados tenham sido diferentes das avaliações iniciais, ficaram ainda menores, não confirmando assim a hipótese formulada.

Na última etapa, além da severidade, foi considerada a localização dos acidentes nos arcos e esquinas para a determinação da área de influência nos mesmos. Desta 
maneira buscou-se distribuir os acidentes nos segmentos da rede de forma mais próxima da realidade, já que um acidente na área de influência de uma esquina não deveria ser considerado como pertencente a um único segmento.

Com este procedimento reduziu-se também a grande quantidade de segmentos com valor zero. Apesar disto a preocupação foi a de determinar a real influência de um acidente em seu entorno. No caso de acidentes em esquinas, por exemplo, a análise poderia ser pelo padrão pontual, o que não reflete a maioria das circunstâncias que envolvem um acidente em cruzamentos.

Com a mudança na distribuição dos atributos houve uma alteração significativa dos valores no resultado final, e esta mudança se deve à redução significativa no número de segmentos com valor zero. Por exemplo, enquanto o resultado de I para o Total de acidentes em 2001 foi 0,15041, na última análise, o valor de I foi de 0,67049, representando um aumento de 3,5 vezes.

Mais importante do esse aumento, é a evidência de autocorrelação espacial. Tal fato se deve principalmente a redução de segmentos com valor zero, visto que nas análises anteriores era provável que determinados segmentos tivessem relação direta com o acidente e, no entanto, o valor do atributo era zero. Com isso pode-se inferir que a maneira de distribuir os valores do atributo é tão ou mais importante do que o próprio valor do atributo em si.

A partir das simulações realizadas em três fases distintas e consecutivas traçouse um comparativo com o trabalho de Santos (2005), conforme proposto na metodologia.

\subsection{OUTRAS ANÁLISES DA DISTRIBUIÇÃO ESPACIAL DOS ACIDENTES}

A comparação direta dos resultados obtidos nessa pesquisa, em que os acidentes foram associados a uma rede, com os resultados da análise dos acidentes associados a pontos, ou mais detalhadamente a áreas, foi possível porque em ambos os casos os dados 
considerados foram aqueles utilizados no trabalho de Santos (2005). Em seu trabalho, Santos primeiramente identificou e analisou os pontos críticos dos acidentes na área urbana. Trabalhando com valores absolutos, o autor pôde perceber que a maioria das ocorrências se dava em alguns cruzamentos da região central, com um deslocamento gradual ao longo dos anos em direção à periferia, mostrando uma tendência ao espalhamento pela mancha urbana.

Uma segunda parte da análise pontual foi quanto à distribuição por ocorrência, em que o autor também majorou os valores absolutos pelos "índices” das UPS. Com isso, pode-se perceber a alta concentração na região central de acidentes leves, ou seja, acidentes com danos materiais, causados principalmente pelo alto volume de tráfego e velocidades menores; enquanto que na periferia os acidentes geralmente são mais graves, com vítimas. Isso pode ser explicado pelo baixo volume de tráfego e velocidades maiores.

Em outra etapa, o autor trabalhou com áreas urbanas, fazendo um paralelo com os pontos críticos, utilizando para isso as mesmas delimitações dos setores censitários. Na análise espacial por áreas, Santos evitou a influência do tamanho da área sobre os resultados, optando pelos índices IAZEV e IUPSZ.

O IAZEV - Índice de Acidentes na Zona por Extensão Viária - é dado pela Equação 5.1.

$$
I A Z E V_{i}=\frac{N A Z \times 100}{E V Z_{i}}
$$

Sendo: $\mathrm{NAZ}_{\mathrm{i}}$ a quantidade de acidentes ocorridos na zona $i$;

$\mathrm{EVZ}_{\mathrm{i}}$ a extensão da malha viária na zona $i$.

Já o IUPSZ - Índice de Unidade Padrão de Severidade por Zona - é dado pela Equação 5.2. 


$$
I U P S Z_{i}=\frac{\sum_{j=i}^{n} U P S_{i} \times 100}{E V Z_{i}}
$$

Sendo: $\sum_{j=i}^{n} U P S_{i}$ a soma dos índices $\mathrm{UPS}_{\mathrm{i}}$ para cada área $i$, considerando $n$ acidentes;

$\mathrm{EVZ}_{\mathrm{i}}$ a extensão da malha viária na zona $i$.

Os índices encontrados são apresentados na Tabela 5.4, onde se pode perceber que os valores do I de Moran foram relativamente altos, principalmente para o IAZEV, mostrando uma autocorrelação positiva, mas com diminuição gradual ao longo dos anos analisados em ambos os casos.

Tabela 5.4 - Valores de I em função dos índices IAZEV e IUPSZ (SANTOS, 2005)

\begin{tabular}{cccc}
\hline \multirow{2}{*}{ Índices analisados } & \multicolumn{3}{c}{ I de Moran } \\
\cline { 2 - 4 } & $\mathbf{2 0 0 1}$ & $\mathbf{2 0 0 2}$ & $\mathbf{2 0 0 3}$ \\
\hline IAZEV & 0,629 & 0,608 & 0,586 \\
IUPSZ & 0,421 & 0,398 & 0,392 \\
\hline
\end{tabular}

As Figuras 5.19 a 5.20 mostram a distribuição dos índices de acidentes de trânsito agrupados segundo os índices considerados por Santos (2005). Em ambos os casos percebe-se uma concentração de valores altos na região central, enquanto a região periférica apresenta grandes áreas (setores) com valores baixos. 


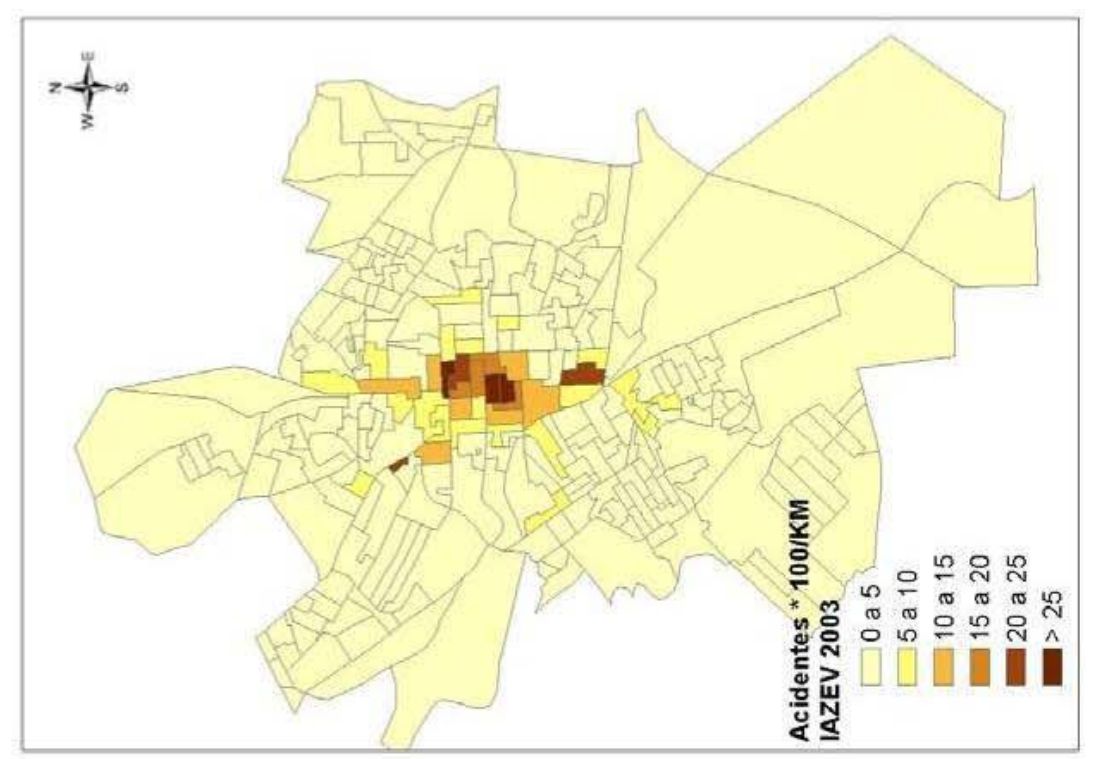

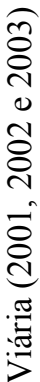

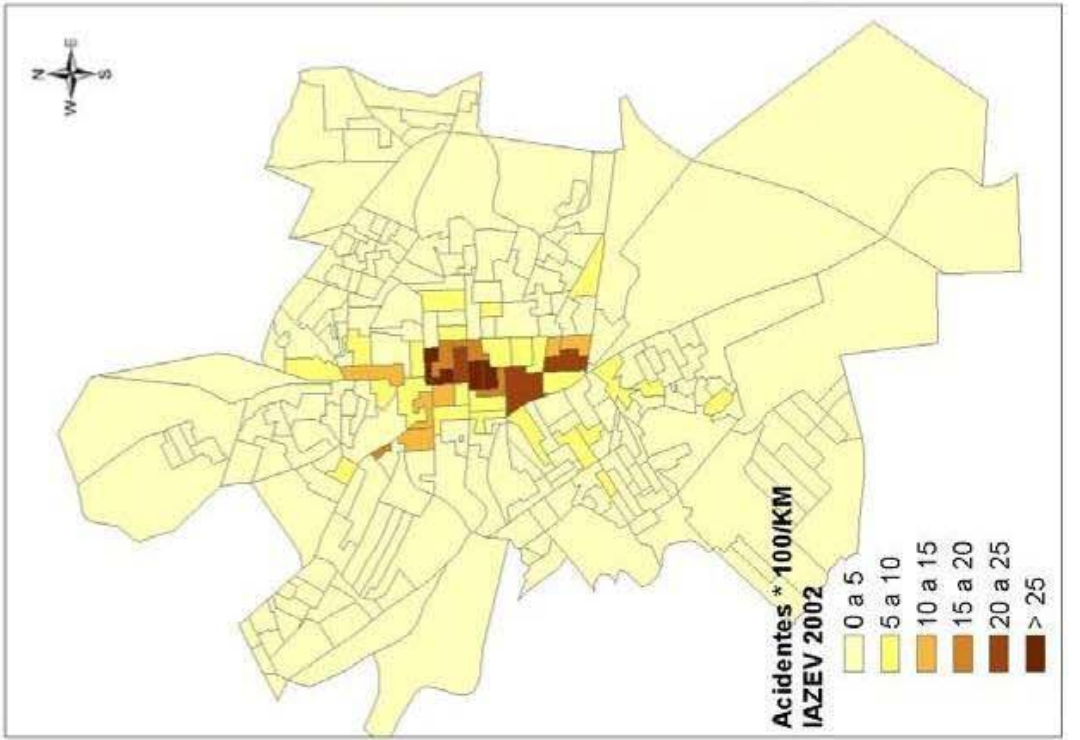

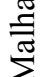

胥

2:

$\stackrel{0}{\stackrel{0}{x}}$

ठั

ซี

ง

$\Xi$

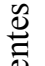

:

\%

:气

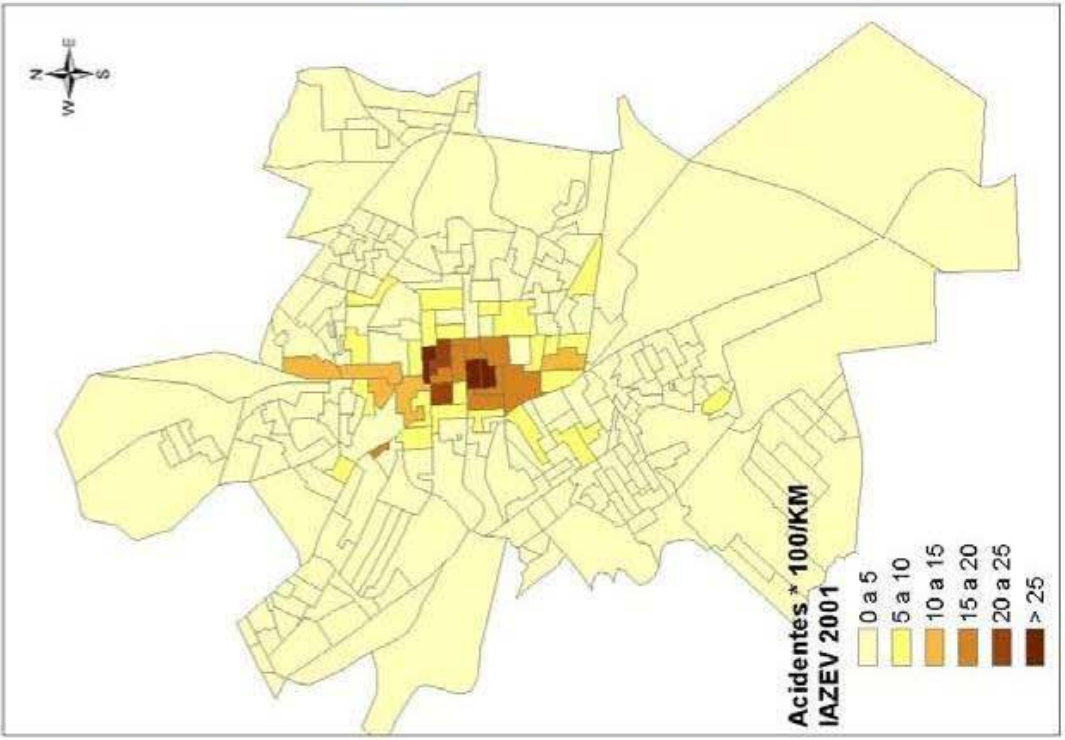




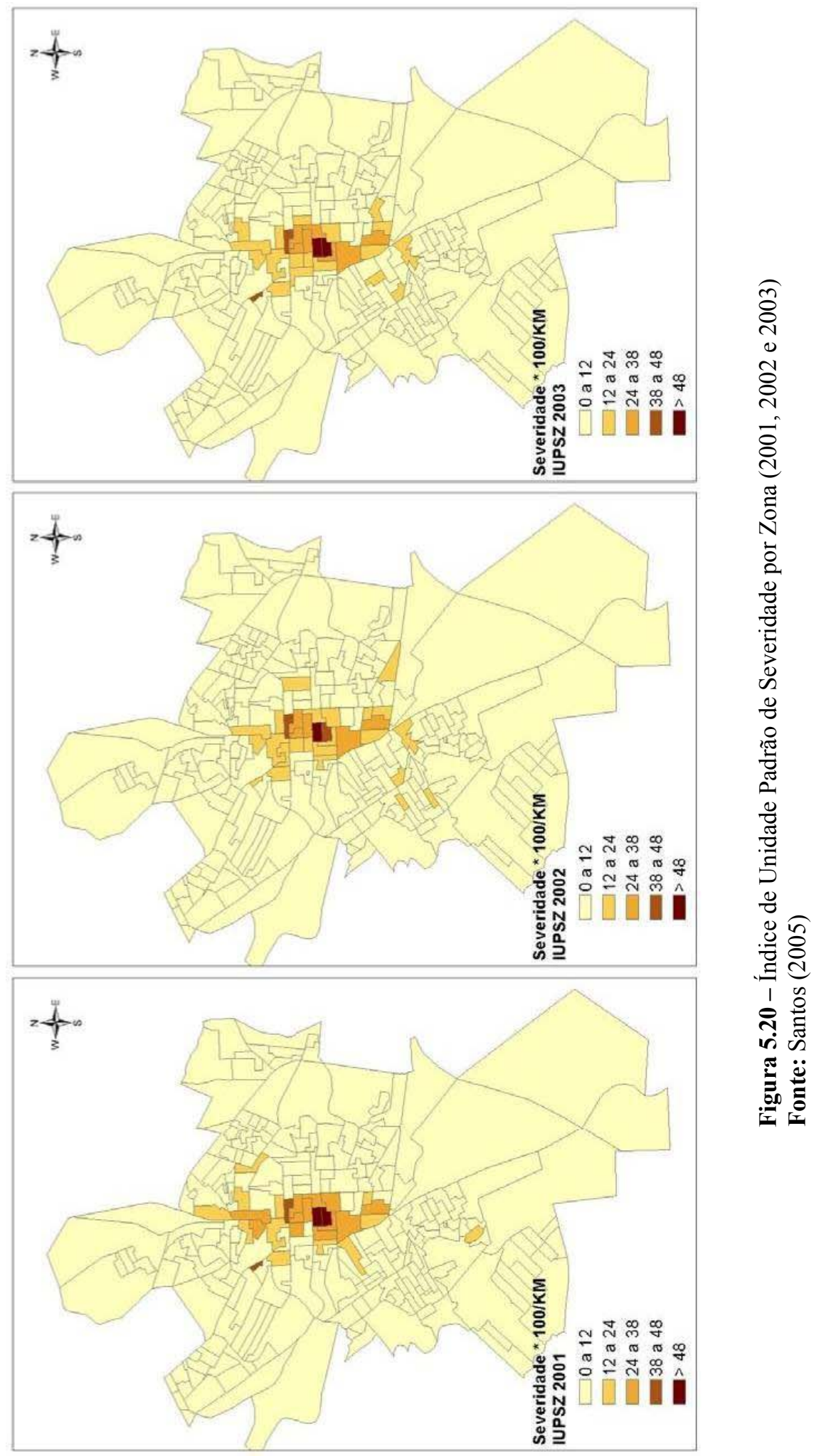


Em uma última etapa de analise, Santos focou naquilo que nomeou de Zonas de Transição. Estas zonas são identificadas a partir dos valores do Diagrama de Espalhamento de Moran, que podem ser representados pelos quadrantes - Q1, Q2, Q3 e Q4. Esses valores resultaram nas Figuras 5.21 (Box Map para IAZEV) e 5.22 (Box Map para IUPSZ), respectivamente.

Ao analisar o resultado na Figura 5.21 percebe-se que as áreas no quadrante Q1 (valor alto e média dos vizinhos alta) concentram-se na região central, ao longo do eixo Norte-Sul (Avenida São Carlos). O quadrante Q2 aparece em toda a periferia da cidade, preenchendo grandes áreas. Já Q3 e Q4 apresentam-se em menores regiões espalhadas pela cidade, formando quase um círculo em torno de Q1. Deve-se salientar que a interpretação dos Q3 e Q4 dada pelo autor está invertida em relação à interpretação dada neste trabalho, o que ocorre com relativa freqüência, mesmo na literatura específica da área.

A Figura 5.22 não apresenta o mesmo padrão que a anterior, apesar dos quadrantes Q1 também se concentrarem na região central. Analisando espacialmente, a ocorrência de Q1 é equivalente tanto na Figura 5.21 quanto na 5.22, porém nos resultados de IUPSZ as áreas de Q1 apresentam alguns outliers (áreas “fora” da região característica).

O quadrante Q2 mostra-se mais evidente em IUPSZ, com grandes setores. Os quadrantes Q3 e Q4 apresentam poucas áreas intercaladas entre os Q1 e Q2. Essa mistura entre os quadrantes reforça a idéia de que ao considerar a severidade das ocorrências fica evidente que os acidentes mais graves acontecem nas regiões das periféricas ao centro da cidade, onde se podem desenvolver maiores velocidades, mesmo que isso signifique desrespeito à regulamentação de velocidade das vias. 

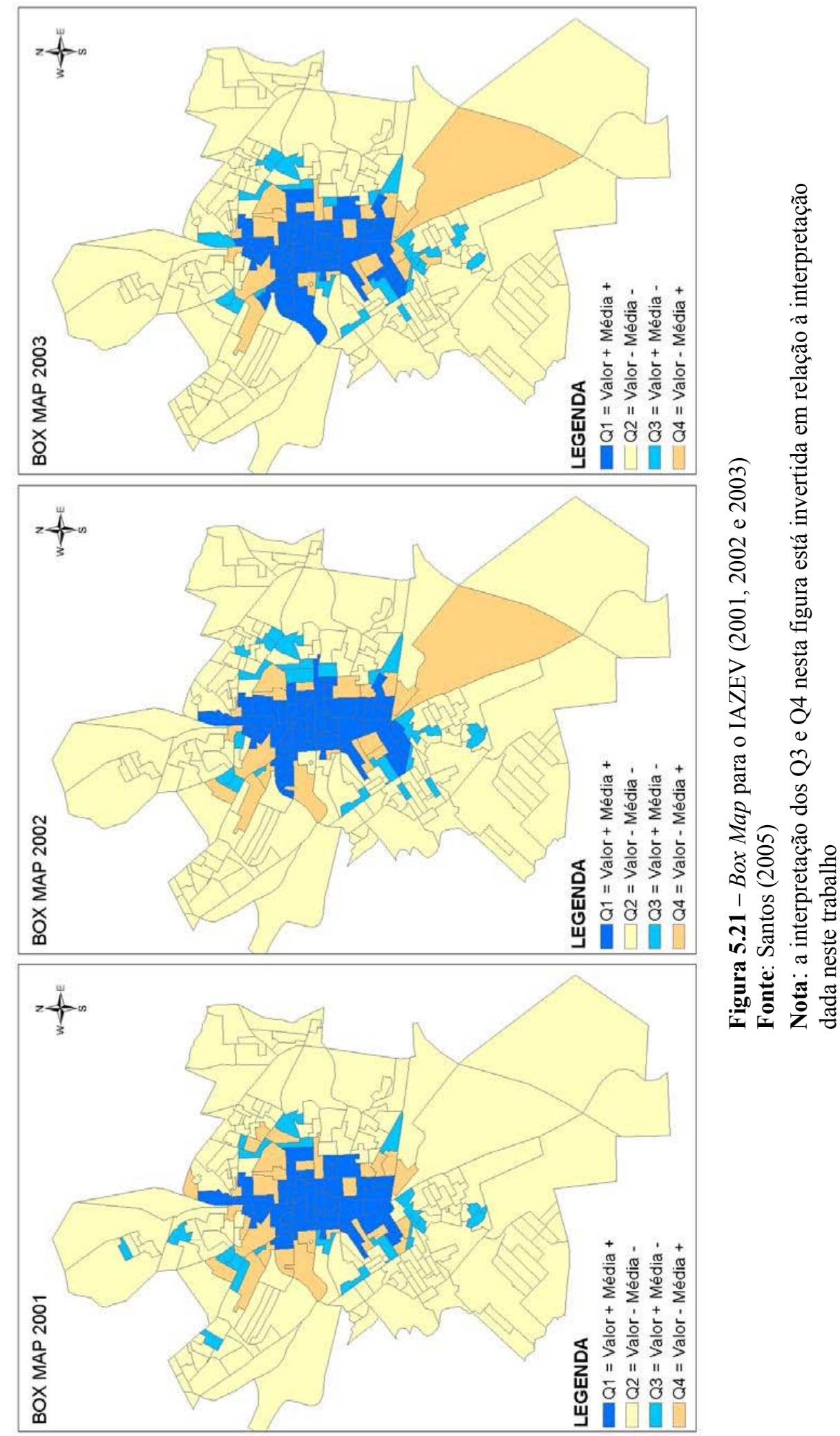

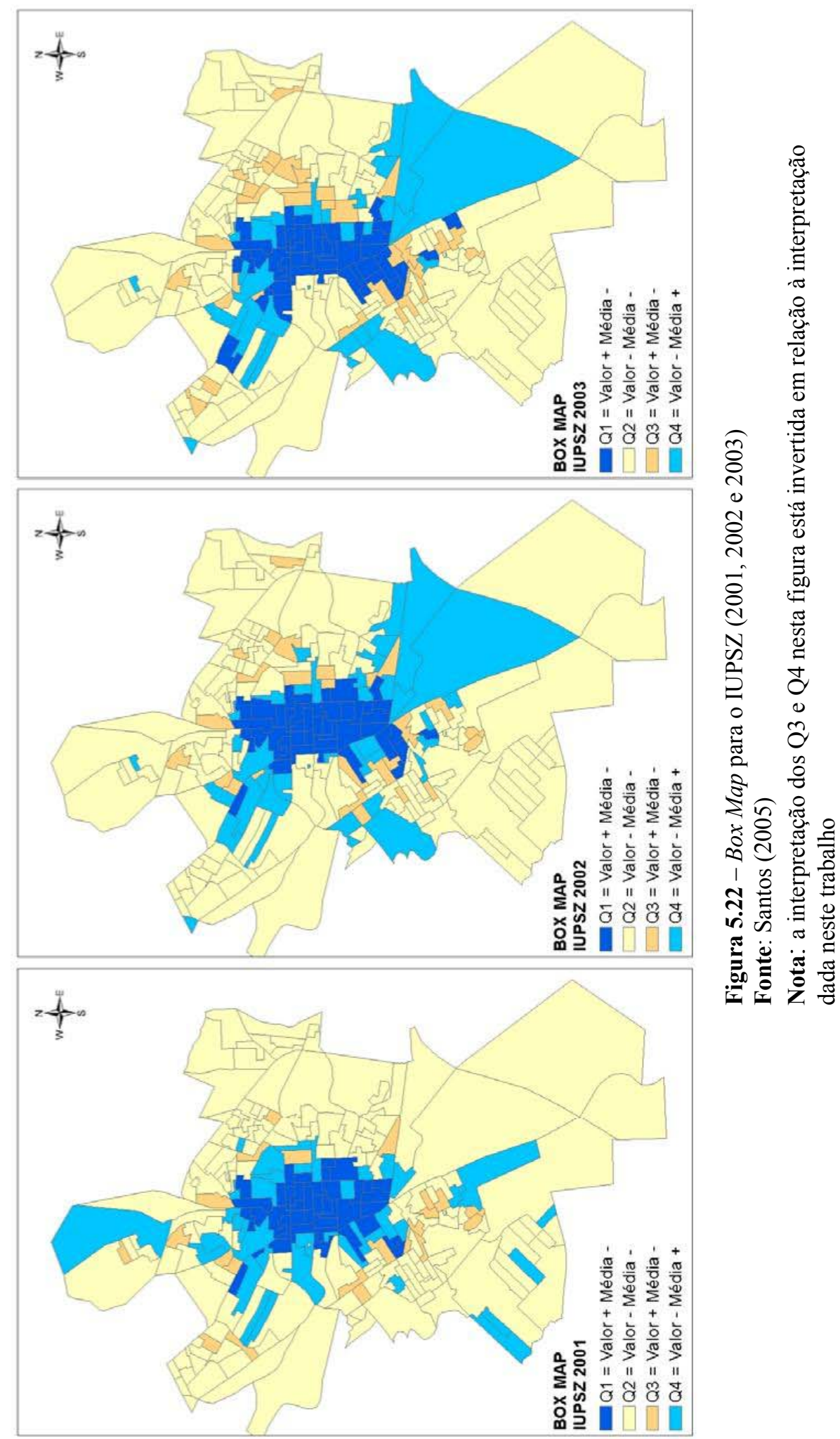


\subsection{ANÁLISE COMPARATIVA DOS RESULTADOS}

A comparação dos resultados encontrados nesta pesquisa com os em Santos (2005) é possível porque ambos os estudos partem das mesmas premissas: o objeto de estudo são os acidentes de trânsito, considerados sob uma ótica de análise comum, a análise espacial, e com aplicação em um mesmo estudo de caso, na cidade de São Carlos.

Em Santos (2005), os acidentes foram analisados segundo a sua representação pontual, ou agrupados em áreas e considerando a extensão viária e a severidade dos acidentes. Neste ponto há a primeira (e principal) divergência entre os dois estudos. Enquanto no trabalho de Santos a extensão viária e a severidade dos acidentes são consideradas separadamente, esta pesquisa procura associar a gravidade dos acidentes a sua representação direta na malha viária.

Partindo-se da premissa de que os acidentes de trânsito ocorrem essencialmente sobre uma rede (viária) admite-se, portanto que são fortemente dependentes das características topológicas dessa rede. Assim, levando-se em consideração a composição da malha viária, buscou-se nesta pesquisa novas formas de cálculo para a autocorrelação espacial. O trabalho de Santos foi essencial nessa proposta, pois além de servir de referência teórica, permitiu uma comparação direta dos resultados obtidos.

Nas primeiras avaliações, os valores de autocorrelação encontrados estavam muito abaixo daqueles encontrados no trabalho antecessor, o que também ocorreu na segunda série de simulações. A preocupação, nesse caso, não era pela diferença de valores em si, mas porque os resultados encontrados não mostravam qualquer tipo de autocorrelação na análise em rede, ao contrário do observado em padrões pontuais e de áreas. Se o fenômeno e os dados eram exatamente os mesmos, tal resultado era absolutamente inesperado.

Na terceira série de simulações, em que a localização foi levada em conta de forma mais precisa, ou seja, acidentes nas esquinas e nos arcos foram considerados de 
maneira diferenciada, a rede apresentou autocorrelação espacial (positiva). Além disso, os valores foram ligeiramente superiores aos encontrados por Santos que também mostraram autocorrelação espacial (positiva). Assim, o principal aspecto positivo da análise em redes reside no fato de assegurar a definição do local onde realmente ocorreu o acidente, além de considerar a severidade do mesmo.

Numa comparação visual entre os resultados aqui apresentados de forma resumida, percebe-se que a análise por áreas não representa bem a realidade, na medida em que dificulta a interpretação dos resultados. Observando as Figuras 5.19 e 5.20 não se tem precisão na localização e nem na gravidade dos acidentes, dando a falsa impressão de que o problema localiza-se "apenas" na região central, embora algumas avenidas apresentem um número elevado de acidentes graves.

Na observação das Figuras 5.21 e 5.22 para comparação da análise por áreas com a de redes pode-se concluir que as áreas conduzem a uma visão muito generalizada, já que grandes áreas podem minorar a quantidade e severidade dos acidentes.

Nas Figuras de 5.1 a 5.18 pode-se perceber a localização exata e real dos segmentos com maiores problemas, auxiliando a percepção visual do mesmo, pois quando nos cálculos levam-se em consideração os fatores localização e gravidade a análise é mais adequada.

A visualização pelos quadrantes torna-se uma maneira fácil de análise e comparação, visto que definido os parâmetros, a interpretação é rápida e direta, diminuindo a possibilidade de erros na interpretação dos resultados. 


\section{CAPÍTULO 6}

\section{CONCLUSÕES E RECOMENDAÇÕES}

A proposta de desenvolvimento de uma metodologia de análise de autocorrelação em redes buscava complementar trabalhos já desenvolvidos com análises de padrões pontuais ou por áreas. De certa forma, isso significava uma nova maneira de tratar a cidade, considerando-a como uma rede (complexa) constituída por segmentos que se conectam entre si.

A partir de problemas que essencialmente ocorrem em redes, que neste estudo são os acidentes de trânsito, se desenvolveu uma metodologia que permitiu inclusive uma comparação dos resultados obtidos com trabalho anterior.

A primeira conclusão relevante desse estudo é que a forma de caracterização geográfica dos acidentes pode interferir significativamente nos resultados da análise. Isso foi evidenciado pelas diversas análises realizadas, pois apesar dos valores - quantitativos de acidentes - serem iguais em todas as simulações, os valores encontrados para o I de Moran foram muito díspares.

Trabalhando a rede com os dados originais e com a ponderação em função da UPS os resultados apresentaram uma quase ausência de autocorrelação espacial. Já trabalhando os acidentes divididos entre os ocorridos ao longo das quadras ou nas áreas de influência dos cruzamentos, com sua conseqüente distribuição entre os segmentos vizinhos, os resultados passaram a apontar uma autocorrelação espacial positiva.

A análise dos acidentes por sua distribuição pela localização e majoração pela gravidade mostrou-se mais adequada, pois integra a necessidade em precisar o local exato com o conhecimento do tipo de acidente a evitar, facilitando assim uma possível intervenção e correção. 
Por exemplo, ao trabalhar com os dados de acidentes leves (danos materiais causam prejuízos menores) percebeu-se que a grande maioria dos acidentes ocorreu na região central, principalmente na Avenida São Carlos - principal eixo estruturador do sistema viário. No caso de alguma ação para correção do problema, a localização das ações seria precisa.

Além da maneira como são caracterizados geograficamente os dados, outro ponto em questão foi quanto à dispersão dos pontos de acidentes na rede viária, já que ao longo dos três anos percebeu-se o deslocamento na quantidade e tipo dos mesmos. Levandose em consideração a dispersão e a geografia dos acidentes, estes apresentaram certo padrão ao longo do tempo. Acidentes mais leves ocorreram ao longo do eixo Norte-Sul no centro da cidade e suas imediações, e acidentes mais graves espalhados pelas regiões periféricas mais afastadas. Isto se repetiu ao longo dos três anos analisados.

Esta pesquisa confirmou a tendência de que os acidentes estão se tornando mais freqüentes na periferia da cidade do que no centro, inclusive os mais graves. Este é mais um fator que interfere numa análise de autocorrelação, principalmente quando são considerados pesos para representar a severidade de acidentes. Com o crescimento do número e gravidade dos acidentes na periferia, que inclusive resultam em vítimas, os valores finais, obtidos após a ponderação pela sua gravidade, poderão se diluir na malha urbana mascarando os resultados, apresentando um cenário menos grave do que realmente acontece.

Com relação ao resultado das últimas análises verificou-se que a rede viária apresentou autocorrelação positiva, indicando que a variação do atributo (número de acidentes) de um segmento é pequena em relação a seus vizinhos. Em outras palavras, os acidentes não são fatos isolados; um acidente interfere no segmento em que ocorre, influenciando os segmentos vizinhos e vice-versa.

Esta metodologia, quando considera os acidentes de esquina e meio de quadra de forma diferenciada, bem como a sua gravidade, mostrou-se mais adequada que a análise de 
áreas conduzida por Queiroz (2003) e Santos (2005) para o problema em questão, já que o acidente é considerado na sua intensidade (UPS) e sua localização de forma mais próxima da realidade. Ainda assim, não se pode dizer que esta seja uma forma definitiva de tratamento e análise dos dados. Mais estudos devem ser realizados, considerando diferentes alternativas.

Desta forma, a metodologia desenvolvida para esta análise correspondeu ao esperado, ou seja, permitiu demonstrar que alguns fenômenos que são intrinsecamente relacionados a redes (caso dos acidentes de trânsito) podem ser representados e analisados com ferramentas e técnicas de análise espacial, em particular, a autocorrelação espacial.

Na busca por soluções de problemas atuais, a utilização de técnicas de análise espacial pode ser eficiente, principalmente neste caso em que se leva em consideração tanto a cidade como um todo, como a localização precisa e a gravidade dos acidentes, traçando assim um panorama realista e consideravelmente preciso.

Como próximos passos, poder-se-ia pensar os acidentes também em função do sentido da via, sobretudo aqueles na área de influência das interseções, o que permitiria levar em consideração os segmentos que provavelmente interferiram de forma direta no acidente. Poder-se-ia também optar por estudar as interferências que o pedestre causa no sistema viário, ou seja, levar em conta o comportamento do pedestre, o que nesse caso pressupõe uma maior liberdade nos movimentos, praticamente sem restrições de sentido. Em síntese, a solução adotada para considerar os acidentes em cruzamentos ainda pode e deve ser objeto de outras investigações, de forma a refletir de maneira mais próxima da realidade o fenômeno representado. 


\section{REFERÊNCIAS BIBLIOGRÁFICAS}

ALLEN, Peter M. Cities and regions as self-organizing systems: models of complexity. Amsterdam: Gordon and Breach. 1997.

ALLEN, W.Bruce; LIU, Dong; SINGER, Scott. Accessibility measures of U.S. metropolitan areas. Transportation Research B - Methodological, v. 27, n. 6, p. 439-449, 1993.

ANSELIN, L; BAO, S. Exploratory spatial data analysis linking SpaceStat and ArcView. In FISHER, M.; GETIS, A. (Eds.) Recent Developments in Spatial Analysis, Berlin; SpringerVerlag, 1997.

ANSELIN, L.; SMIRNOV, O. The SpaceStat Extension for ArcView 3.0. Regional Research Institute, West Virginia University, Morgantown,1998.

ANTP. Racionalidade redução de custos levarão cidades a buscar novamente os sistemas de transporte público. Informativo ANTP, v.79, p. 4-5, 2001.

APPLEYARD, Donald. Livable streets. Berkeley, CA: University of California Press, 1981.

BANNAVAN, Jayanth R.; MARITAN, Amos; RINALDO, Andrea. Size and form in efficient transportation networks. Nature, v. 399, p. 130-132, 1999.

BARABASI, Albert László.; ALBERT, R. Emergence of scaling in random networks. Science. v. 286, p. 509, 1999.

BATTY, Michael. Polynucleated urban landscapes. Urban Studies, v.38, n. 4, p. 635-655, 2001.

BEN JOSEPH, Eran; SOUTHWORTH, Michael. Streets and the shaping of towns and cities. New York: McGraw Hill, 1997.

BLACK, Willian R. e THOMAS, Isabelle. Accidents on Belgium's motorways: a network autocorrelation analysis. Journal of Transport Geography. v.6, n. 1, p. 23-31,1998 
BOSSELMANN, Peter; MACDONALD, Elizabeth; KRONEMEYER, Thomas. Livable streets revisited. Journal of the American Planning Association. v. 65, n. 2, p. 168-180, 1999.

BRUTON, Michael J. Introdução ao Planejamento dos Transportes. Trad. Joao Bosco F. Arruda. São Paulo, Interciência/Edusp, 1979

CALIANDRO, Victor Street form and use. In: ANDERSON, S. On Streets. Massachusetts, The MIT Press. pp. 151-186,1978.

CALTHORPE, P. Next American Metropolis: ecology, community and the American Dream. New York: Princeton Architectural Press, 1993.

COSTA, Marcela da Silva. Mobilidade urbana sustentável: um estudo comparativo e as bases de um sistema de gestão para Brasil e Portugal. São Carlos, 184 p. Dissertação (Mestrado). Escola de Engenharia de São Carlos - USP. São Carlos, 2003

DENATRAN - DEPARTAMENTO NACIONAL DE TRÂNSITO. Anuário Estatístico de Acidentes de Trânsito - $2005 . \quad$ Disponível em: http://www.infoseg.gov.br/renaest/detalheNoticia.do?noticia.codigo=115, Acessado em: 19 de julho de 2007.

DETRAN - DEPARTAMENTO DE TRÂNSITO DO PARANÁ - Anuário Estatístico 2006. Disponível em: http://www.detran.pr.gov.br/arquivos/File/estatisticasdetransito/anuario2006.pdf, Acessado em: 19 de julho de 2007.

DILL, Jennifer. Measuring Network Connectivity for Bicycling and Walking. Leuven. The Joint Congress of ACSP-AESOP. Belgium, 2003.

DUCKHAM, Matt e KULIK, Lars. Simplest paths: automated route selection for navigation. In: Kuhn, W., Worbys, M. e Timpf, S. (eds.) Lecture Notes in Computer Science 2825. Springer-Verlag. p. 1269-185, 2003.

DUPUY, G. L’Urbanisme Des Réseaux, Paris: Armand Colin, 1991.

DUPUY, G. Les Territoires de l'Automobile, Paris: Anthropos, 1995. 
ESCOLANO, Severino. On the information contents of urban layouts. Fourth International Space Syntax Conference. London, 2003

EWING, Reid Counterpoint: is Los Angeles-style sprawl desirable? Journal of the American Planning Association, v. 63, n. 1, p. 107-126, 1997.

FERRAZ, Antonio C. P.; RAIA JÚNIOR, Archimedes A. Segurança no Trânsito. Notas de aula, São Carlos, 2007.

GEHL, Jan. Life between buildings. Using public space. New York: Van Nostrand Reinhold, 1987.

GIRVAN, M.; NEWMAN, M. E. J. Community structure in social and biological networks. Proceedings of the National Academy of Science USA, v. 99, p. 7821-7826, 2002.

GONICK, Larry, SMITH, Woollcott. The Cartoon Guide to Statistics. Harper Perennial, 1993.

GOLD, Philip. A. Segurança de Trânsito - Aplicação de Engenharia para reduzir acidentes. Banco Interamericano de Desenvolvimento, 1998.

GORDON, Peter; RICHARDSON, Harry W. Gasoline consumption and cities - a reply. Journal of the American Planning Association, v. 55, n. 3, p. 342-346, 1989.

GORDON, Peter; RICHARDSON, Harry W. Are compact cities a desirable planning goal? Journal of the American Planning Association, v. 63, n. 1, p. 95-106, 1997.

GORDON, P.; WONG, H. L. The costs of urban sprawl: some new evidence. Environment and Planning A, v. 17, n. 5, p. 661-666, 1985.

GOULD, Peter; WHITE, R. Mental maps. England: Pelican Books, 1974.

HAGGET, Peter; CHORLEY, Richard J. Network analysis in geography. New York: St. Martin's Press, 1969.

HALL, Peter. G. Can cities be sustainable? In: Serageldin, J., Cohen, M. A. e Sivaramkrishnan, K. C. (eds.) The human face of the urban environment: Proceedings of 
The Second Annual World Bank Conference on Environmentally Sustainable Development. Washington, D.C., World Bank, 1994.

HANDY, S.; PATERSON, R. G.; BUTLER, K. S. Planning for street connectivity - Getting from to there. APA Planning Advisory Service, 2003.

HANDY, Susan L. Urban form and pedestrian choices: study of Austin neighbourhoods. Transportation Research Record. v.1552, p. 135-144, 1996.

HILLIER, Bill; HANSON, Julienne. The social logic of space. Cambridge: Cambridge University Press, 1984.

HILLIER, Bill. Space is the machine. Cambridge: Cambridge University Press, 1996.

HIRTLE, Stephen C.; JONIDES, John. Evidence of hierarchies in cognitive maps. Memory and Cognition. v. 3, p. 208-217, 1985.

INGRAM, D. R. The concept of accessibility: a search for an operational form. Regional Studies, v. 5, p. 101-107, 1971.

IPEA - INSTITUTO DE PESQUISA ECONOMICA APLICADA. Impacto sociais e econômicos dos acidentes de trânsito nas rodovias brasileiras, Brasilia, 2006. Disponível em: http://www.ipea.gov.br/default.jsp, acessado em 19 de julho de 2007.

JIANG, Bin. Agent-based approach to modelling urban and environmental systems within GIS. Proceedings of 9th International Symposium on Spatial Data Handling. Beijing, 2000 .

JIANG, Bin; CLARAMUNT, Christophe. Topological analysis of urban street networks, Environment Planning B. v. 31, n. 1, p. 151-162, 2004.

KENWORTHY, Jeffrey R.; LAUBE, Felix B. Patterns of automobile dependence in cities: an international overview of key physical and economic dimensions with some implications for urban policy. Transportation Research A -Policy and Practice, v. 33, n. 7-8, p. 691723, 1999.

KUIPERS, Benjamin. Modelling spatial knowledge. Cognitive Science. 2, p. 129-153, 1978. 
KUIPERS, Benjamin (2001). The skeleton in the cognitive map: a computational hypothesis. In: J. Peponis, J., Wineman, J., S. Bafna, S. (eds.) Space syntax: proceedings of the Third International Symposium (pp. 10.1-10.7). Ann Arbor, University of Michigan, 2001.

LIMA, Renato da Silva. Expansão Urbana e Acessibilidade - O caso das cidades médias brasileiras. São Carlos, 81 p. Dissertação (Mestrado). Escola de Engenharia de São Carlos USP, 1998.

LIMA, Renato da Silva; SILVA, Antônio Nélson R. The influence of city form on transportation accessibility. In: International Conference on Modeling and Management in Transportation, Cracow, Polônia: Cracow University of Technology. Anais, v. 2, p. 53$58,1999$.

LIMA, Renato S.; SILVA, Antônio N. R., EGAMI, Cintia Y.; ZERBINI, Luiz F. Promoting $a$ more efficient use of urban areas in developing countries: an alternative. Transportation Research Record, v. 1726, p. 8-15, 2000.

LIMA, Renato S., SILVA, Antônio N. R., WAERDEN, Peter Van Der. Espalhamento urbano: mito ou realidade no Brasil? O caso das cidades médias. Revista dos Transportes Públicos, v. 23, n. 91, p. 75-86, 2003.

LYNCH, Kevin. The image of the city. Cambridge, MIT Press, 1960.

LYNCH, Kevin. Good city form. Cambridge, MIT Press, 1981.

LOPES, Simone B. Efeitos da dependência especial em modelos de previsão de demanda por transportes. São Carlos, 137 p. Dissertação (Mestrado) Escola de Engenharia de São Carlos, 2005.

MARCHAND, D. Representation of the city and image of the centre in two different structures: a modern and a traditional one. In: G. Moser E. Pol, Y. Bernard, M. Bonnes, J. Corraliza e V. Giuliani (eds.) Places, peoples and sustainability. Gottingen, Germany. Hogrefe and Huber. p. 11-24, 2002.

MORAN, Patrick A. P. The interpretation of Statistical Maps. Proceedings of the Cambridge Philosophy Society, n. 44, p. 342-344, 1947. 
MT - Ministério dos Transportes. Programa Pare de Redução dos Acidentes Procedimentos para o Tratamento de Locais Críticos de Acidentes de Transito - Brasília, 2002 .

NEWMAN, M. E. J. The structure and function of complex networks. SIAM Review. v. 45, p. 167-256, 2003.

NEWMAN, P. W. G. The compact city: an Australian perspective. Built Environment, v. 18, n. 4, p. 285-300, 1992.

NEWMAN, P. W. G.; KENWORTHY, Jeffrey R. The transportation energy trade-off: fuel efficient traffic versus fuel-efficient cities. Transportation Research A - Policy and Practice, v. 22, n. 3, p. 163-174, 1988.

ODLAND, John. Spatial Autocorrelation. California: Sage Publications, 1988.

OWENS, Peter M. Neighborhood form and pedestrian life: taking a closer look. Landscape and urban planning. v. 26, p. 115-135, 1993.

POOLER, James A. The use of spatial separation in the measurement of transportation accessibility. Transportation Research B - Methodological, v. 29, n. 6, p. 421-428, 1995.

PROSHANSKY, Harold M.; FABIAN, Abbe K.; KMINOFF, Robert. Place identify: physical world socialization of the self. Journal of Environmental Psychology. v. 3, n. 1, p. 57-83, 1983.

QUEIROZ, Marcelo Pereira. Análise espacial dos acidentes de trânsito do município de Fortaleza. Fortaleza. 124p. Tese (Mestrado). Universidade Federal do Ceará, 2003.

RAIA JUNIOR, Archimedes A.; SILVA, Antônio N. R. Um método expedito para verificação da consistência de redes para uso em um SIG-T. In: $\mathbf{1 2}^{\circ}$ Congresso de Pesquisa e Ensino em Transportes, Fortaleza, Brasil. Anais, v. 2, p. 10-17, 1998.

RAIA JUNIOR, Archimedes A. Acessibilidade e mobilidade na estimativa de um índice de potencial de viagens utilizando Redes Neurais Artificiais e Sistemas de Informação Geográfica. São Carlos. 201p. Tese (Doutorado). Escola de Engenharia de São Carlos, Universidade de São Paulo, 2000. 
RAPOPORT, Amos. Human aspects of urban form. Oxford: Pergamon Press, 1977.

REAL ESTATE RESEARCH CORPORATION. The costs of sprawl: vol. 1, Executive summary, vol. 2, Detailed cost analysis, vol. 3, Literature review and bibliography. Washington, D.C.: U.S. Government Printing Office, 1974.

SALINGAORS, Nikos Connecting the fractal city. Fifth Biennial of Town Planners in Europe, Barcelona, 2003.

SANTOS, Luciano. Análise dos Acidentes de Trânsito do Município de São Carlos - SP utilizando Sistema de Informação Geográfica SIG e ferramentas de Análise Espacial. São Carlos. 136p. Dissertação (Mestrado). Departamento de Engenharia Civil, Universidade Federal de São Carlos, 2005.

SIEGEL, A. W.; WHITE, S. H. The development of spatial representations of largescale environments, In: H. W. Reese (ed) Advances in Child Development and Behavior. v. 10, p. 9-55. New York: Academic Press, 1975.

SILVA, Antônio N. R Sistema de informações geográficas para o planejamento de transportes. São Carlos. 112p. Tese (Livre-docência). Escola de Engenharia de São Carlos, Universidade de São Paulo, 1998.

SILVA, Antônio N. R.; LIMA, Renato S.; WAERDEN, Peter Van Der The evaluation of urban network pattern with a global accessibility index in a GIS environment. In: 6th International Conference on Computers in Urban Planning and Urban Management, Veneza -Italia. Anais ... (em CR-Rom). Veneza, Istituto Universitario di Architettura di Venezia, 1999.

SOUTHWORTH, Michael Walkable suburbs? An evaluation of neotraditional communities at the urban edge. Journal of the American Planning Association. v. 63, n. 1, p. 28-44, 1997.

SOUTHWORTH, Michael; OWENS, P. M The evolving metropolis: studies of community, neighborhood and street form at the urban edge. Journal of the American Planning Association. v. 59, n. 3, p. 271-287, 1993. 
SOUTHWORTH, Michael; BEN-JOSEPH, Eran. Street standards and the shaping of suburbia, Journal of the American Planning Association. v. 61, n. 1, p. 65-81, 1995.

SOUZA, Léa C. L.; SILVA, Antônio N. R. Compact city: could this be an option for medium sized Brazilian cities? In: Maldonado, E. e Yannas, S. (eds.), Environmentally friendly cities. 15th International Conference on Passive and Low Energy Architecture, Lisboa, Portugal. London. James \& James, p. 103-106, 1998.

STEVENS, Albert e COUPE, Patty. Distortions in judged spatial relations. Cognitive Psychology. v. 10, p. 422-437, 1978.

TALEN, Emily Traditional urbanism meets residential affluence: an analysis of the variability of suburban preference. Journal of the American Planning Association, v. 67, n.2, p. 199-216, 2001.

THORNDYKE, Perry W.; HAYES-ROTH, Barabara. Differences in spatial knowledge acquired from maps and navigation. Cognitive Psychology, v. 14, p. 560-589, 1982.

UZZELL, David; POL, Enric, BADENAS, David. Place identification, social cohesion and environmental sustainability. Environment and Behavior. v. 34, n. 1, p. 26-53, 2002.

VALCARCE, Esther Vayá; SERRANO, Rosina Moreno. Técnicas enconometricas para el tratamiento de datos espaciales: La econometría espacial. Barcelona, Edicions Universitat de Barcelona, 2000.

WATTS, Duncan J.; STROGATZ, Steven H. Collective dynamics of small world networks, Nature. v. 393, p. 440-442, 1998.

WHYTE, Willian $H$. The social life of small urban spaces. Washington, D.C. The Conservation Foundation, 1980. 



\section{APÊNDICE}

\section{EXEMPLOS NUMÉRICOS}

A partir da malha urbana da cidade de São Carlos e dos dados de acidentes nos anos de 2001, 2002 e 2003, iniciou-se a contagem do número de acidentes em cada segmento. Para isso procedeu-se da seguinte maneira:

\section{A.1 Dataview de Pontos}

Com os segmentos e os pontos de acidentes ativados (Figura A.1), sendo a de pontos a camada de trabalho, abre-se um Dataview conforme Figura A.2. Neste Dataview ou Banco de Dados, há dados referentes a cada ponto, como: ID (número identificador), latitude, longitude, data e endereço da ocorrência, etc. 


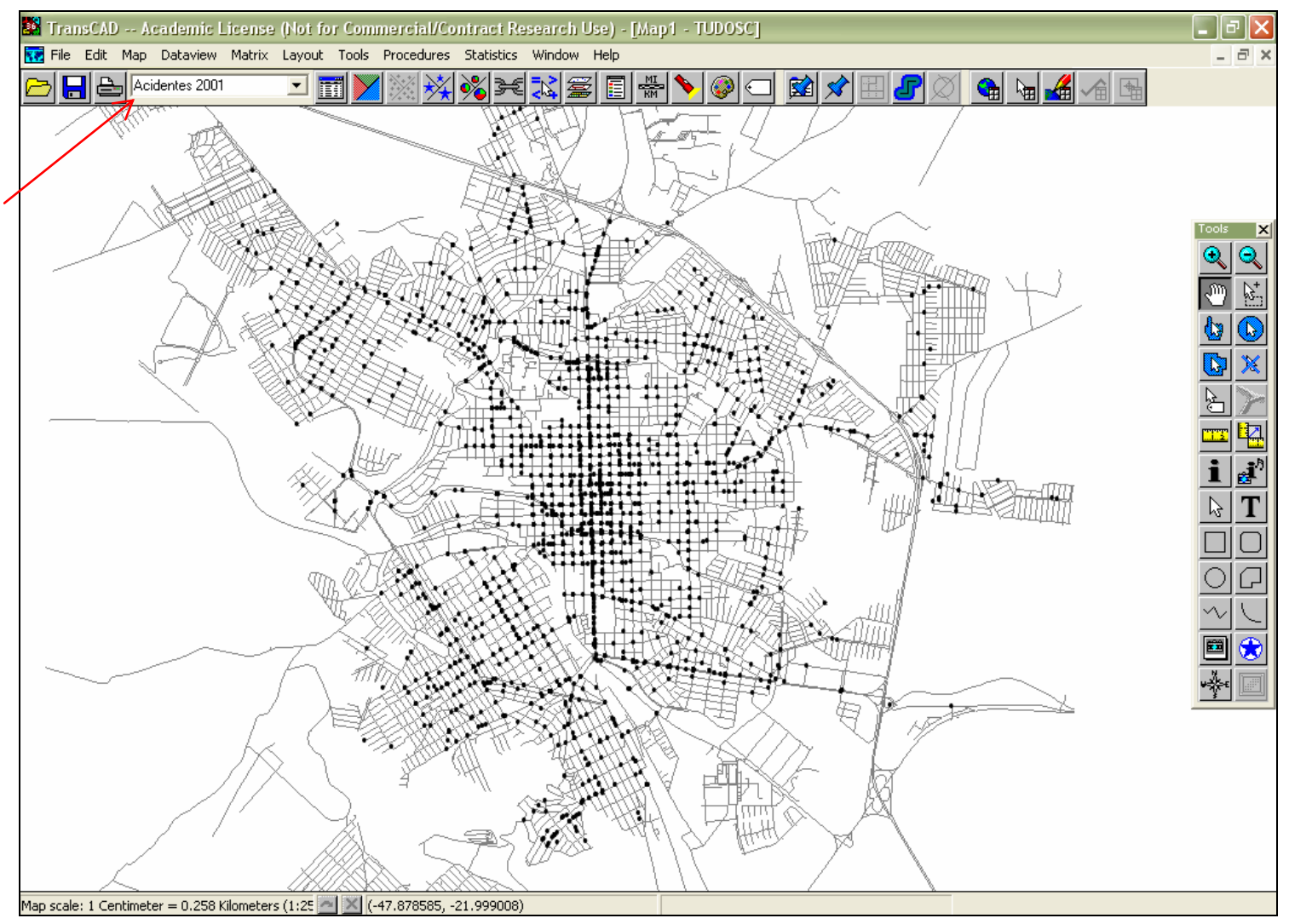

Figura A.1 - Mapa dos eixos de vias de São Carlos e dos locais de acidentes

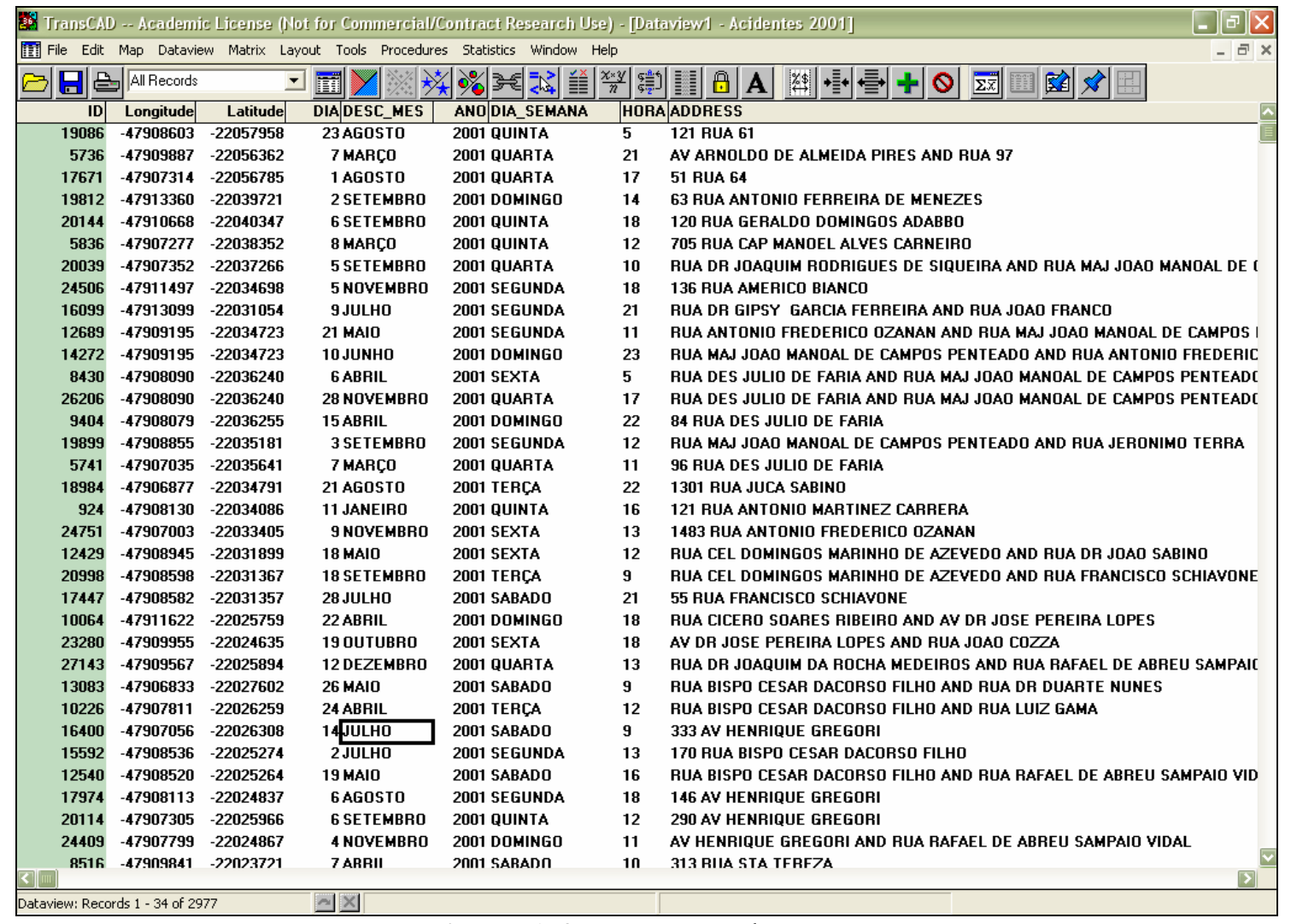

Figura A.2 - Dataview de pontos 
O próximo passo é acrescentar uma coluna a este banco de dados, com o comando: Dataview > Modify Table..., que faz surgir a janela da Figura A.3.

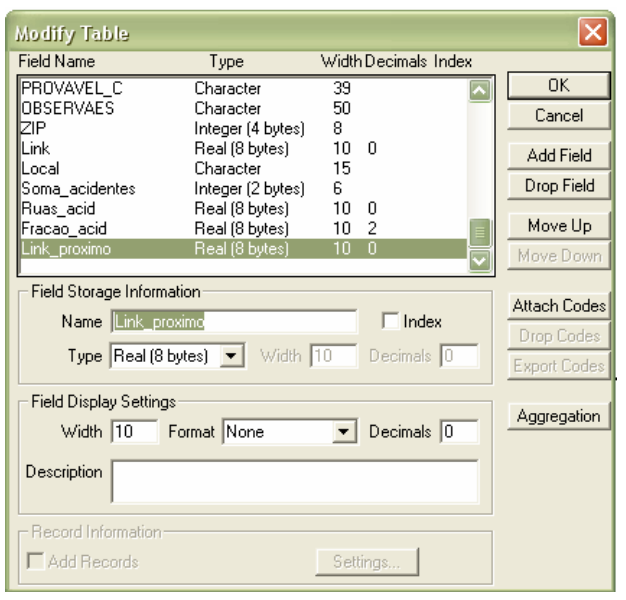

Figura A.3 - Janela obtida com o comando: Dataview > Modifiy Table

O comando Add Field permite preencher os campos Name (nome da coluna), Type (Real) e Width (10). As opções $O K$ e Yes criam a nova coluna, conforme demonstrado na Figura A.4. 


\begin{tabular}{|c|c|c|c|c|c|}
\hline \multicolumn{5}{|c|}{ 20 TransCAD - Academic Liense (Not for Commercial/Contract Research Use) - [Dataviewn - Acidentes 2001] } & \multirow{2}{*}{$\begin{array}{r}-\sqrt{x} x \\
-a x\end{array}$} \\
\hline 睢 File & Edit Map Dataview Matrix Layou & It Tools Procedures Statistics Window $H$ & Help & & \\
\hline \multicolumn{6}{|c|}{ E } \\
\hline TEMPO & ILUMINAO & PROVAVEL_C & OBSERVAES & ZIPC & oximo|: $\wedge$ \\
\hline CHU & NOITE COM LUZ ARTIFICIAL & Dirigir sem cuidados e atenção & Animal na pista. & 13566000 & \\
\hline Вом & NOITE COM LUZ ARTIFICIAL & Falha da sinalização & v2 evadiu-se & 13566000 & -- \\
\hline BOM & ENTERDECER OU AMANHECER & Desrespeito às regras de circulação & Um cachorro entrou na frente do veíc. & 13566000 & -- \\
\hline вом & LUZ SOLAR & Dirigir sem cuidados e atenção & & 13566000 & -- \\
\hline Вом & LUZ SOLAR & Dirigir sem cuidados e atenção & Veíc2 estacionado. & 13566000 & -- \\
\hline CHU & LUZ SOLAR & Dirigir sem cuidados e atenção & & 13566000 & -- \\
\hline Вом & LUZ SOLAR & Desobediência à sinalização & Cond2 desobedeceu à sinalização. & 13566000 & -- \\
\hline BOM & LUZ SOLAR & Dirigir sem cuidados e atenção & & 13566000 & -- \\
\hline BOM & NOITE COM LUZ ARTIFICIAL & Desrespeito às regras de circulação & & 13566000 & -- \\
\hline BOM & LUZ SOLAR & Desrespeito às regras de circulação & Veíc2 manobrava p/ adentrar rua 2 & 13566000 & -- \\
\hline BOM & NOITE COM LUZ ARTIFICIAL & Falha da sinalização & & 13566000 & -- \\
\hline BOM & NOITE COM LUZ ARTIFICIAL & Desobediência à sinalização & faltam dados de $\mathrm{v} 2$ & 13566000 & -- \\
\hline CHU & NOITE COM LUZ ARTIFICIAL & Desobediência à sinalização & & 13566000 & -- \\
\hline вом & NOITE COM LUZ ARTIFICIAL & Desrespeito às regras de circulação & v2 na contra mao & 13566000 & -- \\
\hline вом & LUZ SOLAR & Desobediência à sinalização & Cond2 desobedeceu à sinalização. & 13566000 & -- \\
\hline вом & LUZ SOLAR & Desobediência à sinalização & & 13566000 & -- \\
\hline BOM & NOITE COM LUZ ARTIFICIAL & Dirigir sem cuidados e atenção & Veíc1 estacionado. & 13566000 & -- \\
\hline Вом & LUZ SOLAR & Dirigir sem cuidados e atenção & & 13566000 & -- \\
\hline вом & LUZ SOLAR & Desrespeito às regras de circulação & 0 COND 1 ABRIU A PORTA SEM OBSERVAR O TRAFEGO & 13566000 & -- \\
\hline Вом & LUZ SOLAR & Dirigir sem cuidados e atenção & Veícs parados no cruzamento. & 13566000 & -- \\
\hline BOM & LUZ SOLAR & Desrespeito às regras de circulação & & 13566000 & -- \\
\hline вом & NOITE COM LUZ ARTIFICIAL & Dirigir sem cuidados e atenção & Veíc1 estacionado. & 13566000 & -- \\
\hline BOM & NOITE COM LUZ ARTIFICIAL & Desrespeito às regras de circulação & & 13566000 & -- \\
\hline BOM & ENTERDECER OU AMANHECER & Desrespeito às regras de circulação & & 13566000 & -- \\
\hline CHU & LUZ SOLAR & Desobediência à sinalização & & 13566000 & -- \\
\hline вом & LUZ SOLAR & Desobediência à sinalização & Cond2 desobedeceu à sinalização. & 13566000 & -- \\
\hline BOM & LUZ SOLAR & Desobediência à sinalização & v2 evadiu-se & 13566000 & -- \\
\hline BOM & LUZ SOLAR & Dirigir sem cuidados e atenção & Visão cond1 atrapalhada por 1 onibus.Manobrava. & 13566000 & -- \\
\hline BOM & ENTERDECER OU AMANHECER & Dirigir sem cuidados e atenção & Veíc1 estacionado. Veíc2 saía da garagem. & 13566000 & -- \\
\hline Вом & LUZ SOLAR & Dirigir sem cuidados e atenção & Cond1 fazia conversão à esquerda. & 13566000 & -- \\
\hline BOM & ENTERDECER OU AMANHECER & Dirigir sem cuidados e atenção & Veíc1 estacionado. & 13566000 & -- \\
\hline BOM & LUZ SOLAR & Dirigir sem cuidados e atenção & Veíc2 estacionado. & 13566000 & -- \\
\hline CHU & LUZ SOLAR & Dirigir sem cuidados e atençāo & & 13566000 & -- \\
\hline \begin{tabular}{|l} 
RnM \\
$\vdots$
\end{tabular} & III SחI AR & Dirinir sem r.uidadns $\mathrm{P}$ ałenn:ãn & v) pvadiu-se & 13566 nnก & $-\sqrt{n}$ \\
\hline Dataview: & : Records 1 - 34 of 2977 & $\Delta x$ & & & \\
\hline
\end{tabular}

Figura A. 4 - Coluna criada no Dataview

Para o preenchimento da coluna, a mesma deve ser selecionada, clicando-se com a opção: Edit > Fill, que abrirá a janela da Figura A.5, deve-se selecionar a opção Tag e preencher Using layer com a opção do nome da Layer de segmentos e Tag with com ID.

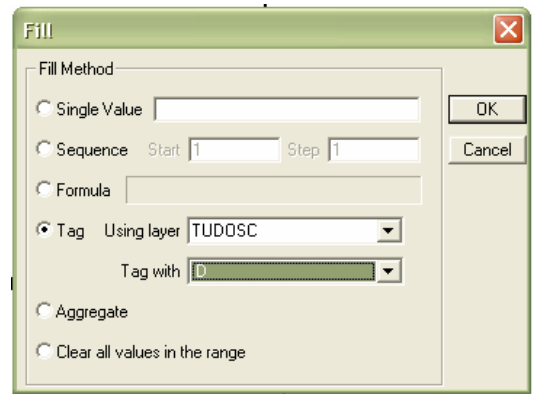

Figura A.5 - Janela obtida com o comando Edit $>$ Fill

Com este procedimento a coluna é preenchida com os dados do Dataview de segmentos (Figura A.6), neste caso com o ID do segmento mais próximo ao ponto (acidente); assim vincula-se o ID dos pontos ao dos segmentos. 
Terminada esta etapa, segue-se com o refinamento dos dados, em uma planilha eletrônica. Para isso, seleciona-se File $>$ Save As, preenchendo o nome do arquivo e a opção $d B A S E$ file (*.dbf) - Figura A.7. A extensão (*.dbf) pode ser selecionada, por ser compatível com diversas planilhas eletrônicas.

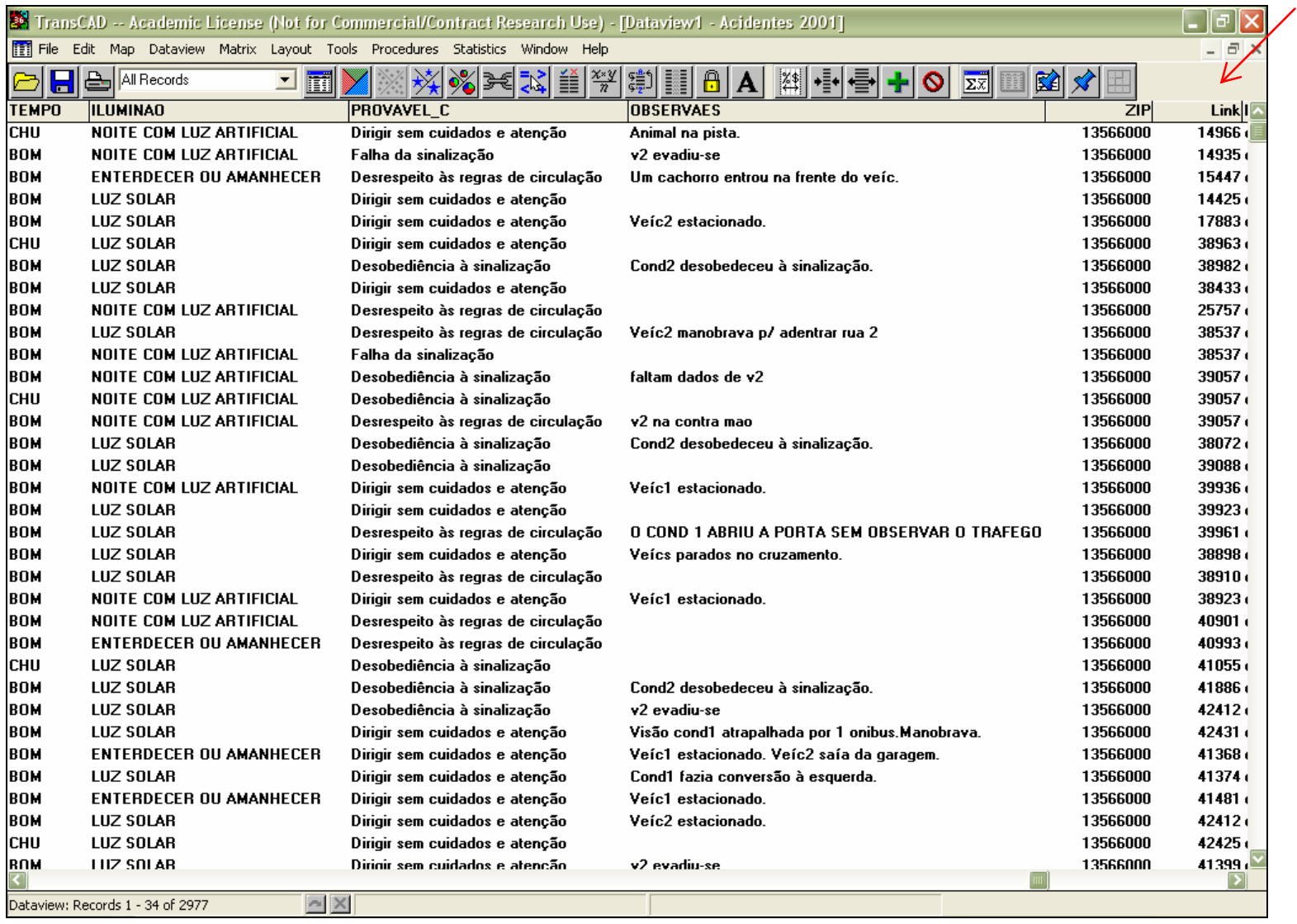

Figura A.6 - Coluna preenchida com ID dos segmentos 


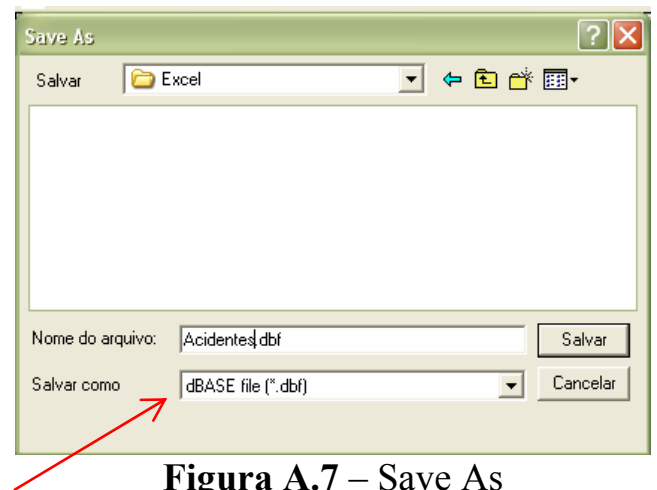

Figura A.7 - Save As

\section{A.2 Excel}

A razão de trabalhar no Excel é que em planilhas eletrônicas há uma maior flexibilidade na manipulação dos dados, como neste caso em que se necessita fazer uma contagem de quantos e quais tipos de acidente há em cada segmento, associando-os aos IDs dos pontos.

Nesta segunda fase em que o arquivo é aberto no Excel, cabe lembrar que, o nome do arquivo gravado não aparecerá em Arquivos do tipo automaticamente na opção, em conseqüência da extensão (*.dbf). Para abrir este arquivo, seleciona-se a opção Todos os arquivos, seguido do nome.

Com o arquivo aberto, a seleção de todos os dados pode ser feita clicando na célula superior à esquerda ( $1^{\mathrm{a}}$ linha e $1^{\mathrm{a}}$ coluna) como indicada na Figura A.8. A opção: Dados $>$ Relatórios de tabela e gráfico dinâmicos, leva a seqüência de janelas mostradas na Figura A.9, que conduzem a uma nova planilha, conforme a Figura A.10. 


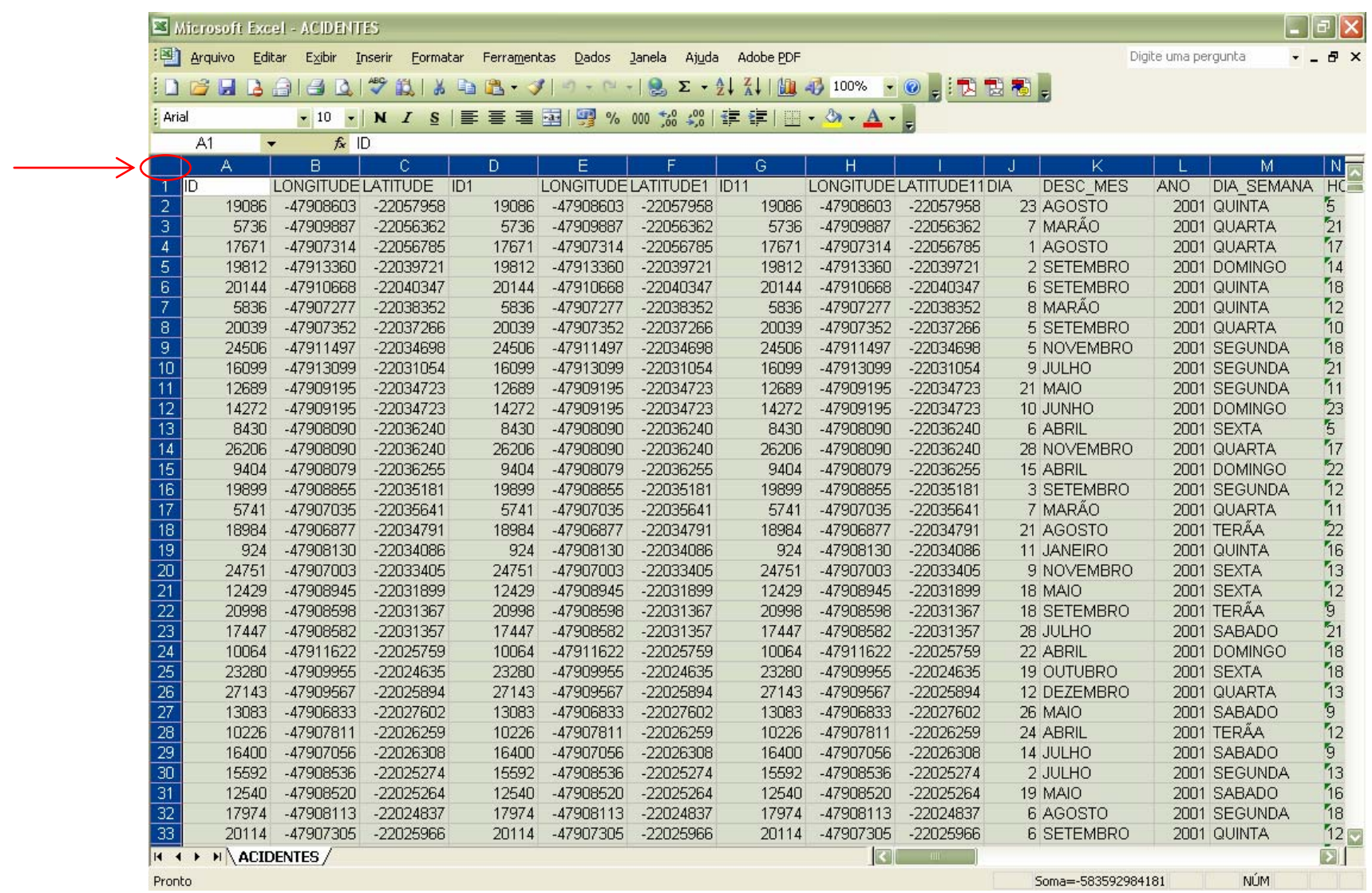

Figura A.8 - Seleção de dados no Excel 

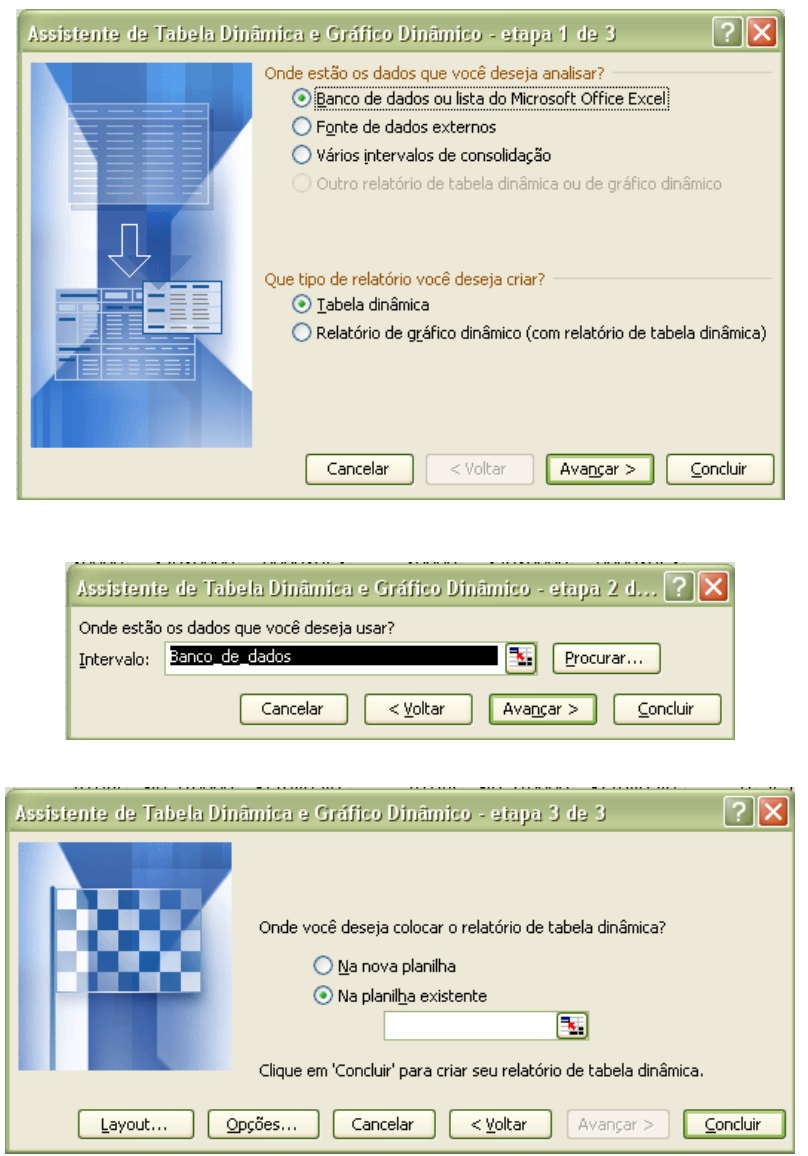

Figura A.9 - Seqüência de janelas da opção Dados

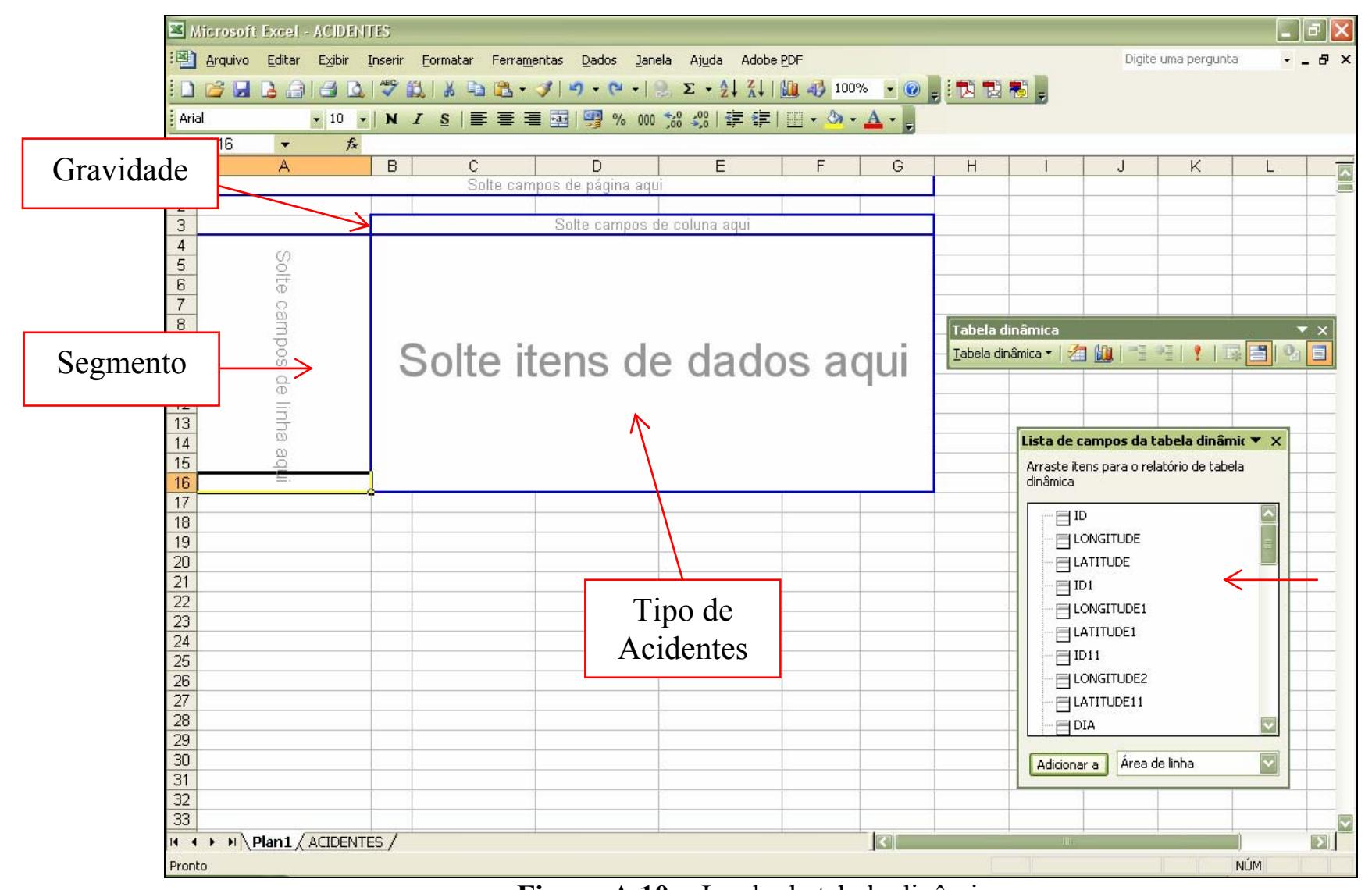

Figura A.10 - Janela da tabela dinâmica 
Aberta esta nova planilha; para o seu preenchimento deve-se clicar com o botão direito do mouse sobre o ícone escolhido na lista de campos, arrastando os selecionados para as áreas associadas dos quadros indicativos (em vermelho).

Assim, o campo de linhas da nova planilha é preenchido com a coluna dos segmentos, lembrando que esta foi preenchida com o ID dos segmentos onde houve acidentes. O campo das colunas é preenchido com a classificação dos acidentes - Gravidade - neste caso, quatro categorias: danos materiais (1), com vítimas (4), atropelamento (6) e vítimas fatais (13) e os itens de dados são preenchidos com a coluna - Tipos de acidentes. Realizado o deslocamento dos dados para a nova planilha, automaticamente gera-se uma contagem do total de acidentes ocorridos em cada segmento, conforme Figura A.11.

Em seguida selecionam-se somente os dados, excluindo as somas finais e o cabeçalho, conforme as indicações na Figura A.12, copiando-os e colando-os em uma nova planilha (Figura A.13). Além disso, a primeira coluna deve ser renomeada para ID. 


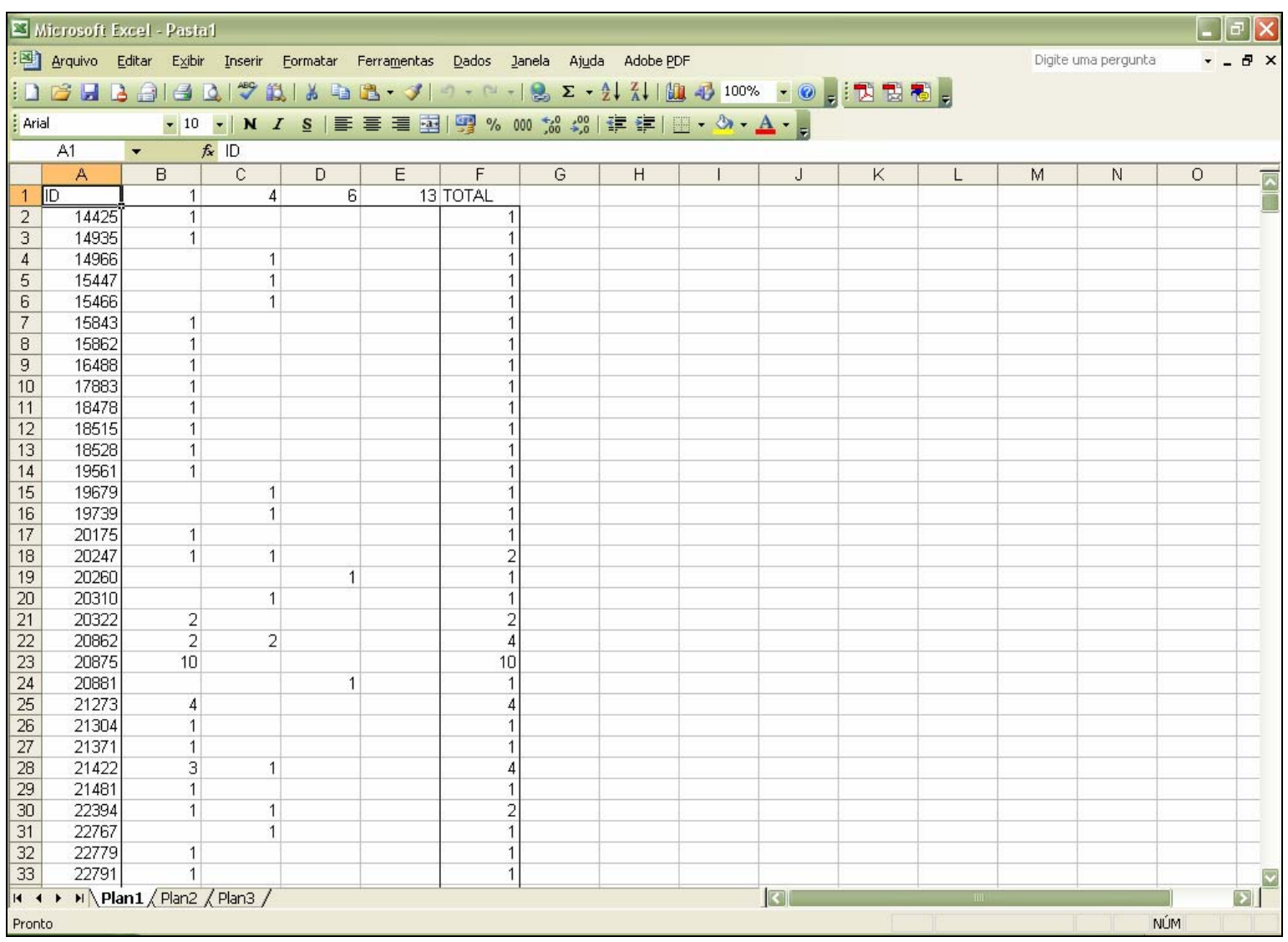

Figura A.13 - Nova planilha com dados extraídos da Tabela dinâmica

A nova planilha é nomeada e salva. Entretanto, para este procedimento antes devem ser selecionados todos os dados, como já realizado anteriormente (Figura A.14). Para salvá-los, seleciona-se em Salvar como tipo a opção DBF 4 (dBASE IV), nomear e salvar Figura A.15. Aparece uma nova janela questionando a incompatibilidade deste tipo de arquivo com os recursos do Excel, o que pode ser desconsiderado, selecionando-se a opção Sim - Figura A.16. A fase no Excel encerra-se com o salvamento da planilha. 


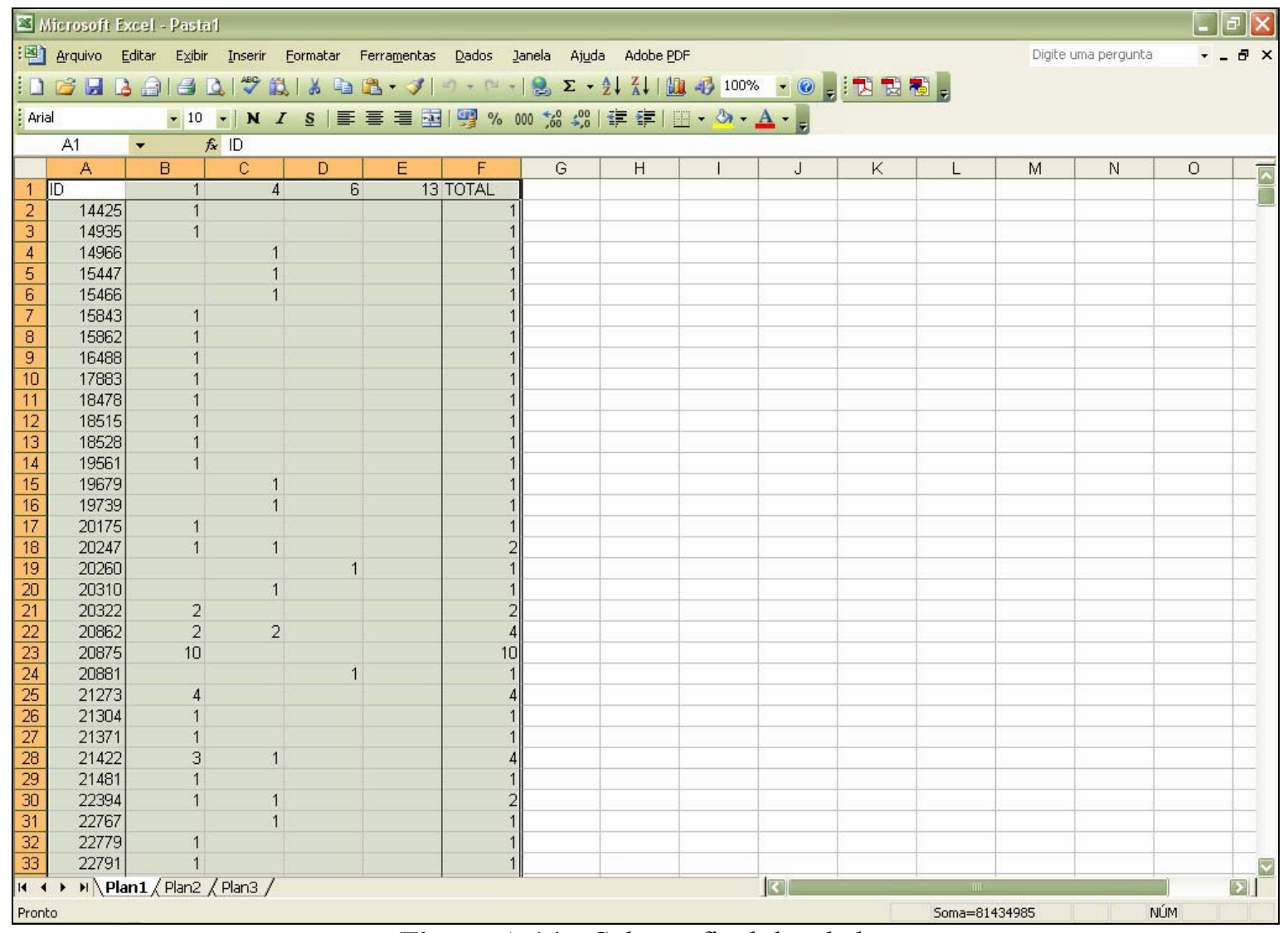

Figura A.14 - Seleção final dos dados

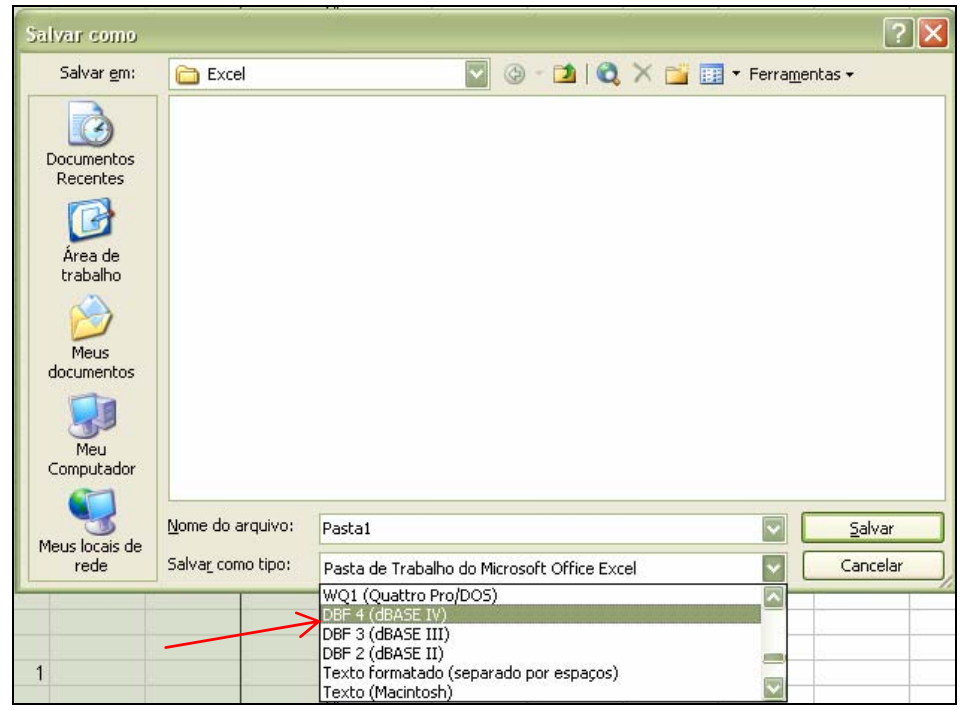

Figura A.15 - Opção para salvamento

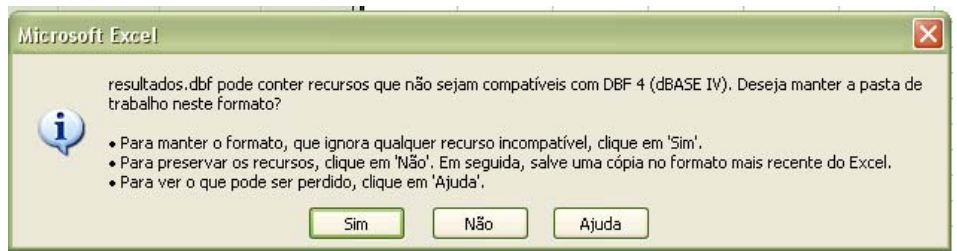

Figura A.16 - Janela de advertência do Excel 


\section{A.3 Preparação dos Dados no Transcad e criação da Matriz de Adjacência}

De volta ao Transcad, abre-se o arquivo gerado no Excel através da barra de ferramentas File $>$ Open $>$ Arquivos do tipo $>$ Dbase file - Figura A.17. Abre-se um Dataview conforme a Figura A.18. Este Dataview estará preenchido com os resultados do refinamento dos dados no Excel, ou seja, estarão somente os IDs dos segmentos com algum acidente e também divididos nos quatro tipos de acidentes.

Entretanto, percebe-se que muitas células não são preenchidas, sendo necessário que as mesmas sejam preenchidas, pois o programa não executa as operações de forma correta ignorando as células sem qualquer numeral inscrito.

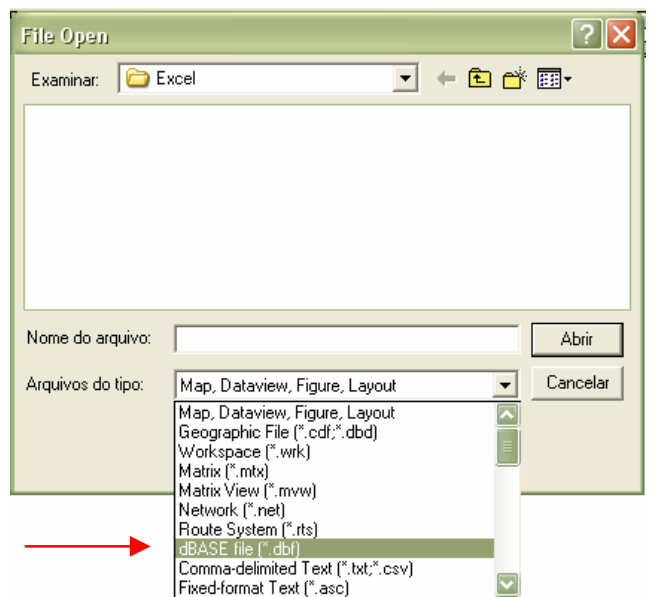

Figura A.17 - Opção de arquivos 


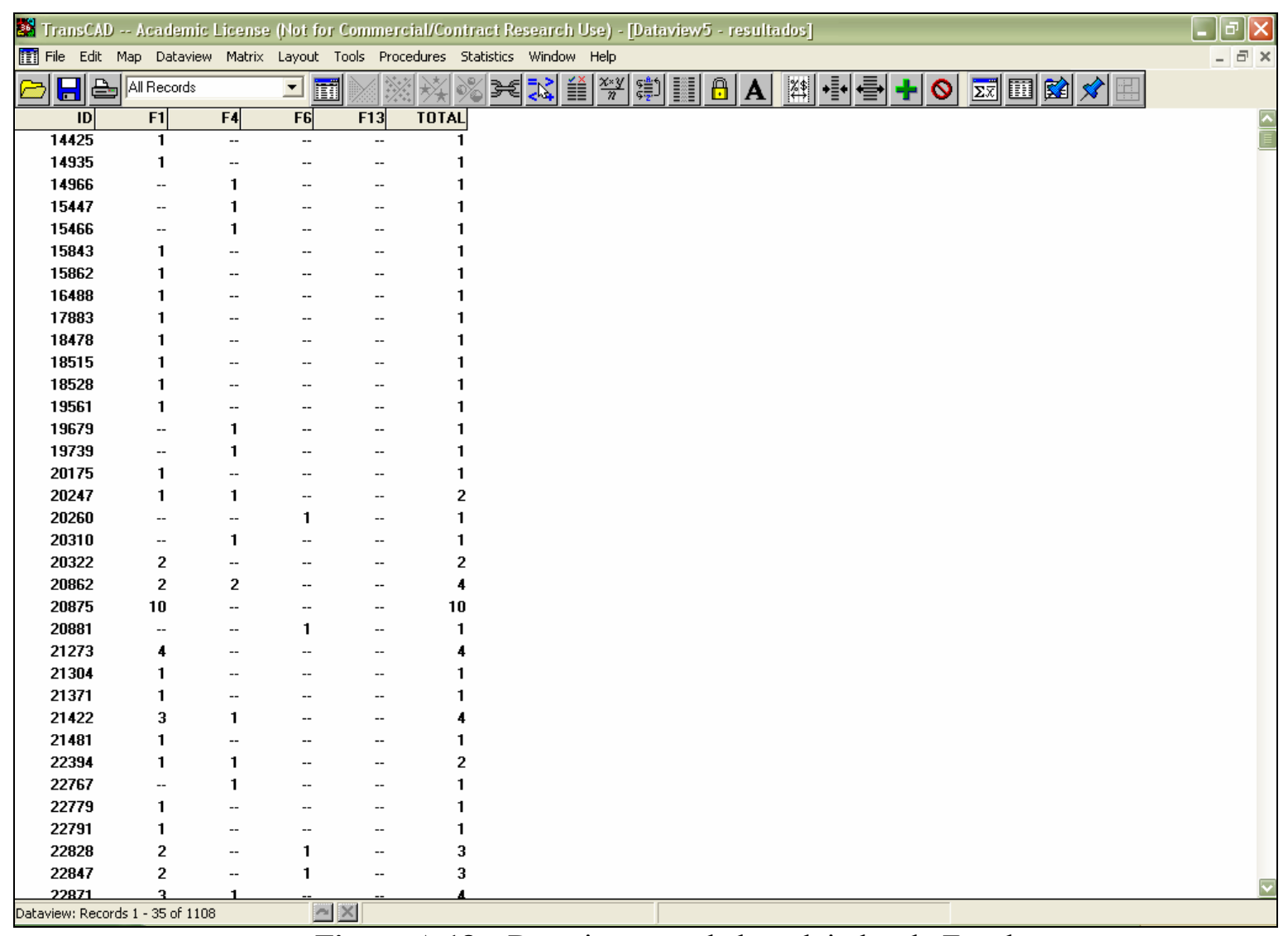

Figura A.18 - Dataview com dados advindos do Excel

O preenchimento das células vazias pode ser feito manualmente, ou seja, célula por célula. Quando se tem um Dataview com poucos dados o trabalho não é muito, contudo, na maioria das vezes a quantidade de dados inviabiliza um trabalho manual, por isso, é necessário recorrer a alguns artifícios de modo a facilitar e acelerar o preenchimento dos dados. Neste caso, a grande quantidade de células vazias numa coluna é multiplicada por quatro, já que os tipos de acidentes são divididos em quatro categorias.

Há uma ferramenta no Transcad - Sort Dataview (indicado na Figura A.20) muito útil, já que ordena os dados da coluna selecionada, facilitando a visualização dos resultados e identificando as células vazias.

Para o preenchimento das células vazias é necessário o acréscimo de uma nova coluna, procedimento já descrito em etapas anteriores.

Preenche-se a nova coluna selecionando na barra de ferramentas: Edit $>$ Fill $>$ Formula (Figura A.19), no campo Formula Builder há três campos com opções - Field List, 
Operator List e Function List; no campo Field List seleciona-se a coluna F1, a opção OK e a coluna Cópia automaticamente será preenchida com os mesmos valores da coluna $F 1$.

Seleciona-se a coluna Cópia, clicando sobre o nome e em seguida no ícone Sort Dataview a coluna será ordenada, sendo que as células vazias ficarão no topo da coluna e os valores maiores no final.

A coluna F1 estará então na mesma ordem que a coluna Cópia. O mouse pode ser usado para selecionar somente as células vazias (Figura A.20). Na barra de ferramenta, selecione Edit $>$ Fill $>$ Single Value e na lacuna digite o valor zero (Figura A.21), seguido de $O K$. A coluna é totalmente preenchida. Repita a operação de preenchimento com as outras três colunas.

Ao final a coluna Total pode ser preenchida da maneira descrita acima ou selecionando-se a coluna seguida de Edit $>$ Fill $>$ Clear all value in the range $>O K$. Mantendo a coluna selecionada: Edit $>$ Fill $>$ Formula $>$ (campo Field List) $F 1+F 4+F 6+$ F13 > OK (Figura A.22). Desta maneira garante-se que a coluna estará totalmente preenchida e que este é o resultado da somatória dos valores das demais colunas. 


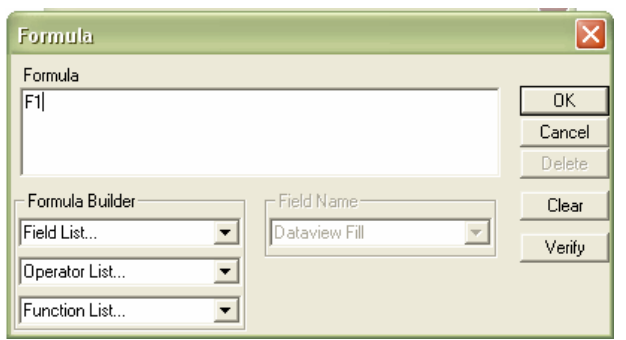

Figura A.19 - Janela Edit $>$ Fill $>$ Formula

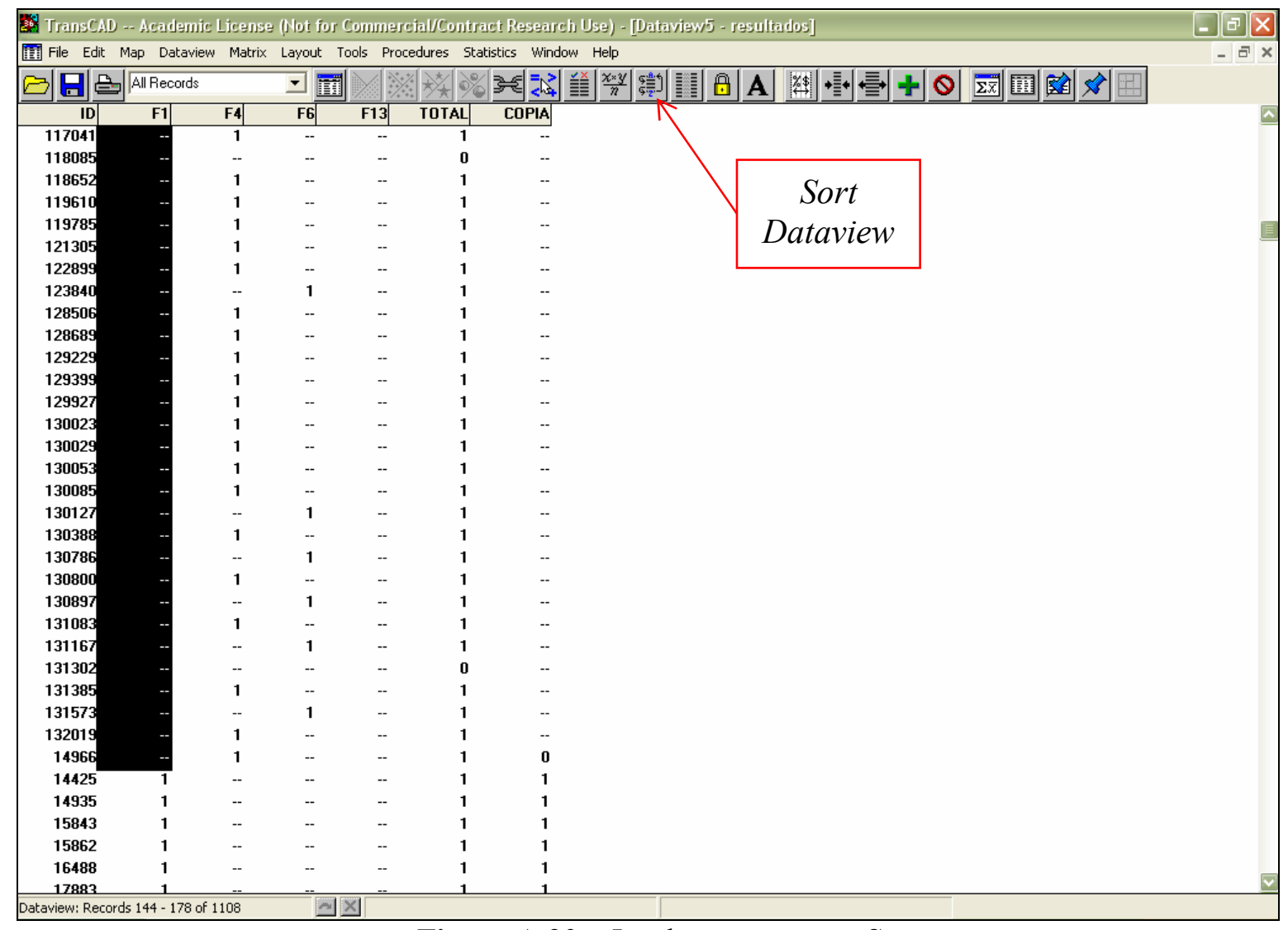

Figura A.20 - Janela com a opção Sort

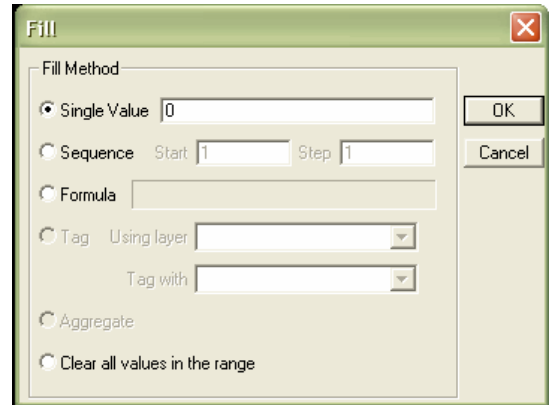

Figura A.21 - Janela Edit $>$ Fill $>$ Single Value 


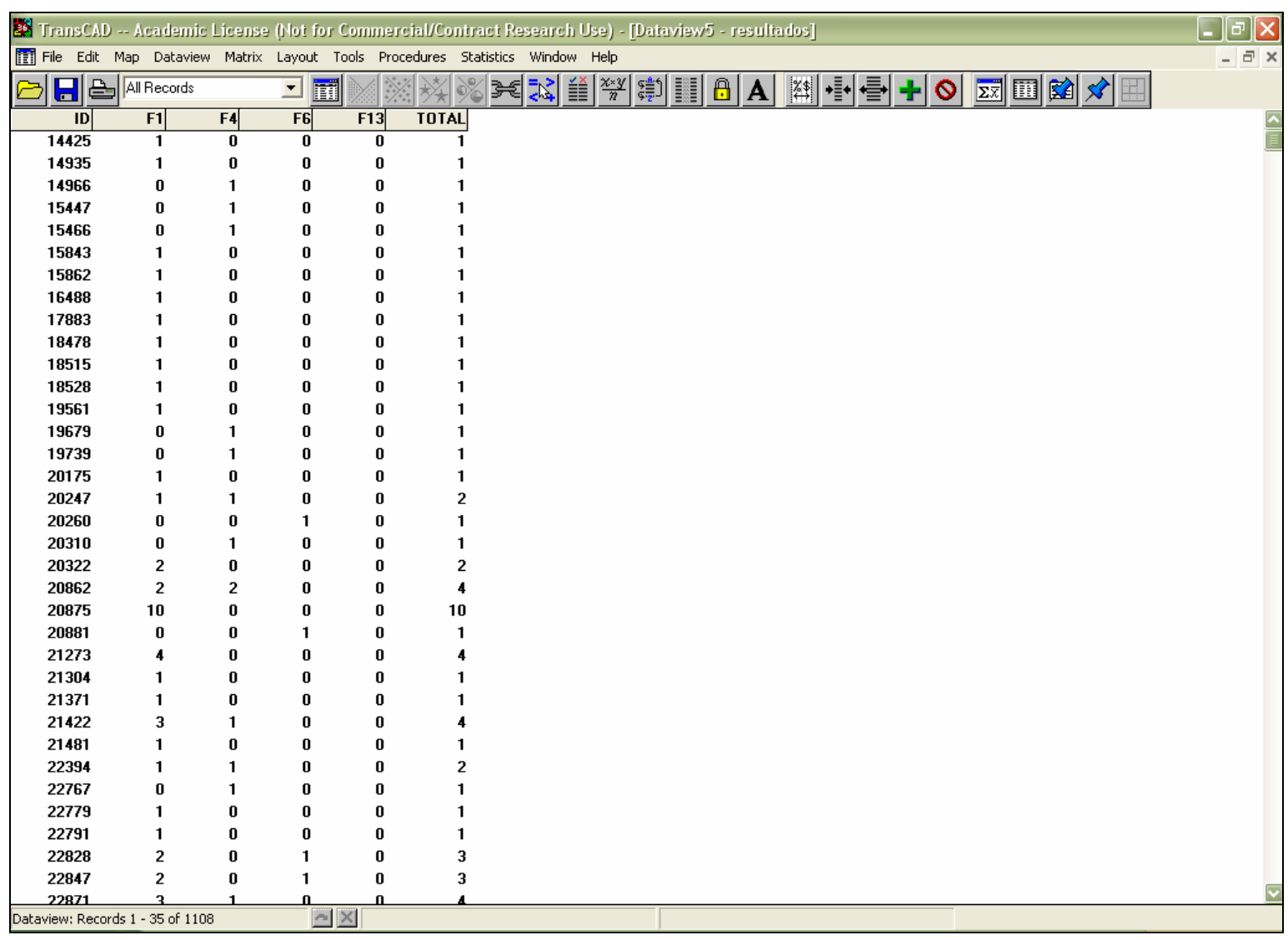

Figura A.22 - Dataview com todas as células preenchidas

Estando o Dataview dos resultados totalmente preenchido inclusive com zeros, o próximo passo é transferir os valores para o Dataview dos segmentos, para isso é necessário que uma nova coluna tenha sido criada (Figura A.23). Antes, porém é necessário utilizar a ferramenta Join, para assim criar os dados do preenchimento.

O Join, como o nome diz, une Dataviews a partir de algum elemento em comum, neste caso, o ID. Para executar um Join é necessário que os Dataviews envolvidos estejam ativados.

Com o Dataview de segmentos ativo na tela deve-se ir à barra de ferramentas Dataview $>$ Join... aparecendo uma nova janela - Figura A.24. Na janela há duas abas, mas o preenchimento é da aba Settings. Para o Join devem-se indicar quais os Dataviews e quais campos serão unidos, conforme indicado na Figura A.24. 
Percebe-se que no campo Create Joined View em Name, surge automaticamente um nome, que nada mais é que a junção dos dois Dataviews. Este recurso é um meio de conferir se a união está correta.

Feitas as opções em Table e Field, o comando $O K$ faz surgir um novo Dataview (Figura A.25), composto com as colunas dos dois Dataviews, inclusive as fixas (fundo verde).

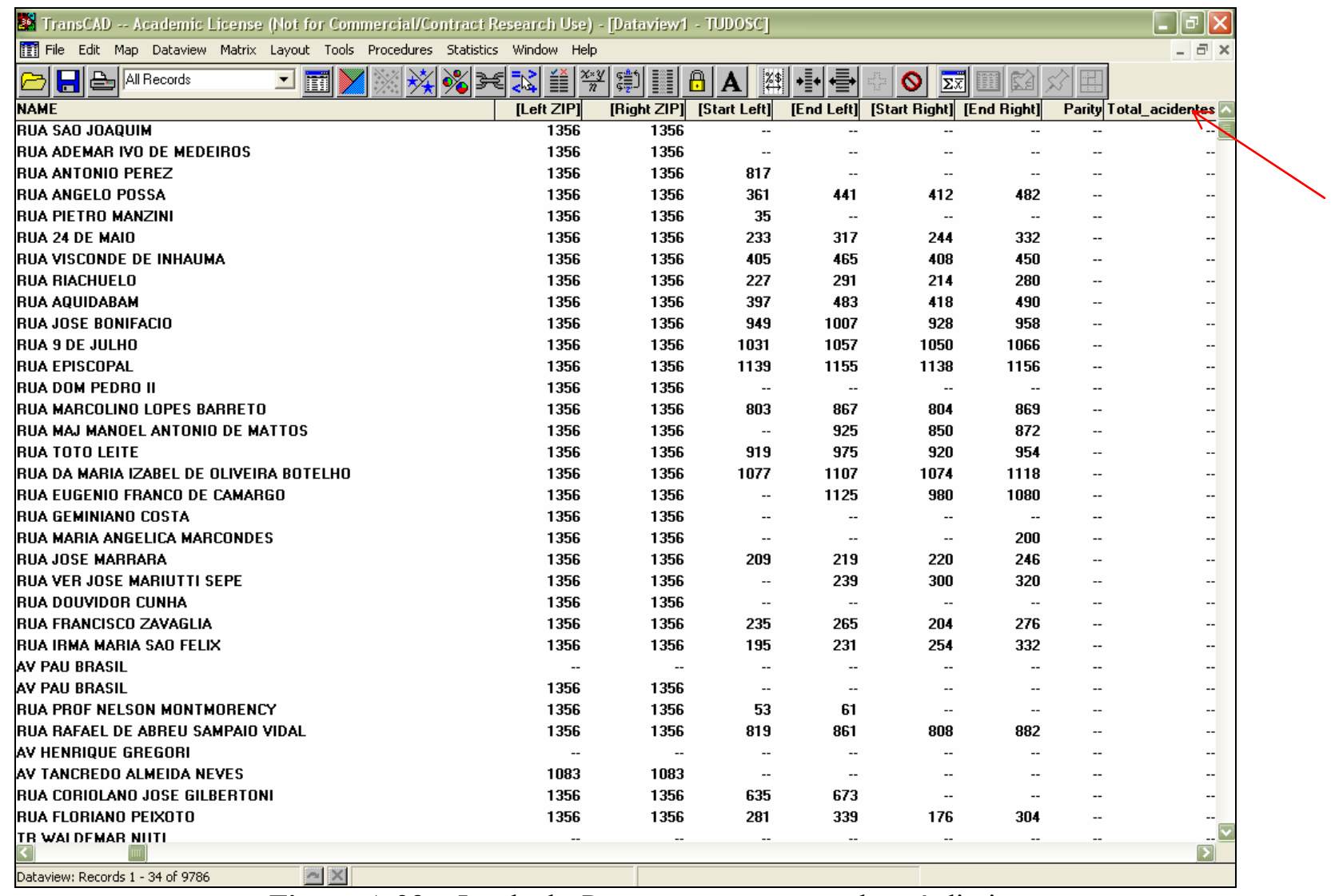

Figura A.23 - Janela do Dataview com nova coluna à direita

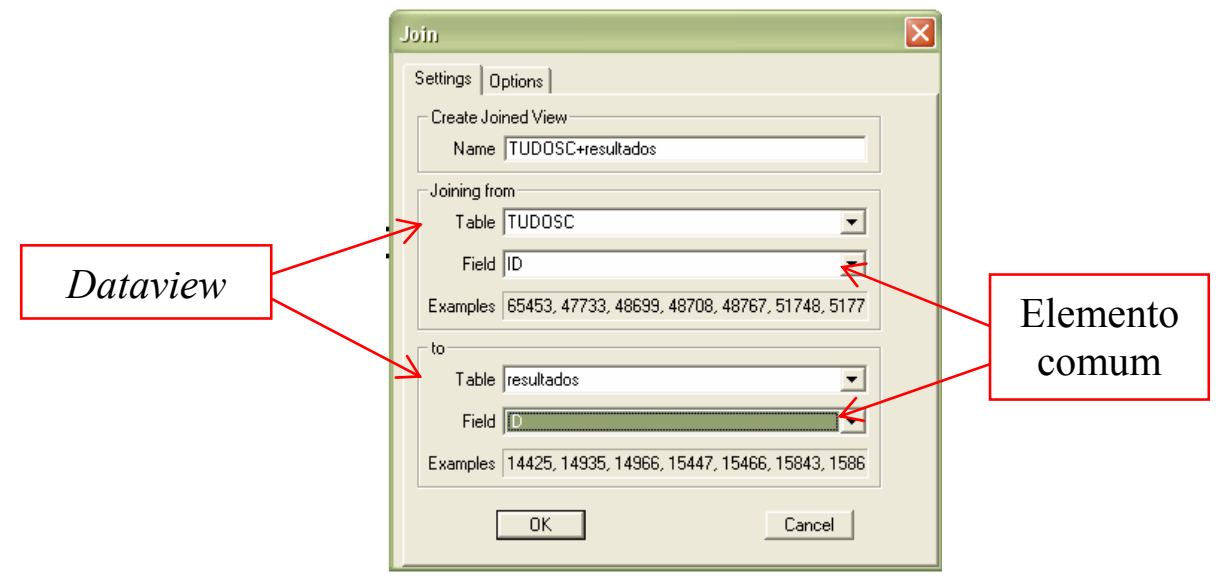


Figura A.24 - Janela da opção Joined View

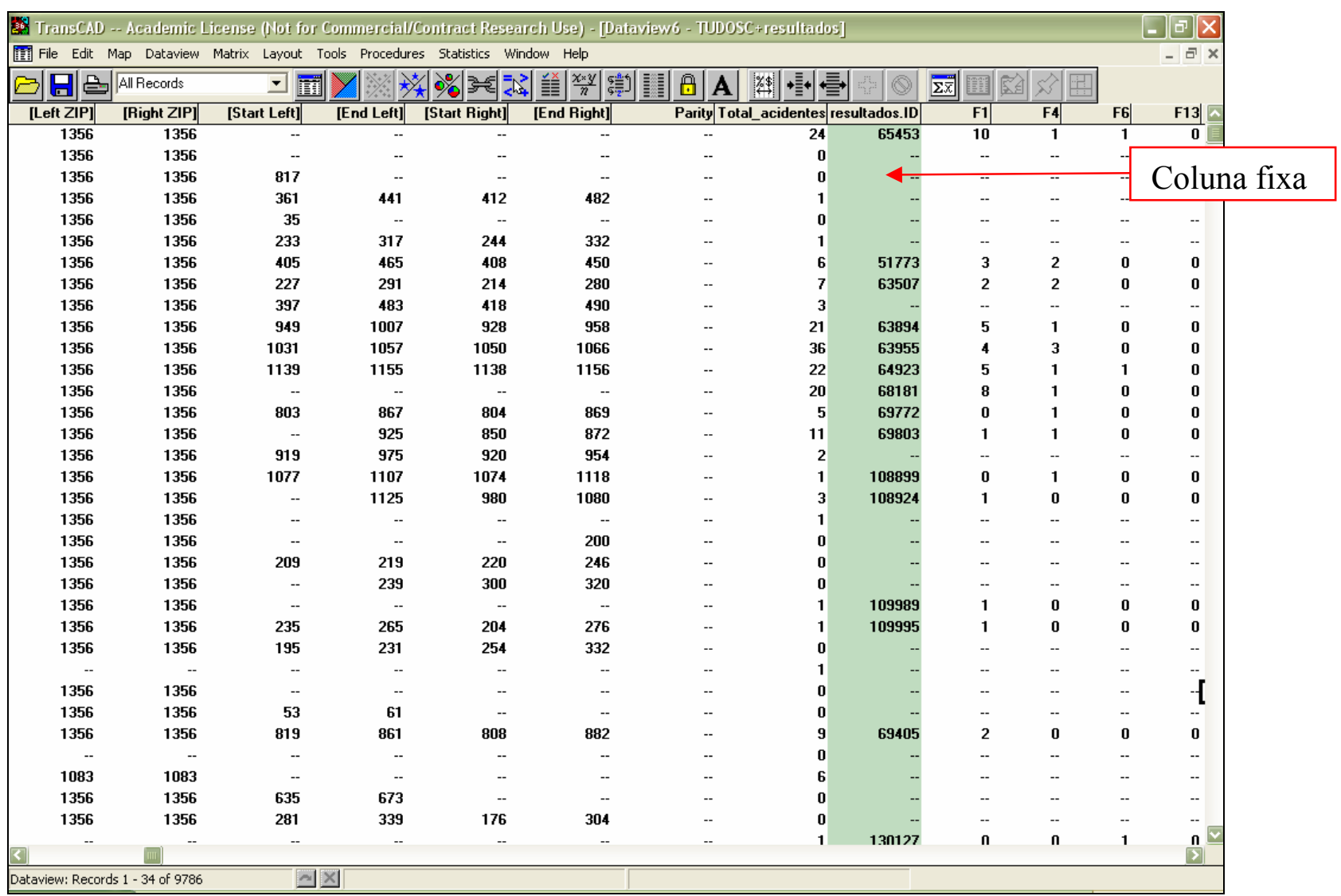

Figura A.25 - Janela do Dataview com Join

Na Figura A.25 percebe-se que algumas linhas advindas do Dataview dos resultados estão vazias, justamente aquelas que não existiam na base de dados Resultados, ou seja, são os segmentos onde não houve acidentes.

O próximo passo é transferir os dados de um Dataview para outro, lembrando que apesar de estarem juntos fazem parte de banco de dados diferentes e a partir do momento em que se desfizer a junção voltam a ter os dados originais.

Seleciona-se a coluna que receberá os novos dados - Figura A.26 - com a opção: Edit $>$ Fill $>$ Formula, a lacuna da fórmula é preenchida com os valores da coluna do Dataview de resultados. As opções de preenchimento estão em Formula Builder > Field List.

Terminada a cópia dos dados, desfaz-se o join, com a opção: Dataview > Drop Join... . Na nova janela que surge a Figura A.27 - clique sobre o nome do Dataview criado, seguido de Drop, e os Dataviews se separam. 
Todo este procedimento levou a transferência dos dados de acidentes dos pontos para os segmentos, neste caso, para um único ano (2001). Como a análise se estenderá para os anos de 2002 e 2003, todo procedimento deve ser repetido outras duas vezes para os anos citados, totalizando 12 colunas de dados (fora os totais).

\begin{tabular}{|c|c|c|c|c|c|c|c|c|}
\hline 3ed TransCAD - Academic License (Not for Comn & reial/Contract P & search Use & 9)-[Datavien & (6-TUDOSC & +resultados] & & & $\square(a x$ \\
\hline 击 File Edit Map Dataview Matrix Layout Tools & ocedures Statistic & Window $\mathrm{He}$ & & & & & & $-a x$ \\
\hline E⿹ & 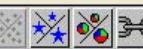 & 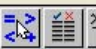 & 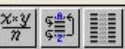 & (A) & 尔 & (9) & 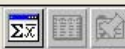 & Sर|⿴囗十 \\
\hline NAME & & [Left ZIP] & [Right ZIP] & [Start Left] & [End Left] [ & [Start Right] & [End Right] & Parity_Total_acidentes \\
\hline RUA SA0 JOAQUIM & & 1356 & 1356 & -- & -- & - & -- & \\
\hline RUA ADEMAR IVO DE MEDEIROS & & 1356 & 1356 & -. & -- & -- & -- & .. \\
\hline RUA ANTONIO PEREZ & & 1356 & 1356 & 817 & -- & -- & -- & .. \\
\hline RUA ANGELO POSSA & & 1356 & 1356 & 361 & 441 & 412 & 482 & $\ldots$ \\
\hline RUA PIETRO MANZINI & & 1356 & 1356 & 35 & -- & -- & -- & - \\
\hline RUA 24 DE MAIO & & 1356 & 1356 & 233 & 317 & 244 & 332 & -. \\
\hline RUA VISCONDE DE INHAUMA & & 1356 & 1356 & 405 & 465 & 408 & 450 & .. \\
\hline BUA RIACHUELO & & 1356 & 1356 & 227 & 291 & 214 & 280 & -- \\
\hline RUA AQUIDABAM & Fitl & & & & $x^{\prime}$ & 418 & 490 & 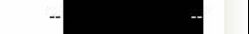 \\
\hline RUA JOSE BONIFACIO & & & & & & 928 & 958 & -. \\
\hline RUA 9 DE JULHO & Formula & & & & $x$ & 1050 & 1066 & .. \\
\hline RUA EPISCOPAL & Formula & & & & & 1138 & 1156 & -- \\
\hline RUA DOM PEDRO II & & & & & OK & -- & - & 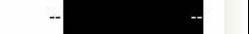 \\
\hline RUA MARCOLINO LOPES BARRETO & & & & & Cancel & 804 & 869 & -- \\
\hline RUA MAJ MANOEL ANTONIO DE MATTOS & & & & & Delete & 850 & 872 & \\
\hline RUA TOTO LEITE & & & & & Delere & 920 & 954 & .. \\
\hline RUA DA MARIA IZABEL DE OLIVEIRA BOTELHO & Formula Builder - & & Field Name- & & Clear & 1074 & 1118 & $\ldots$ \\
\hline RUA EUGENIO FRANCO DE CAMARGO & Field List... & - & Dataview Fill & 7 & Verify & 980 & 1080 & - \\
\hline RUA GEMINIANO COSTA & Operator List... & \pm & & & & - & 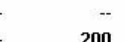 & - \\
\hline $\begin{array}{l}\text { RUA MARIA ANGELICA MARCONDES } \\
\text { RUA JOSE MARRARA }\end{array}$ & Function List... & $=$ & & & & 220 & $\begin{array}{l}200 \\
246\end{array}$ & -- \\
\hline RUA VER JOSE MARIUTTI SEPE & & & & & T & 300 & 320 & 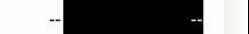 \\
\hline RUA DOUVIDOR CUNHA & & & & & & -. & -. & $\ldots$ \\
\hline RUA FRANCISCO ZAVAGLIA & & 1356 & 1356 & 235 & 265 & 204 & 276 & -- \\
\hline RUA IRMA MARIA SAO FELIX & & 1356 & 1356 & 195 & 231 & 254 & 332 & - \\
\hline AV PAU BRASIL & & -- & -- & - & - & -- & -- & - \\
\hline AV PAU BRASIL & & 1356 & 1356 & -- & -- & - & -- & - \\
\hline RUA PROF NELSON MONTMORENCY & & 1356 & 1356 & 53 & 61 & -- & -- & -. \\
\hline RUA RAFAEL DE ABREU SAMPAIO VIDAL & & 1356 & 1356 & 819 & 861 & 808 & 882 & .. \\
\hline AV HENRIQUE GREGORI & & -- & -- & -- & -- & -- & -- & -. \\
\hline AV TANCREDO ALMEIDA NEVES & & 1083 & 1083 & -- & -- & - & -- & -. \\
\hline RUA CORIOLANO JOSE GILBERTONI & & 1356 & 1356 & 635 & 673 & -- & - & -. \\
\hline RUA FLORIANO PEIXOTO & & 1356 & 1356 & 281 & 339 & 176 & 304 & 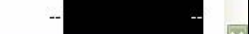 \\
\hline TR WAI DFMAR NIITI & & -. & & .. & .- & -- & .- & (7) \\
\hline Dataview: Records 1 - 34 of 9786 & & & & & & & & \\
\hline
\end{tabular}

Figura A.26 - Edit $>$ Fill $>$ Formula

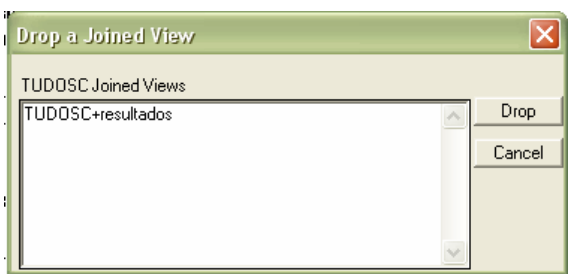

Figura A.27 - Janela do Drop Join

A Figura A.28 mostra o Dataview de segmentos com todos os dados, onde a primeira coluna tem o valor Total de Acidentes nos três anos, a coluna seguinte o Total do Ano de 2001, a próxima o Total do Ano de 2002, depois Total de 2003, seguido pelo valor dos Atropelamentos em 2001, 2002 e 2003, Danos Materiais em 2001, 2002 e 2003, 
Acidentes com Vitimas em 2001, 2002 e 2003 e Acidentes Fatais em 2001, 2002 e 2003.

Nesta mesma Figura a linha em destaque está mostrando um exemplo: o valor 22 é a soma da $2^{\mathrm{a}}, 3^{\mathrm{a}}$ e $4^{\mathrm{a}}$ colunas $(7+10+5)$, o valor 7 é a soma da $5^{\mathrm{a}}+8^{\mathrm{a}}+11^{\mathrm{a}}+14^{\mathrm{a}}$ colunas $(1+5+1+$ $0)$, o valor 10 é a soma da $6^{\mathrm{a}}+9^{\mathrm{a}}+12^{\mathrm{a}}+15^{\mathrm{a}}$ colunas $(1+9+0+0)$, o valor 5 é a soma da $7^{\mathrm{a}}$ $+10^{\mathrm{a}}+13^{\mathrm{a}}+16^{\mathrm{a}}$ colunas $(1+3+1+0)$.

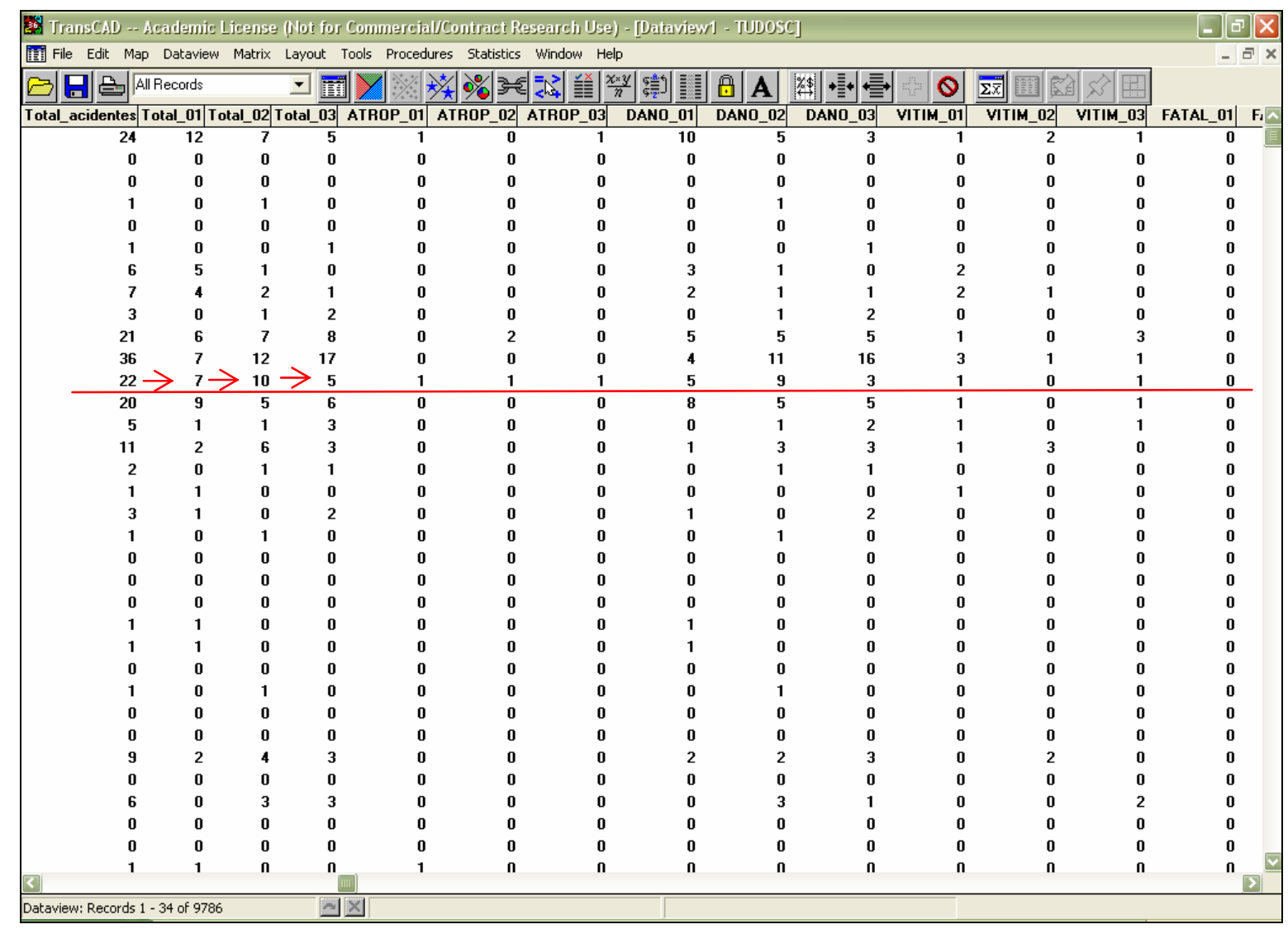

Figura A.28 - Dados dos acidentes

\section{A.4 Índice de Moran - via Transcad}

Com o Dataview de segmentos totalmente preenchido, o próximo passo é o cálculo do Índice de Moran. Este índice indica se um segmento está conectado a outro e quanto esta conexão interage e interfere um no outro.

Lembrando a fórmula: 


$$
I=\frac{Z^{t} \times W_{Z}}{Z^{t} \times Z}
$$

Em que: $\quad Z$ : atributo - média;

$$
\begin{aligned}
& \mathrm{Z}^{\mathrm{t}} \text { : } \mathrm{Z} \text { transposto; } \\
& \mathrm{W}_{\mathrm{Z}} \text { : matriz } \mathrm{W} \times \mathrm{Z} .
\end{aligned}
$$

A matriz de adjacência consiste em creditar valores à proximidade entre segmentos. Por exemplo, consideram-se a rede da Figura A.29 formada por segmentos de $1 \mathrm{a}$ 10 e cada segmento com um índice atribuído (valor); o segmento $\mathrm{i}=1$ é vizinho do segmento $j=2$, mas não-vizinho dos segmentos $j=3, j=4, j=5, j=6, j=7, j=8, j=9$ e $j=10$; o segmento $i=2$ é vizinho do $j=1$ e do $j=3$ e não-vizinho do $j=4, j=5, j=6, j=7, j=8 j=9$ e $j=10$, e assim por diante.

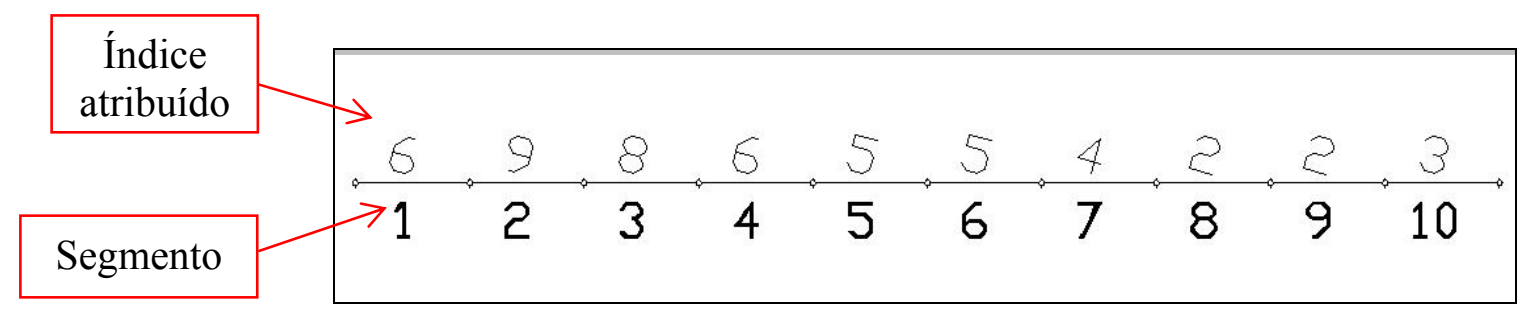

Figura A.29 - Exemplificação de Rede

Neste caso, a matriz de adjacências é uma matriz 10x10 e os valores creditados são 1 para segmentos vizinhos e 0 para não-vizinhos, ou seja, na exemplificação acima, entre o índice 6 e 9 o valor é 1 enquanto que entre 6 e 8, 6 e 6,6 e 5, 6 e 5, 6 e 4, 6 e 2, 6 e 2 e 6 e 3 o valor será 0 ; entre 9 e 6, 9 e 8 , o valor é 1 , para as demais conexões é 0 .

Na rede mostrada acima o preenchimento da matriz é muito simples e rápido, contudo ao considerar uma cidade como uma rede, o procedimento da matriz de adjacências tornar-se-á impraticável seu preenchimento manualmente. Para isso, são necessários mecanismos que agilizem o processo. 
O Transcad tem ferramentas que processam matrizes de adjacências, mas somente para analises de áreas. Para análise de segmentos, são necessários alguns procedimentos adicionais.

Na janela do mapa (Figura A.30), além da camada de segmentos deve-se também ativar a de nós (Endpoints). Através do ícone ou ao menu principal: Map > Layers pode-se obter a janela da Figura A.31, onde aparecem as duas layers, a de pontos (nós) e a de linhas, sendo que a primeira está escondida (Hidden) e a segunda está à mostra. Para “mostrá-la" clique sobre o nome da layer, em seguida em Show Layer e em Close; aparecerão os Endpoints (Figura A.32). Para a construção da matriz de adjacências, esta camada deve estar ativada.

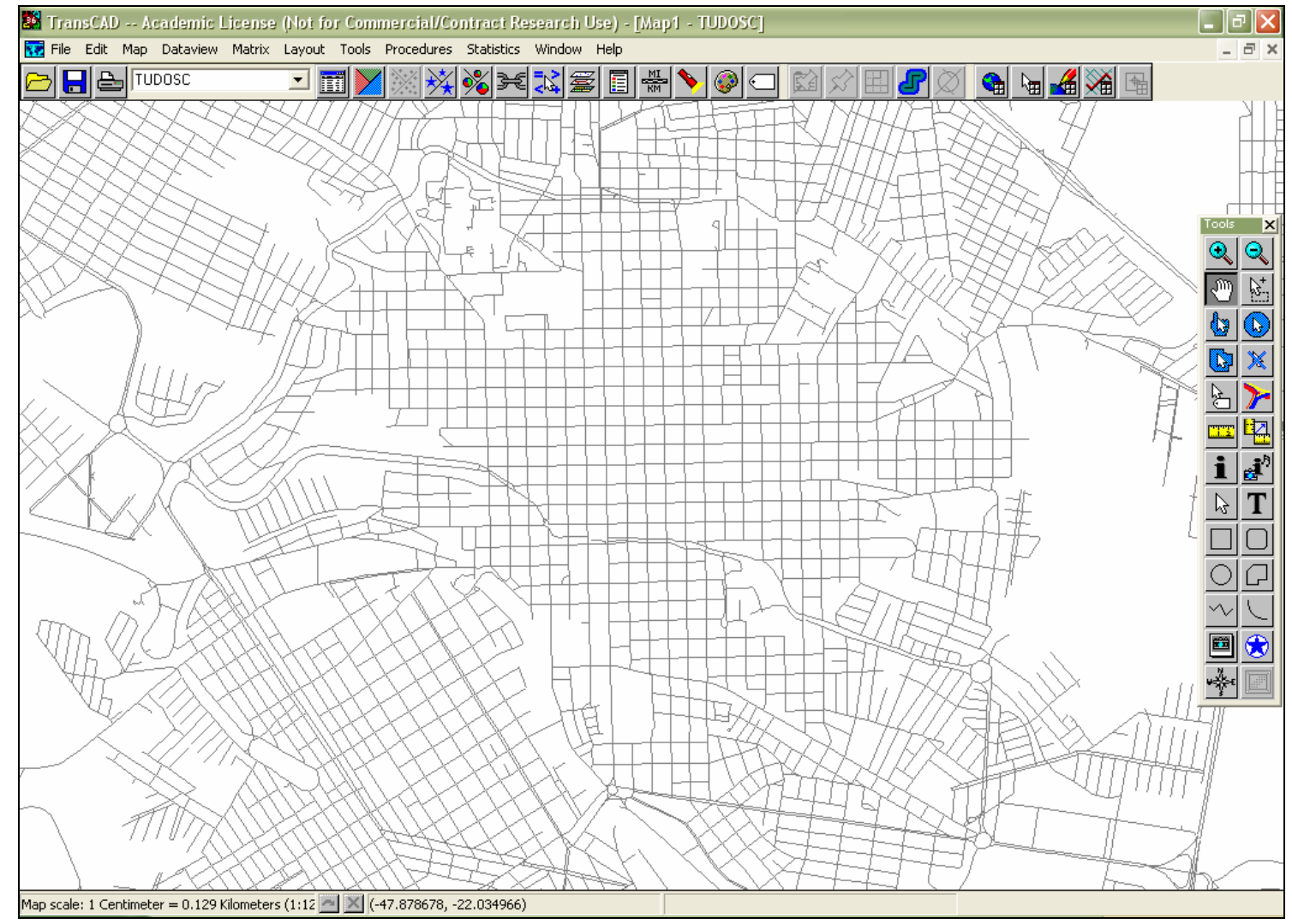

Figura A.30 - Mapa com os segmentos 


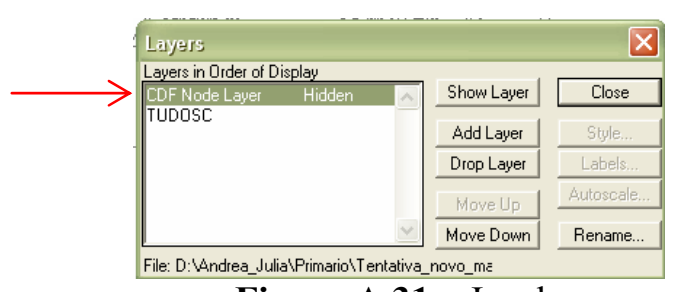

Figura A.31 - Janela

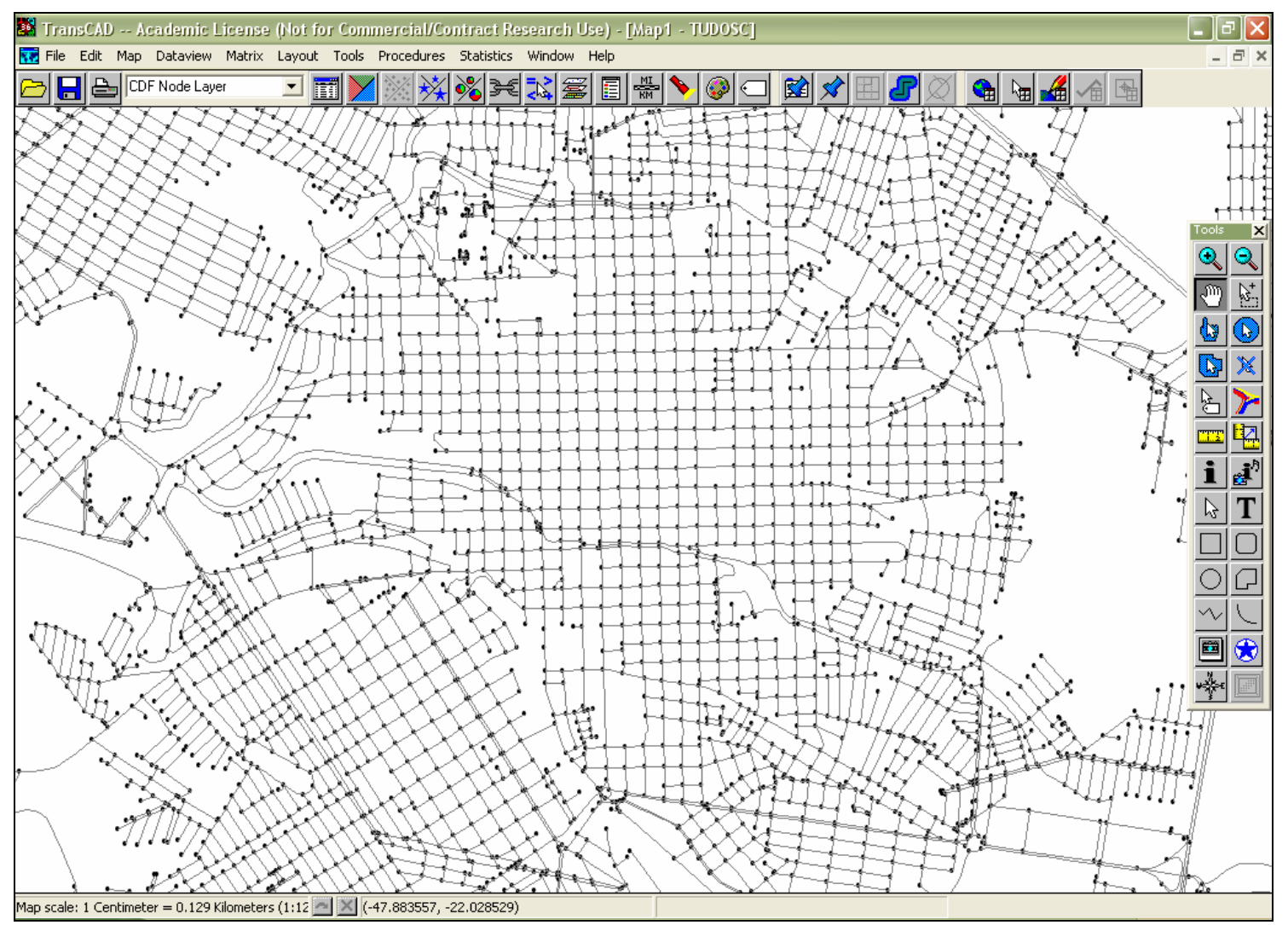

Figura A.32 - Mapa com Linhas e Pontos

A construção da matriz está vinculada à execução de um algoritmo devido ao fato de o programa não executar a função para arquivos de linhas, conforme mencionado.

Com a camada de Endpoints ativada, a opção: Tools $>$ Add Ins... abre a janela da Figura A.33. Clicando em GIS Developer's Kit seguido de $O K$, aparece nova janela (Figura A.34). O $1^{\circ}$ ícone à esquerda abre outra janela (Figura A.35), que permite escolher um arquivo no diretório para compilar, clicando $O K$.

$\mathrm{O}$ arquivo selecionado, que pode ser editado em um bloco de notas, mas que deve ter a extensão é *.rsc, e conter o algoritmo que processa a matriz de adjacência de linhas, como segue. 


\section{A.4.1 Algoritmo da Matriz de Adjacências}

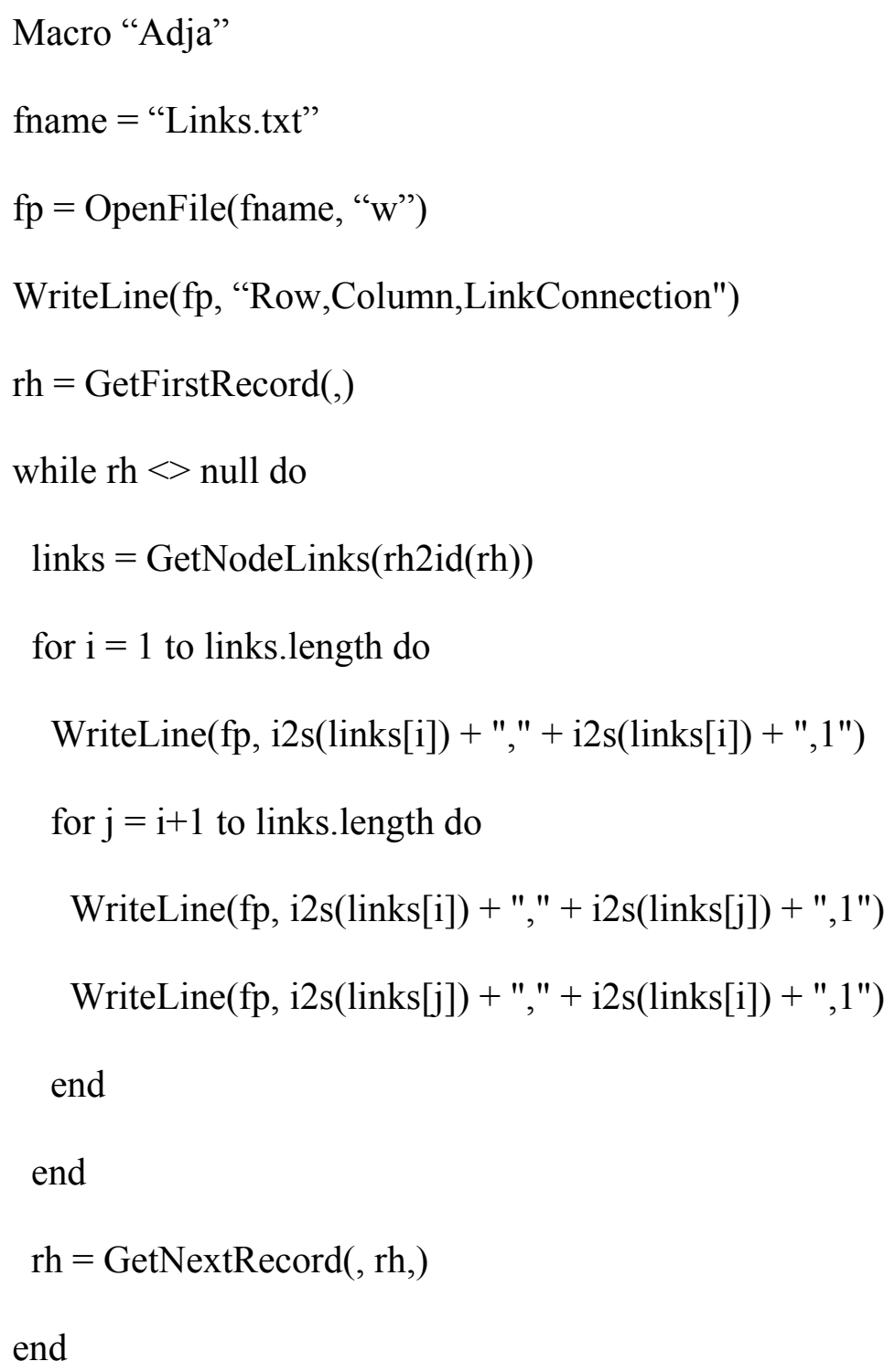

EndMacro

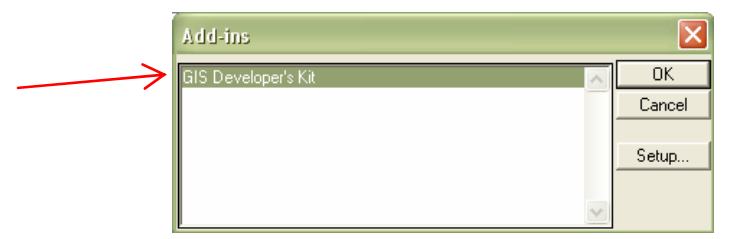

Figura A.33 - Janela Add ins...

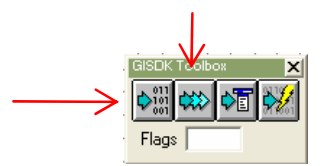

Figura A.34 - Janela GISDK 


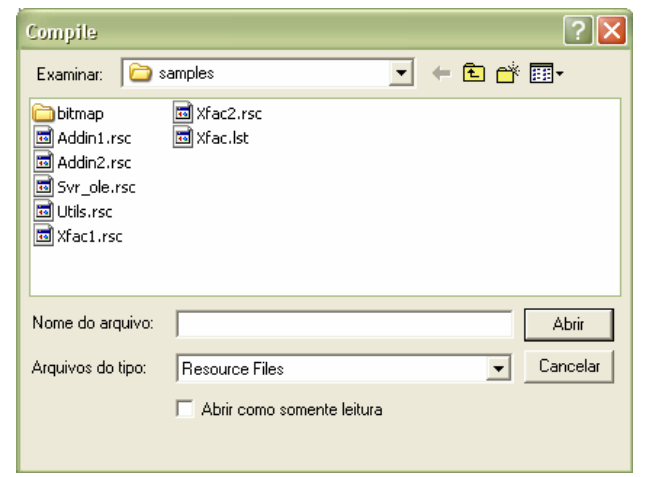

Figura A.35 - Janela Compilar

Para testar o algoritmo, basta clicar no $2^{\circ}$ ícone da janela da Figura A.34. Na nova janela (Figura A.36) seleciona-se Macro e $O K$. Abra o arquivo com o mesmo nome (que tinha a extensão *.rsc), mas agora com extensão .dbf ou .dbd.

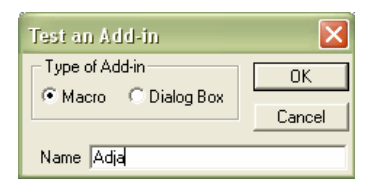

Figura A.36 - Janela Macro

Quando se processa o algoritmo, este gera um arquivo que não se abre automaticamente, é necessário procurá-lo para abrir, porque durante o processamento o computador salvará o arquivo gerado em local que ele (computador) destina.

O arquivo gerado consiste numa lista de dados em que consta a linha, a coluna com conexão direta e o valor atribuído a esta conexão, no caso igual a 1 (Row, Column, LinkConnection) (Figura A.37) sendo necessário transformar esta listagem em matriz. 


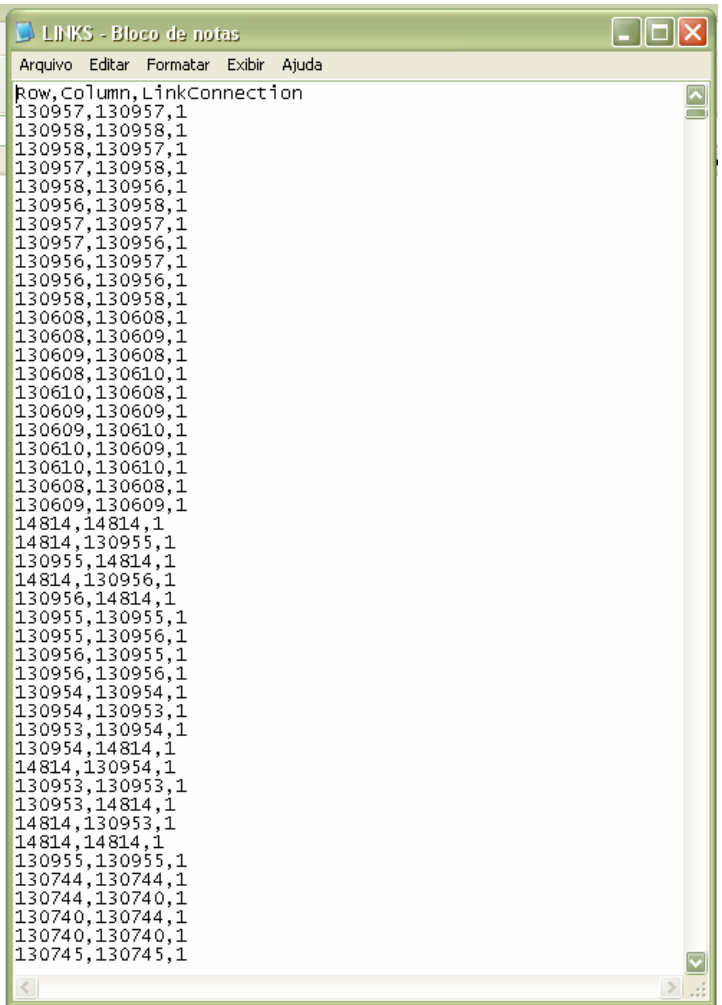

Figura A.37 - Listagem gerada pelo algoritmo

Na opção: File > New... aparece a janela da Figura A.40, selecione Matrix File, surge nova janela (Figura A.38), clique $O K$ e a matriz é criada. O próximo passo é seu preenchimento.

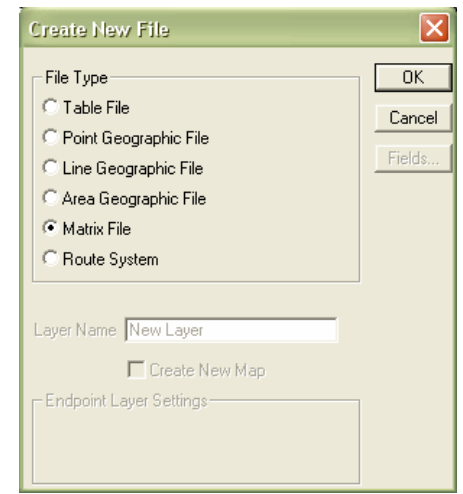

Figura A.38 - Janela de criação de Matriz 


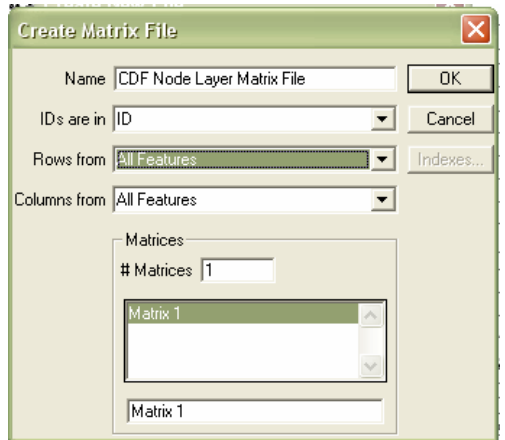

Figura A.39 - Janela de criação da Matriz

Vá à barra de ferramenta: Matrix > Import from Dataview..., o que abre a janela da Figura A.39. Lembrando que a listagem gerada anteriormente apresenta dados que são transformados em matriz, nas lacunas Row IDs e Column IDs selecione a opção ID e em Data Fields, opte por Selected e Linkconnection. Dessa maneira a matriz é composta por um valor atribuído às conexões, ou seja, onde houver relação de vizinhança a célula correspondente será preenchida com o valor 1, as demais células ficarão vazias. Em seguida deve-se criar uma nova matriz. Através do ícone 2 , que abre a janela da Figura A.40, selecione Add Matrix, seguido de $O K$ e está criada a nova matriz (Figura A.41).

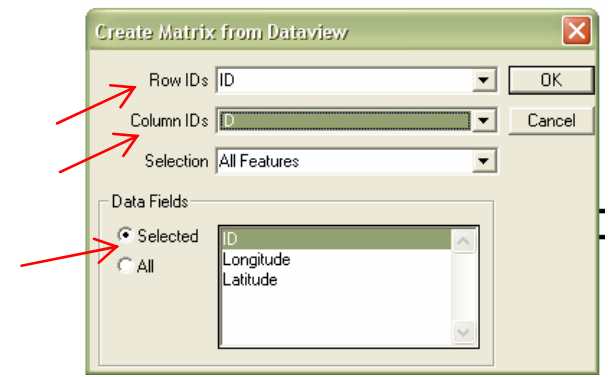

Figura A.40 - Janela de preenchimento da matriz

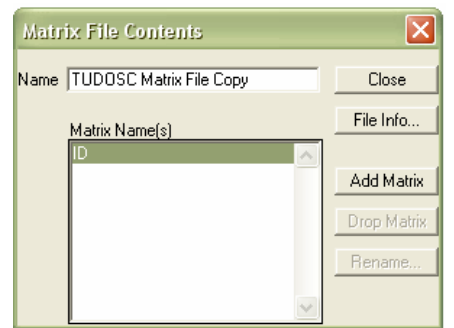

Figura A.41 - Janela de adição de matrizes 


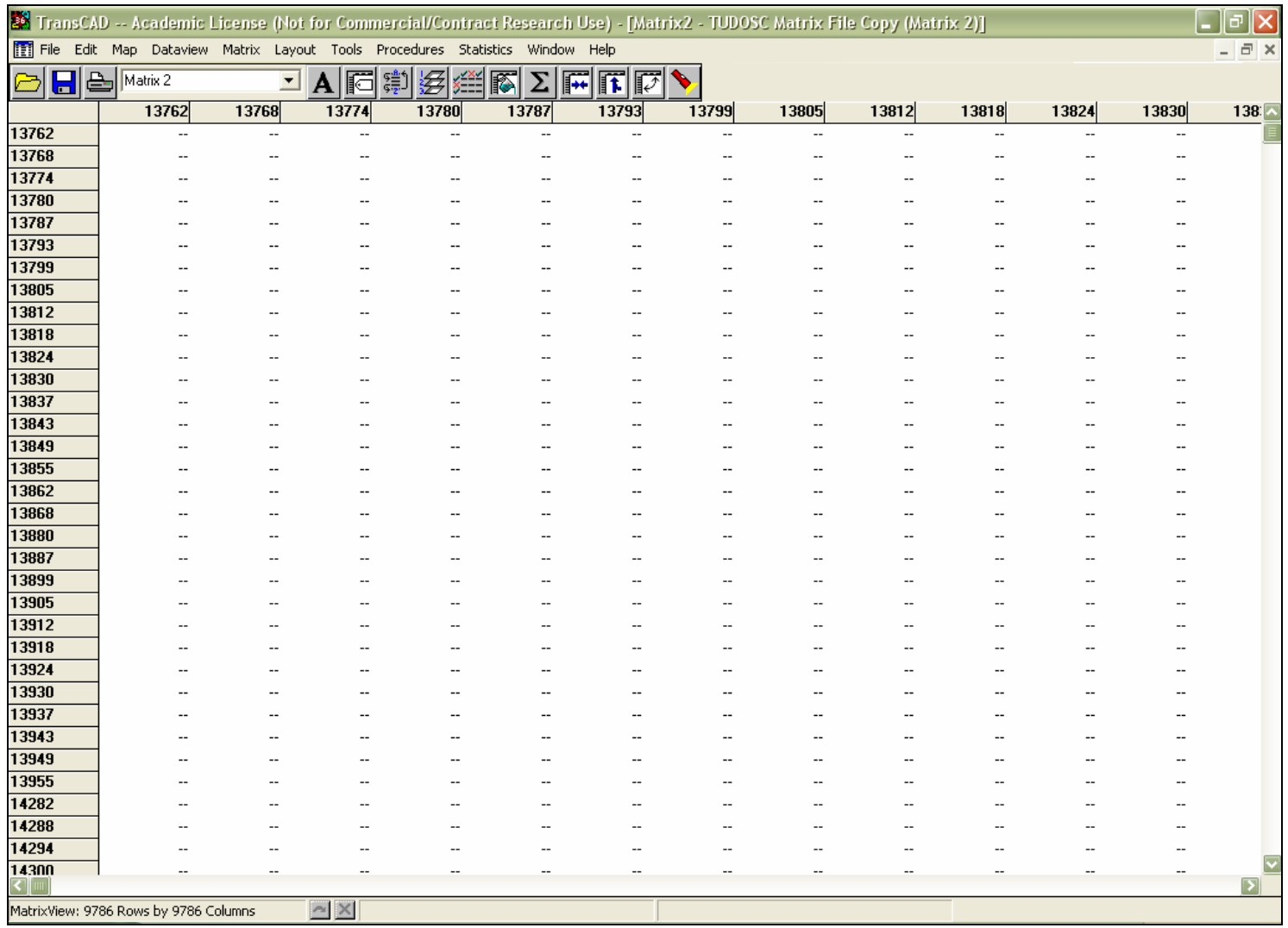

Figura A.42 - Janela da nova matriz

Esta nova matriz deve ser preenchida com valor zero, através da opção: Matrix $>$ Fill, que abre a janela da Figura A.43. Preenche-se com zero a lacuna da opção Fill With, seguido de $O K$.

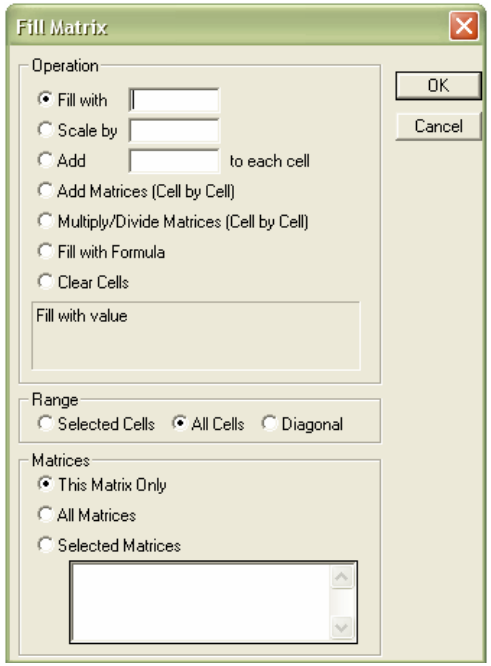

Figura A.43 - Janela de preenchimento da matriz com valor 0

Após o preenchimento da segunda matriz, utiliza-se o comando: Matrix > Quicksum para criar uma terceira matriz, preenchida com a soma das duas primeiras matrizes, 
sendo que os valores serão zero e um. É preciso criar as duas matrizes, pois o Transcad não reconhece as células que não estejam ocupadas com algum numeral e como na importação dos dados somente os valores 1 foram trazidos, torna-se necessário completar as demais células.

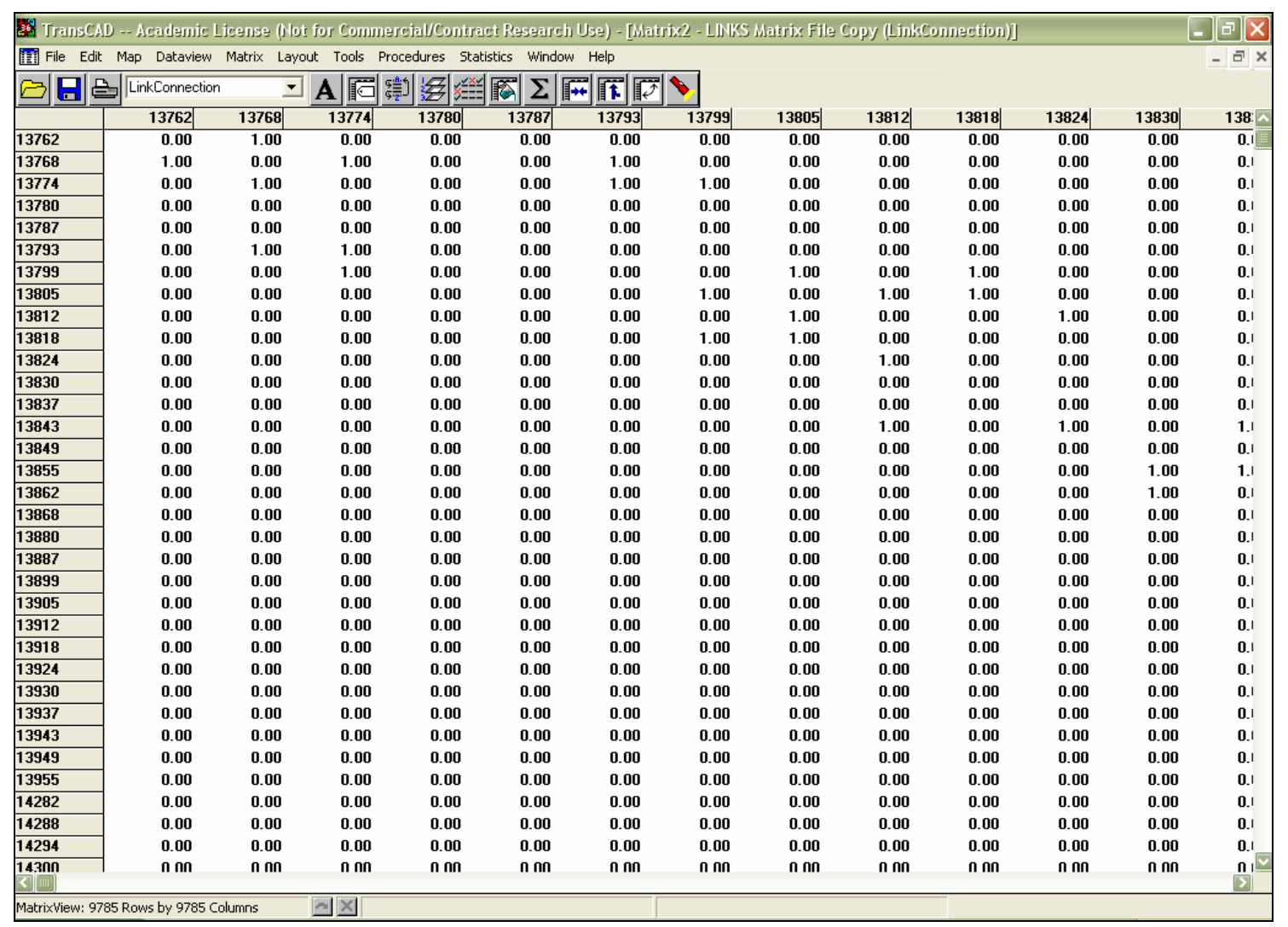

Figura A.44 - Matriz de Adjacência a partir do QuickSum

\section{A.5 Cálculo do Índice de Moran}

Com a matriz de adjacência preenchida, o próximo passo é a execução dos cálculos do Índice de Moran. Para isso é necessária a criação de outras matrizes no mesmo arquivo. No total serão cinco matrizes: Matriz de Adjacência, Soma_marginal, Normalizada, $\mathrm{Z}$ e W

Além das novas matrizes, são necessárias novas colunas no Dataview. Para cada coluna de dados (Total do ano de 2001, 2002, 2003, Atropelamentos em 2001, 2002 e 2003, Danos Materiais em 2001, 2002 e 2003, Acidentes com Vitimas em 2001, 2002 e 2003 
e Acidentes Fatais em 2001, 2002 e 2003) serão acrescidas outras três: Z, $W_{z}$ e Quadrante. Nesta etapa, é conveniente acrescentar apenas uma por vez, por isso facilita os próximos preenchimentos.

Primeiramente, são necessários alguns dados estatísticos, que podem ser obtidos com a opção: Dataview $>$ Statistics $>$ Save as, gerando um arquivo com extensão *.dbf. Embora o arquivo gerado tenha inúmeros registros estatísticos, só serão utilizadas as

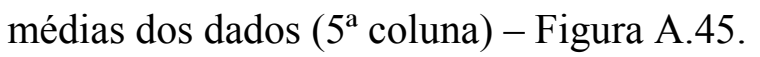

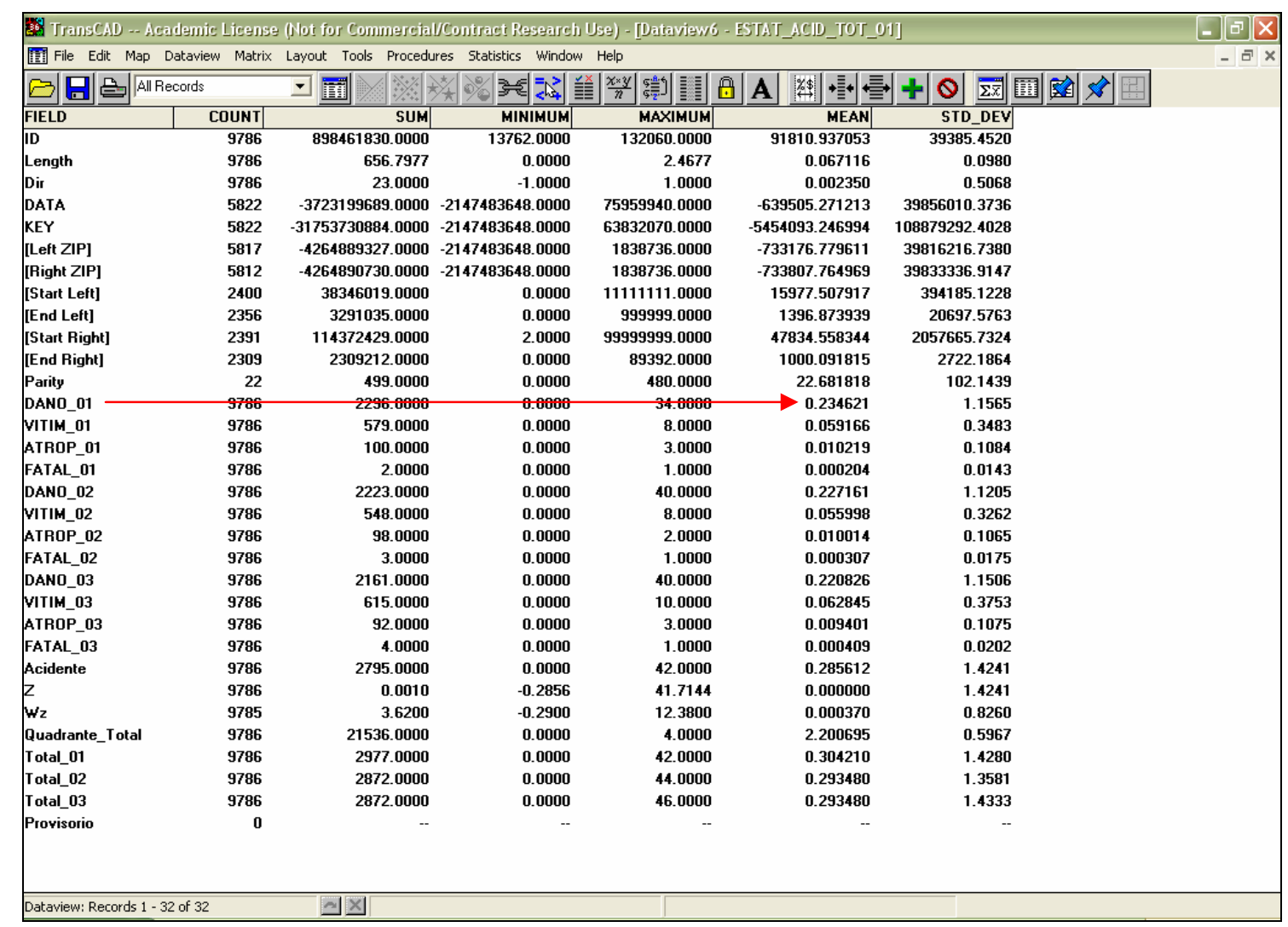

Figura A.45 - Dados estatísticos

A explicação a seguir é para uma nova coluna, mas deve-se repeti-la para as outras colunas. Selecione a nova coluna, vá a barra de ferramenta: Edit $>$ Fill $>$ Formula $>$ Dano_01 - 0,234621 (por exemplo) $>O K$. Nesse caso, a coluna será preenchida com o Z de Danos Materiais de 2001, procedimento que deve ser repetido para as demais colunas (Danos Materiais em 2002 e 2003, Atropelamentos em 2001, 2002 e 2003, Acidentes com Vitimas 
em 2001, 2002 e 2003 e Acidentes Fatais em 2001, 2002 e 2003, Total do ano de 2001, 2002 e 2003).

O arquivo de matriz deve ser composto por cinco matrizes. Continuando os preenchimentos, é necessária a soma marginal da matriz de adjacência, o que pode ser obtido com o comando: Matrix > Settings..., que abre nova janela (Figura A.46). Em Options $>$ Marginals, seleciona-se Sum, seguido de $O K$.

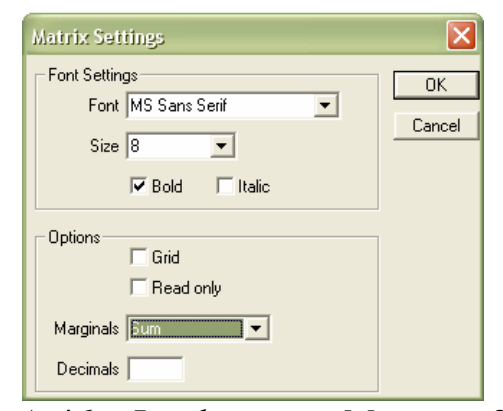

Figura A.46 - Janela opção Matrix > Settings

Ainda na matriz de adjacência opção: Matrix > Export Rows or Colums, abre a janela da Figura A.47. Seleciona-se Row Marginals, clica $O K$. Nomeie e salve.

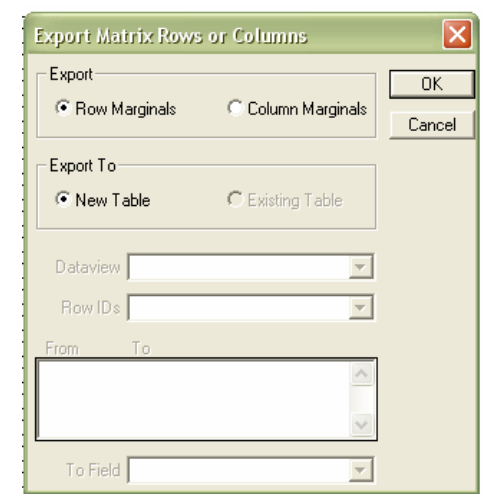

Figura A.47 - Janela opção Export rows or columns

De volta ao arquivo de matrizes, na matriz Soma_marginal, selecione uma coluna clicando no topo da mesma (Figura A.48). O comando: Matrix > Import from Dataview abre a janela da Figura A.49. Preencha as lacunas conforme as setas indicativas, lembrando de selecionar a opção All para que todas as células sejam preenchidas (Figura A.50), caso contrário somente a coluna selecionada será preenchida. 


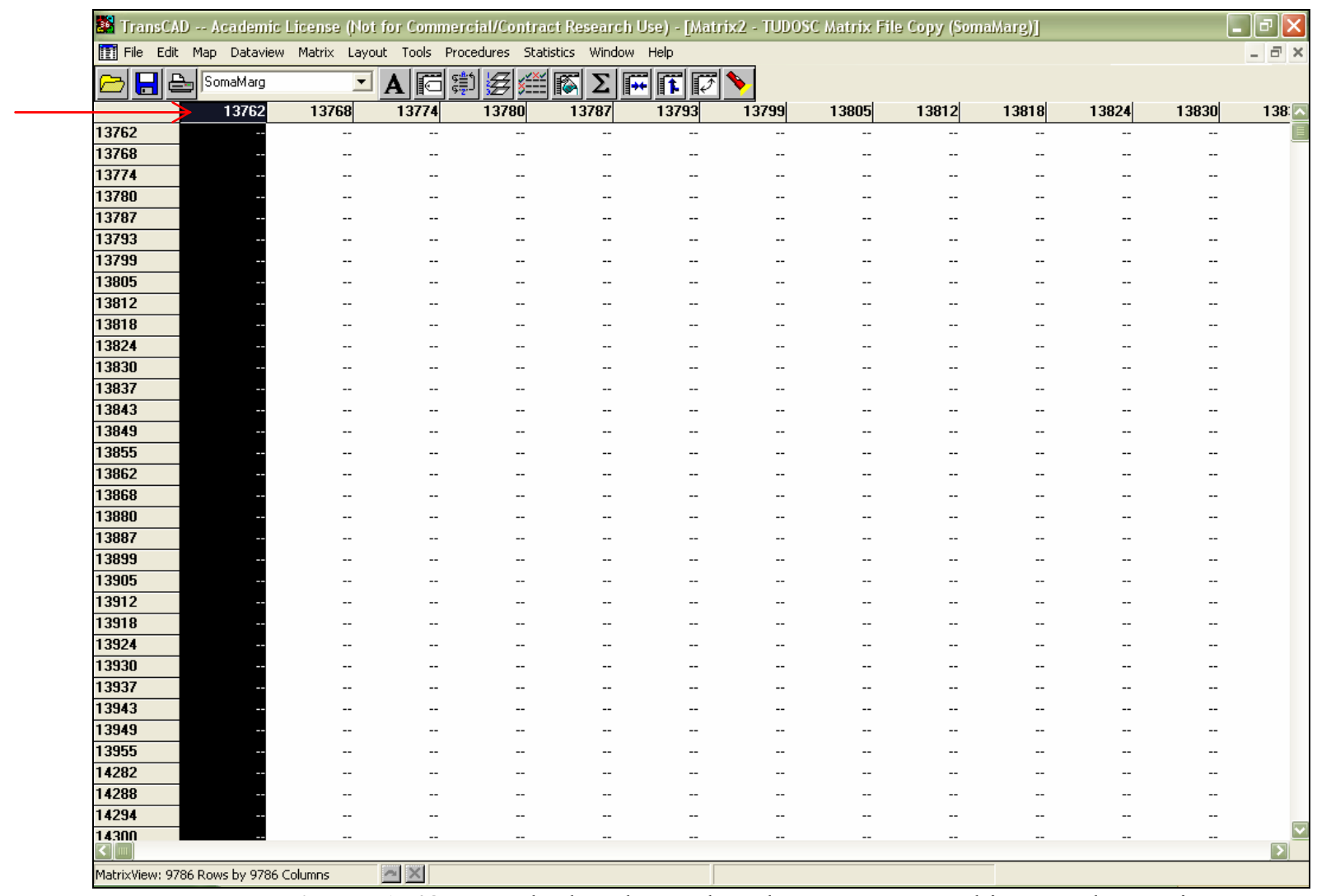

Figura A.48 - Janela da seleção de coluna para preenchimento da matriz

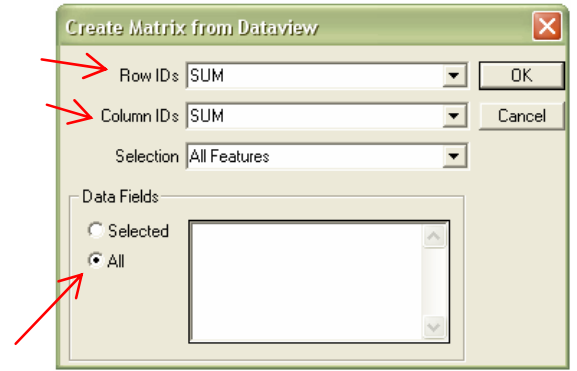

Figura A.49 - Janela de preenchimento da matriz 


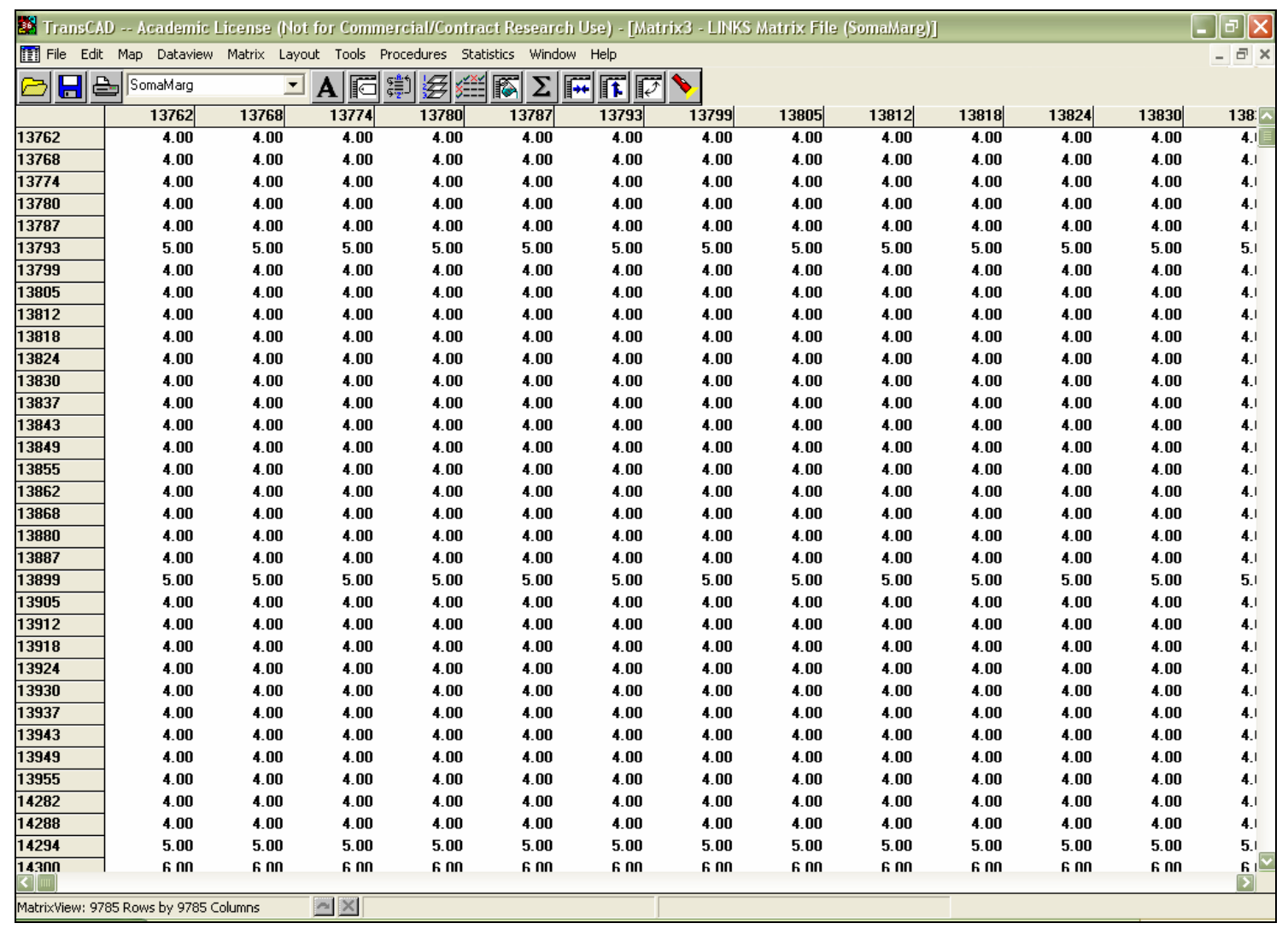

Figura A.50 - Matriz de soma marginal

Selecione a matriz "Normalizada", vá à barra de ferramentas: Matrix > Fill (Figura A.51) $>$ Fill with formula - preencha as lacunas conforme a Figura A.52. O preenchimento da matriz é demorado por causa do processamento entre duas matrizes com grande quantidade de dados.

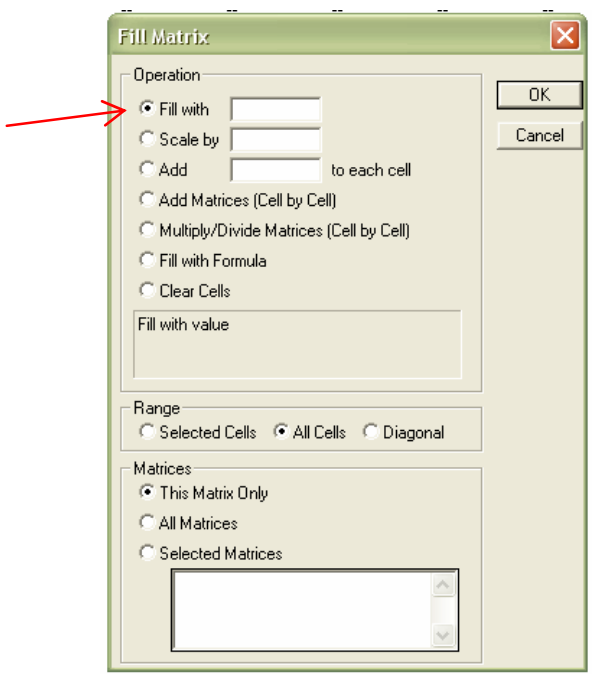

Figura A.51 - Janela opção: Matrix > Fill 


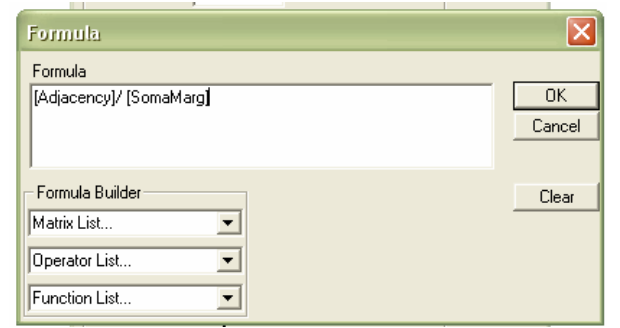

Figura A.52 - Janela opção Fill with formula

\begin{tabular}{|c|c|c|c|c|c|c|c|c|c|c|c|c|c|}
\hline TransCAD & --Academic L & icense ( $\mathrm{N}$ ) & for Coms & mercial/Conts & t Resear & ch Use) - [Mat & 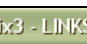 & atrix Fill & [ormaliz)]] & & & & 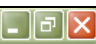 \\
\hline 茴 File Edit & Map Dataview & Matrix Lay & ut Tools & Procedures St & tics Wind & ow Help & & & & & & & $-a x$ \\
\hline E回回 & Normaliz & 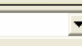 & \begin{tabular}{|l|l|}
$\mathbf{A}$ & $\mathbf{1}$ \\
\end{tabular} & 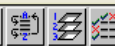 & $\Sigma$ & 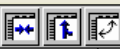 & 8 & & & & & & \\
\hline & 13762 & 13768 & 13774 & 13780 & 13787 & 13793 & 13799 & 13805 & 13812 & 13818 & 13824 & 138 & Sum $\widehat{\wedge}$ \\
\hline 13762 & 0.00 & 0.25 & 0.00 & 0.00 & 0.00 & 0.00 & 0.00 & 0.00 & 0.00 & 0.00 & 0.00 & 0.1 & 1.00 \\
\hline \begin{tabular}{|l|}
3768 \\
\end{tabular} & 0.25 & 0.00 & 0.25 & 0.00 & 0.00 & 0.25 & 0.00 & 0.00 & 0.00 & 0.00 & 0.00 & 0.1 & 1.00 \\
\hline 13774 & 0.00 & 0.25 & 0.00 & 0.00 & 0.00 & 0.25 & 0.25 & 0.00 & 0.00 & 0.00 & 0.00 & 0.1 & 1.00 \\
\hline 13780 & 0.00 & 0.00 & 0.00 & 0.00 & 0.00 & 0.00 & 0.00 & 0.00 & 0.00 & 0.00 & 0.00 & 0.1 & 1.00 \\
\hline 13787 & 0.00 & 0.00 & 0.00 & 0.00 & 0.00 & 0.00 & 0.00 & 0.00 & 0.00 & 0.00 & 0.00 & 0.1 & 1.00 \\
\hline 13793 & 0.00 & 0.20 & 0.20 & 0.00 & 0.00 & 0.00 & 0.00 & 0.00 & 0.00 & 0.00 & 0.00 & 0.1 & 1.00 \\
\hline 13799 & 0.00 & 0.00 & 0.25 & 0.00 & 0.00 & 0.00 & 0.00 & 0.25 & 0.00 & 0.25 & 0.00 & 0.1 & 1.00 \\
\hline 13805 & 0.00 & 0.00 & 0.00 & 0.00 & 0.00 & 0.00 & 0.25 & 0.00 & 0.25 & 0.25 & 0.00 & 0.1 & 1.00 \\
\hline \begin{tabular}{|l}
13812 \\
\end{tabular} & 0.00 & 0.00 & 0.00 & 0.00 & 0.00 & 0.00 & 0.00 & 0.25 & 0.00 & 0.00 & 0.25 & 0.1 & 1.00 \\
\hline 13818 & 0.00 & 0.00 & 0.00 & 0.00 & 0.00 & 0.00 & 0.25 & 0.25 & 0.00 & 0.00 & 0.00 & 0.1 & 1.00 \\
\hline 13824 & 0.00 & 0.00 & 0.00 & 0.00 & 0.00 & 0.00 & 0.00 & 0.00 & 0.25 & 0.00 & 0.00 & 0.1 & 1.00 \\
\hline 13830 & 0.00 & 0.00 & 0.00 & 0.00 & 0.00 & 0.00 & 0.00 & 0.00 & 0.00 & 0.00 & 0.00 & 0.1 & 1.00 \\
\hline 13837 & 0.00 & 0.00 & 0.00 & 0.00 & 0.00 & 0.00 & 0.00 & 0.00 & 0.00 & 0.00 & 0.00 & 0.1 & 1.00 \\
\hline 13843 & 0.00 & 0.00 & 0.00 & 0.00 & 0.00 & 0.00 & 0.00 & 0.00 & 0.25 & 0.00 & 0.25 & 0.1 & 1.00 \\
\hline 13849 & 0.00 & 0.00 & 0.00 & 0.00 & 0.00 & 0.00 & 0.00 & 0.00 & 0.00 & 0.00 & 0.00 & 0.1 & 1.00 \\
\hline 13855 & 0.00 & 0.00 & 0.00 & 0.00 & 0.00 & 0.00 & 0.00 & 0.00 & 0.00 & 0.00 & 0.00 & o.: & 1.00 \\
\hline 13862 & 0.00 & 0.00 & 0.00 & 0.00 & 0.00 & 0.00 & 0.00 & 0.00 & 0.00 & 0.00 & 0.00 & o.: & 1.00 \\
\hline 13868 & 0.00 & 0.00 & 0.00 & 0.00 & 0.00 & 0.00 & 0.00 & 0.00 & 0.00 & 0.00 & 0.00 & 0.1 & 1.00 \\
\hline 13880 & 0.00 & 0.00 & 0.00 & 0.00 & 0.00 & 0.00 & 0.00 & 0.00 & 0.00 & 0.00 & 0.00 & 0.1 & 1.00 \\
\hline 13887 & 0.00 & 0.00 & 0.00 & 0.00 & 0.00 & 0.00 & 0.00 & 0.00 & 0.00 & 0.00 & 0.00 & 0.1 & 1.00 \\
\hline 13899 & 0.00 & 0.00 & 0.00 & 0.00 & 0.00 & 0.00 & 0.00 & 0.00 & 0.00 & 0.00 & 0.00 & 0.1 & 1.00 \\
\hline 13905 & 0.00 & 0.00 & 0.00 & 0.00 & 0.00 & 0.00 & 0.00 & 0.00 & 0.00 & 0.00 & 0.00 & 0.1 & 1.00 \\
\hline 13912 & 0.00 & 0.00 & 0.00 & 0.00 & 0.00 & 0.00 & 0.00 & 0.00 & 0.00 & 0.00 & 0.00 & 0.1 & 1.00 \\
\hline 13918 & 0.00 & 0.00 & 0.00 & 0.00 & 0.00 & 0.00 & 0.00 & 0.00 & 0.00 & 0.00 & 0.00 & 0.1 & 1.00 \\
\hline \begin{tabular}{|l|l|}
13924 \\
\end{tabular} & 0.00 & 0.00 & 0.00 & 0.00 & 0.00 & 0.00 & 0.00 & 0.00 & 0.00 & 0.00 & 0.00 & 0.1 & 1.00 \\
\hline 13930 & 0.00 & 0.00 & 0.00 & 0.00 & 0.00 & 0.00 & 0.00 & 0.00 & 0.00 & 0.00 & 0.00 & 0.1 & 1.00 \\
\hline \begin{tabular}{|l|}
13937 \\
\end{tabular} & 0.00 & 0.00 & 0.00 & 0.00 & 0.00 & 0.00 & 0.00 & 0.00 & 0.00 & 0.00 & 0.00 & 0.1 & 1.00 \\
\hline 13943 & 0.00 & 0.00 & 0.00 & 0.00 & 0.00 & 0.00 & 0.00 & 0.00 & 0.00 & 0.00 & 0.00 & 0.1 & 1.00 \\
\hline 13949 & 0.00 & 0.00 & 0.00 & 0.00 & 0.00 & 0.00 & 0.00 & 0.00 & 0.00 & 0.00 & 0.00 & 0.1 & 1.00 \\
\hline 13955 & 0.00 & 0.00 & 0.00 & 0.00 & 0.00 & 0.00 & 0.00 & 0.00 & 0.00 & 0.00 & 0.00 & 0.1 & 1.00 \\
\hline 14282 & 0.00 & 0.00 & 0.00 & 0.00 & 0.00 & 0.00 & 0.00 & 0.00 & 0.00 & 0.00 & 0.00 & 0.1 & 1.00 \\
\hline 14288 & 0.00 & 0.00 & 0.00 & 0.00 & 0.00 & 0.00 & 0.00 & 0.00 & 0.00 & 0.00 & 0.00 & 0.1 & 1.00 \\
\hline \begin{tabular}{|l|}
142994 \\
Sum
\end{tabular} & $\begin{array}{l}n \mathrm{nn} \\
1.17\end{array}$ & $\begin{array}{l}n \mathrm{nn} \\
1.03 \\
\end{array}$ & $\begin{array}{l}n \mathrm{n} n \\
0.95\end{array}$ & $\begin{array}{l}n \mathrm{nn} \\
1.00\end{array}$ & $\begin{array}{l}n \mathrm{n} n \\
1.00\end{array}$ & $\begin{array}{l}n \mathrm{nn} \\
1.37\end{array}$ & $\begin{array}{l}n \mathrm{nn} \\
1.00\end{array}$ & $\begin{array}{l}n \mathrm{nn} \\
1.00 \\
\end{array}$ & $\begin{array}{l}n \mathrm{nn} \\
1.00 \\
\end{array}$ & $\begin{array}{l}n \mathrm{n} n \\
0.95\end{array}$ & $\begin{array}{l}n \mathrm{nn} \\
0.95\end{array}$ & $\begin{array}{l}n ! \\
0 .\end{array}$ & \begin{tabular}{r|}
$1 \mathrm{nn}$ \\
9784.00 \\
\end{tabular} \\
\hline 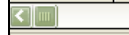 & & & & & & & & & & & & & 7 \\
\hline MatrixView: 9 & Rows by 9785 & umns & 시 & & & & & & & & & & \\
\hline
\end{tabular}

Figura A.53 - Matriz Normalizada

O preenchimento da quarta matriz depende dos dados do Dataview exportados para a matriz. Na matriz Z seleciona-se uma linha qualquer. A opção: Matrix > Import rows or columns, abre a janela da Figura A.54. Selecione: Range $>$ (All rows), Import from $>$ (nome do Dataview), Columns IDs $>$ (ID), From $>$ (nome da coluna Z desejada, p.ex., Z_dano_01) $>O K($ Figura A.55). 


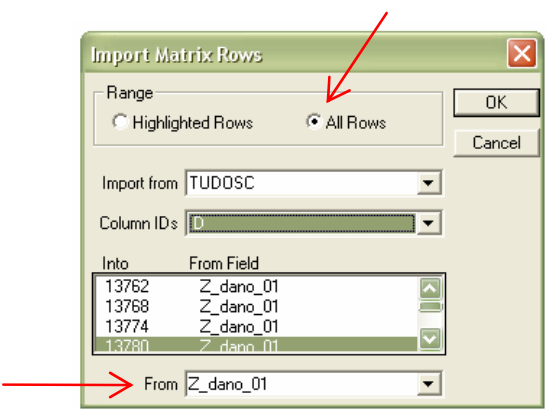

Figura A.54 - Janela opção Import rows or columns

Neste procedimento é conveniente que a coluna importada do Dataview seja a última da listagem para facilitar o preenchimento. É por isso que foi sugerida anteriormente a criação das novas colunas uma a uma. Caso as novas colunas do Dataview tenham sido criadas todas numa única vez, vá à barra de ferramenta: Dataview $>$ Modify Table $>$ clique sobre a coluna a utilizar > Move Down movendo-a até que seja o último nome da lista. Este procedimento deve ser repetido todas as vezes que for preencher matrizes por meio de importação de dados do Dataview.

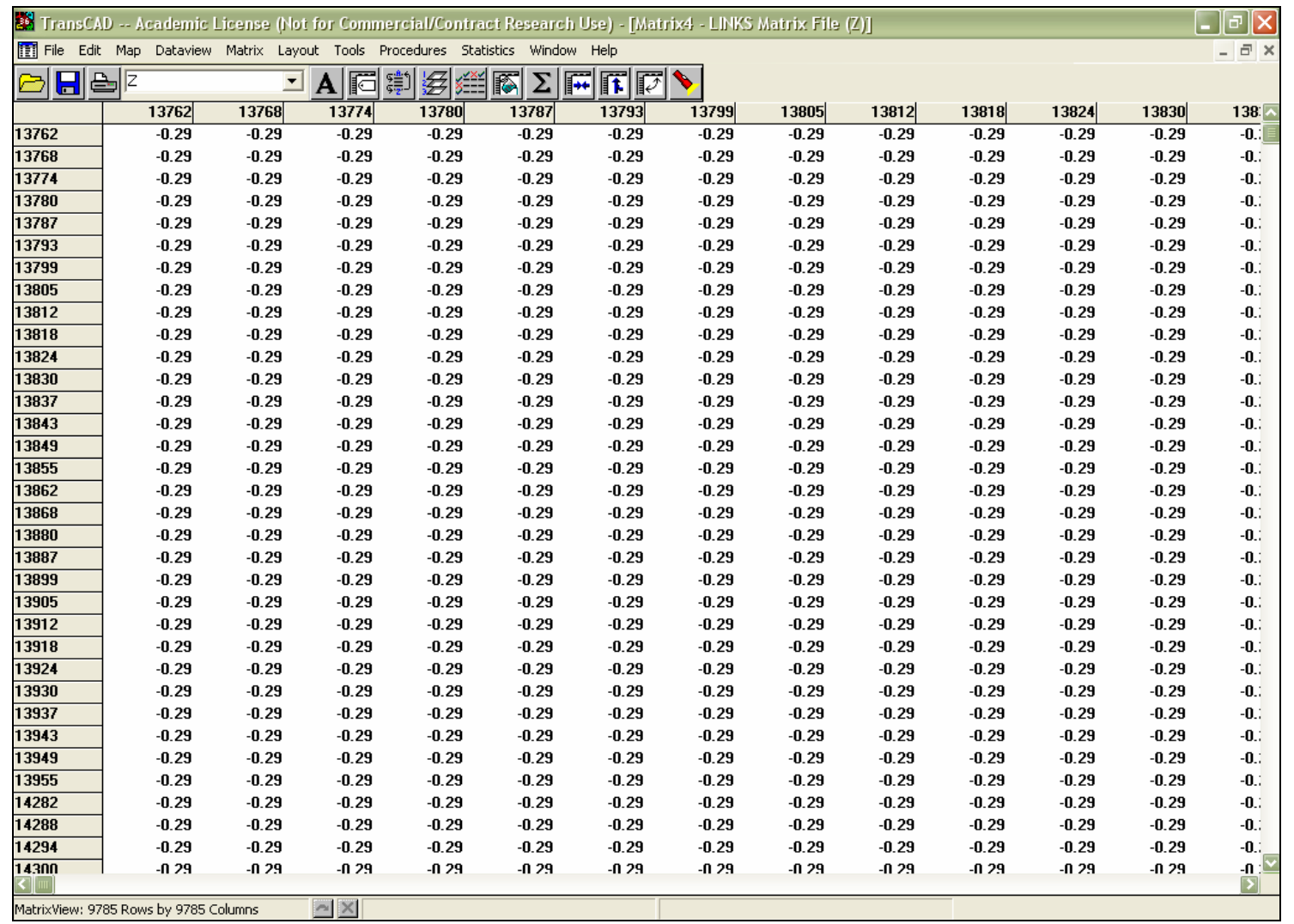

Figura A.55 - Matriz Z 
O preenchimento da quinta matriz é simples, é uma multiplicação de matrizes.

Com o comando: Matrix $>$ Fill $>$ Fill with formula $>($ Normalizada $\mathrm{X}$ Z) $>$ OK $($ Figura A.56).

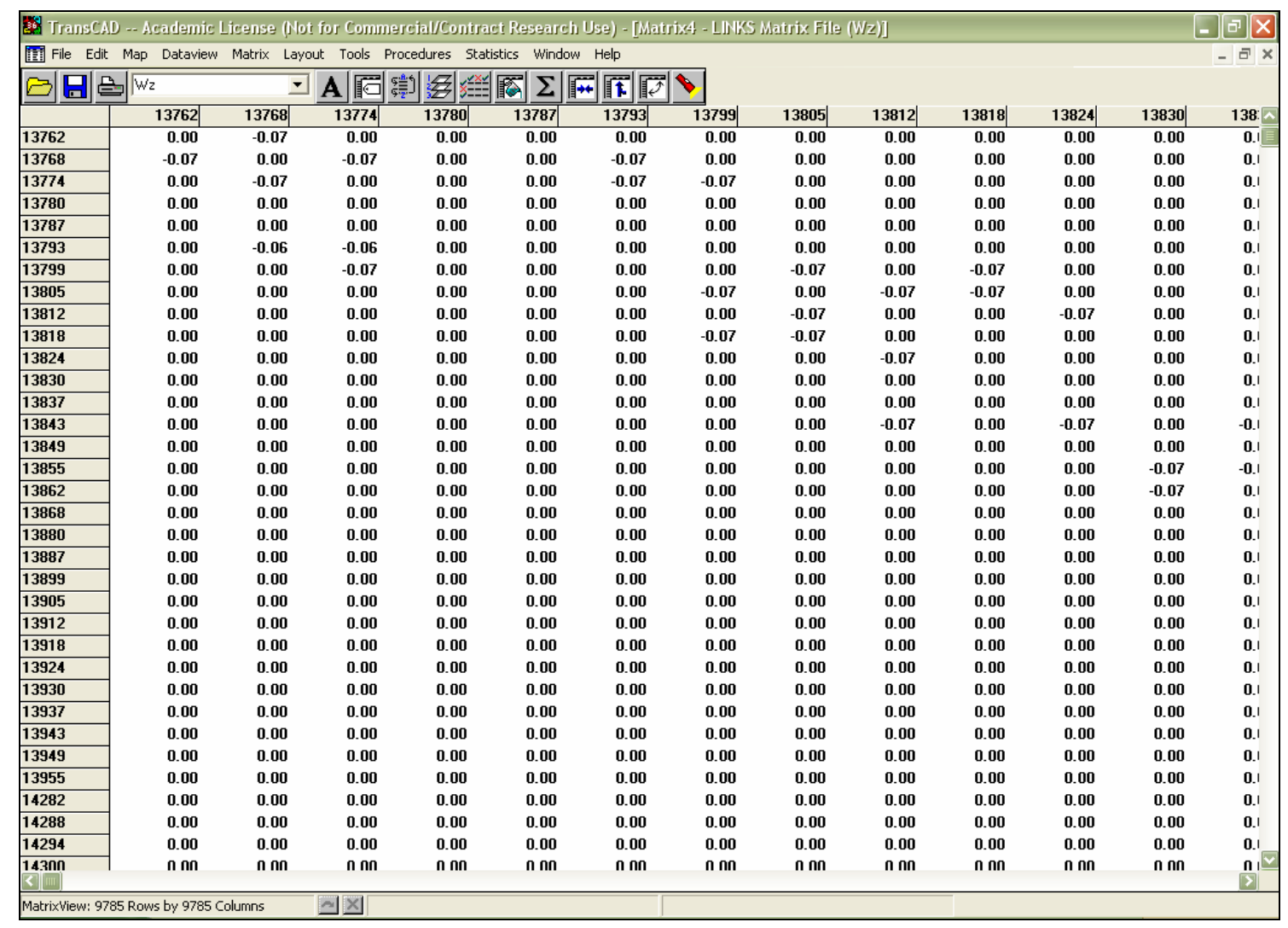

Figura A.56 - Matriz $\mathrm{W}_{\mathrm{z}}$

Concluído o preenchimento das cinco matrizes, devem-se exportar os resultados para o Dataview. Para isso, na matriz Wz vá a barra de ferramenta: Matrix > Settings $>$ Options $>$ Marginals $>$ Sum (Figura A.47). Sem selecionar qualquer linha ou coluna, vá a barra de ferramentas: Matrix $>$ Export rows or columns $>O K>$ Save As.

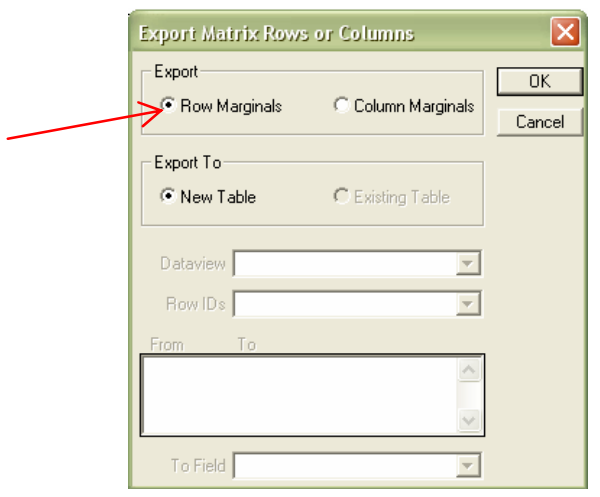

Figura A.57 - Janela para exportar dados da matriz Wz 
De volta ao Dataview de segmentos acrescente mais uma coluna. Faça um join entre o Dataview de segmentos e o Dataview resultante da soma marginal.

No Dataview de segmentos acrescente novas colunas $\left(\mathrm{W}_{\mathrm{z}}\right.$, parcela A e parcela B, por exemplo) através do comando Dataview $>$ Modify Table $>$ Add Field (coluna de números reais e com quatro casas decimais) $>O K$. Selecione a nova coluna e com o comando Edit $>$ Fill $>$ Formula $>$ Field List (escolha a coluna vinda da matriz) $>$ OK. Em seguida desfaz-se o Join, conforme instruções anteriores.

Próximo passo, selecione a coluna Parcela A, vá ao menu de ferramentas: Edit $>$ Fill $>$ Formula $>$ Field List $($ coluna $\mathrm{Z}) \times\left(\right.$ coluna $\left.\mathrm{W}_{\mathrm{z}}\right)>$ OK. A seguir, repita a operação com a coluna Parcela B e no campo Field List, escolha (coluna Z) x (coluna Zt).

Terminado o processamento, no menu de ferramenta, escolha: Dataview > Statistics, nomeie o arquivo e salve.

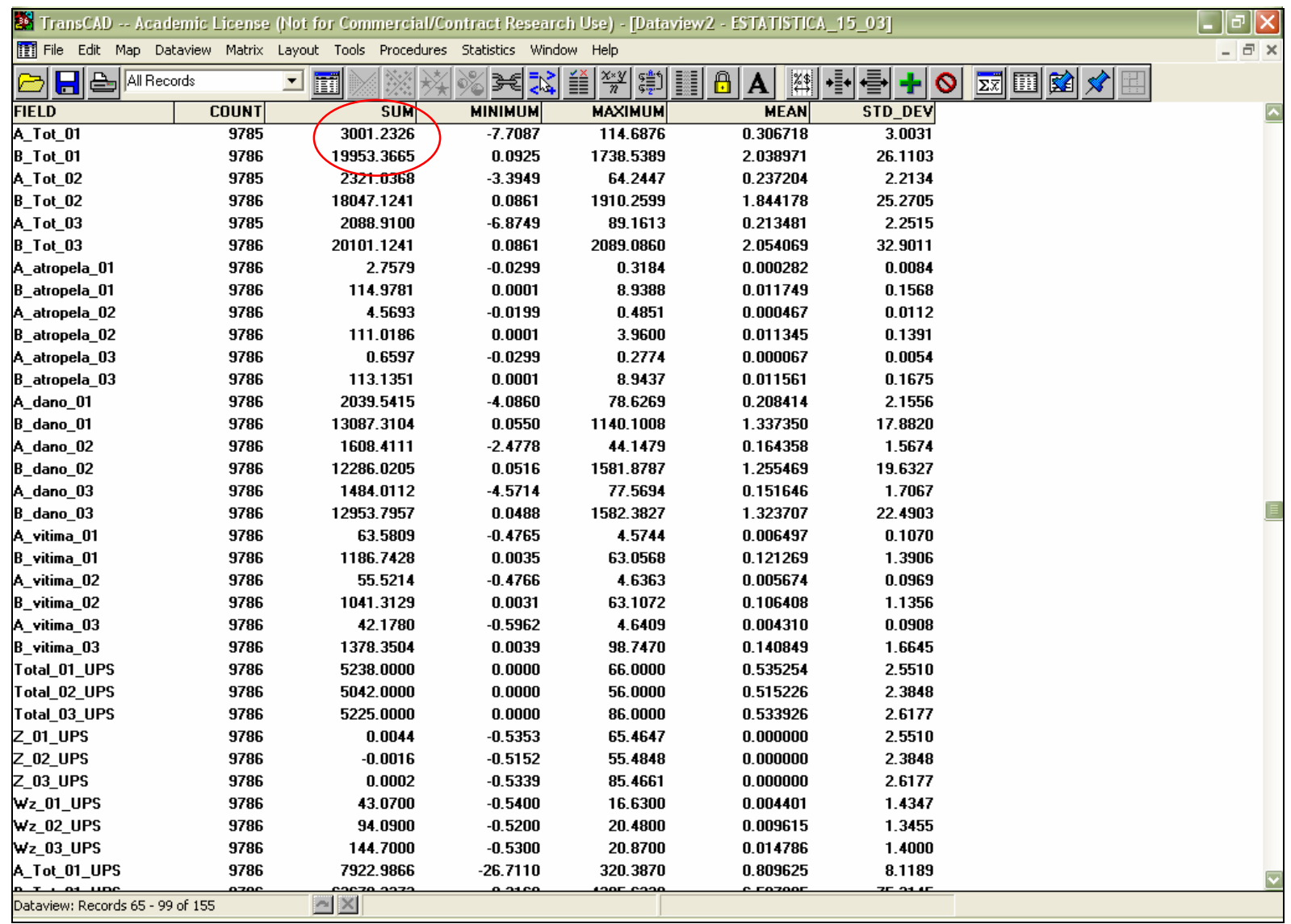

Figura A.58 - Janela com os Dados Estatísticos 
$\mathrm{Na}$ coluna Sum encontre os valores correspondentes às colunas Parcela $A$ e Parcela B. Com uma operação simples divida a Parcela $A$ pela $B$ e encontra-se o valor do Índice $I$.

\section{A.6 Box Map}

Para a confecção dos Box Maps, acrescente nova coluna no Dataview de segmentos, selecione-a e preencha Edit $>$ Fill $>$ Formula: if $(Z>0$ and $W z>0)$ then 1 else if $\left(Z<0\right.$ and $\left.W_{z}<0\right)$ then 2 else if $\left(Z<0\right.$ and $\left.W_{z}>0\right)$ then 3 else if $\left(Z>0\right.$ and $\left.W_{z}<0\right)$ then 4 else 0. O resultado dos Box Maps são as Figuras 5.1 a 5.18.

O procedimento descrito até aqui deve ser executado para o Total de Acidentes e o Total de Acidentes com Severidade, lembrando que os valores dos acidentes com a UPS já foram computados no começo dos cálculos, quando do cálculo do Z.

O Total de Acidentes com UPS em arcos e interseções difere na maneira de calcular os valores dos acidentes já que estes devem ser separados em arcos (quadra) e interseções (esquinas).

\section{A.7 Distribuição dos Acidentes entre esquinas e quadras}

Ative a camada de acidentes, é conveniente ativar um ano de cada vez. Classifique os acidentes pelo local do ocorrido, por exemplo, quando no endereço tiver além do nome de rua e número da casa, este acidente ocorreu no meio da quadra, quando tiver dois nomes de rua e/ou não apresentar qualquer número, então ocorreu em esquina. Isso se faz necessário para poder calcular a fração de acidente. 
Para classificar, crie duas colunas, em uma delas preencha através do Edit $>$ Fill $>$ Formula $>$ condicionando ao endereço do acidente. A outra coluna receberá a contagem do número de segmentos envolvidos no acidente.

No mapa ative a camada dos Endpoints dos segmentos e faça um Buffer de dez metros ao redor dos Endpoints, salve. Vá ao menu de ferramenta: Dataview > Modify Table $>$ Add Field > (acrescente e nomeie doze colunas: Acidentes Totais 2001, 2002, 2003, Acidentes tipo 1 em 2001, 2002, 2003, Acidentes tipo 4 em 2001, 2002, 2003, tipo 6 em 2001, 2002, 2003, tipo 13 em 2001, 2002 e 2003) > OK

A seguir selecione uma coluna: Edit $>$ Fill $>$ Aggregate $>$ From layers: acidentes, Include: total / parciais, Fill with: Count (Figura A.59)

Ainda no Dataview do Buffer: Edit $>$ Fill $>$ Aggregate $>$ From layers: links, Include: all features, Fill with: Count. Por ultimo: Edit $>$ Fill $>$ Formula $>$ acidentes / links, com este último procedimento normaliza-se o número de acidentes. Repete-se este procedimento para cada ano e tipo de acidentes.

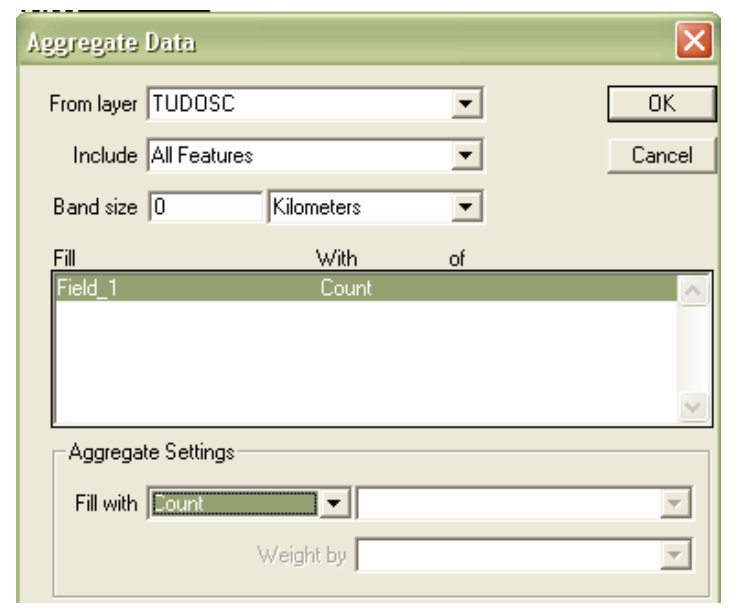

Figura A.59 - Janela para contagem dos dados da camada de vias

Ao final, no Dataview de segmentos acrescenta-se uma coluna (conforme procedimento já descrito); seleciona-a, Edit $>$ Fill $>$ Aggregate $>$ Sum, com isso é feito a contagem dos acidentes. E assim cada ponto será um acidente, portanto uma fração de acidente já será o coeficiente de cálculo dos acidentes. 